\title{
Embracing heterogeneity: coalescing the Tree of Life and the future of phylogenomics
}

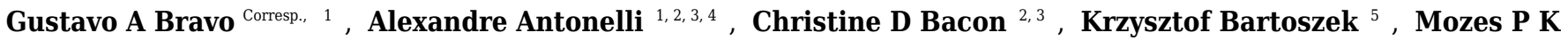 \\ Blom $^{6}$, Stella Huynh ${ }^{7}$, Graham Jones ${ }^{3}$, L. Lacey Knowles ${ }^{8}$, Sangeet Lamichhaney ${ }^{1}$, Thomas Marcussen $^{9}$, \\ Hélène Morlon ${ }^{10}$, Luay K Nakhleh ${ }^{11}$, Bengt Oxelman ${ }^{2,3}$, Bernard Pfeil ${ }^{3}$, Alexander Schliep ${ }^{12}$, Niklas \\ Wahlberg $^{13}$, Fernanda P Werneck ${ }^{14}$, John Wiedenhoeft ${ }^{12,15}$, Sandi Willows-Munro ${ }^{16}$, Scott V Edwards ${ }^{1,17}$ \\ ${ }^{1}$ Department of Organismic Biology and Evolutionary Biology, Museum of Comparative Zoology, Harvard University, Cambridge, MA, United States \\ 2 Gothenburg Global Biodiversity Centre, Göteborg, Sweden \\ 3 Department of Biological and Environmental Sciences, University of Gothenburg, Göteborg, Sweden \\ 4 Gothenburg Botanical Garden, Göteborg, Sweden \\ 5 Department of Computer and Information Science, Linköping University, Linköping, Sweden \\ 6 Department of Bioinformatics and Genetics, Swedish Museum of Natural History, Stockholm, Sweden \\ 7 Institut de Biologie, Université de Neuchâtel, Neuchâtel, Switzerland \\ 8 Department of Ecology and Evolutionary Biology, University of Michigan, Ann Arbor, MI, USA \\ ${ }^{9}$ Centre for Ecological and Evolutionary Synthesis, University of Oslo, Oslo, Norway \\ 10 Institut de Biologie, Ecole Normale Supérieure de Paris, Paris, France \\ 11 Department of Computer Science, Rice University, Houston, TX, United States \\ 12 Department of Computer Science and Engineering, Chalmers University of Technology and University of Gothenburg, Göteborg, Sweden \\ 13 Department of Biology, Lund University, Lund, Sweden \\ 14 Coordenação de Biodiversidade, Programa de Coleções Científicas Biológicas, Instituto Nacional de Pesquisa da Amazônia, Manaus, AM, Brazil \\ 15 Department of Computer Science, Rutgers University, Piscataway, NJ, USA \\ 16 School of Life Sciences, University of Kwazulu-Natal, Pietermaritzburg, South Africa \\ 17 Gothenburg Centre for Advanced Studies in Science and Technology, Chalmers University of Technology and University of Gothenburg, Göteborg, \\ Sweden
}

Corresponding Author: Gustavo A Bravo

Email address: gustavo_bravo@fas.harvard.edu

Building the Tree of Life (ToL) is a major challenge of modern biology, requiring advances in cyberinfrastructure, data collection, theory, and more. Here, we argue that phylogenomics stands to benefit by embracing the many heterogeneous genomic signals emerging from the first decade of large-scale phylogenetic analysis spawned by highthroughput sequencing (HTS). Such signals include those most commonly encountered in phylogenomic datasets, such as incomplete lineage sorting, but also those reticulate processes emerging with greater frequency, such as recombination and introgression. Here we focus specifically on how phylogenetic methods can accommodate the heterogeneity incurred by such population genetic processes; we do not discuss phylogenetic methods that ignore such processes, such as concatenation or supermatrix approaches or supertrees. We suggest that methods of data acquisition and the types of markers used in phylogenomics will remain restricted until a posteriori methods of marker choice are made possible with routine whole-genome sequencing of taxa of interest. We 
discuss limitations and potential extensions of a model supporting innovation in phylogenomics today, the multispecies coalescent model (MSC). Macroevolutionary models that use phylogenies, such as character mapping, often ignore the heterogeneity on which building phylogenies increasingly rely and suggest that assimilating such heterogeneity is an important goal moving forward. Finally, we argue that an integrative cyberinfrastructure linking all steps of the process of building the ToL, from specimen acquisition in the field to publication and tracking of phylogenomic data, as well as a culture that values contributors at each step, are essential for progress. 
Article submission to PeerJ

Manuscript category: Literature Review Articles

Collection: "Endless forms: Advances in evolutionary analyses of biodiversity"

Article title: Embracing heterogeneity: coalescing the Tree of Life and the future of phylogenomics

Gustavo A. Bravo*1, Alexandre Antonelli ${ }^{1,2,3,4}$, Christine D. Bacon ${ }^{2,3}$, Krzysztof Bartoszek ${ }^{5}$, Mozes P. K. Blom $^{6}$, Stella Huynh ${ }^{7}$, Graham Jones ${ }^{3}$, L. Lacey Knowles ${ }^{8}$, Sangeet Lamichhaney ${ }^{1}$, Thomas Marcussen ${ }^{9}$, Hélène Morlon ${ }^{10}$, Luay K. Nakhleh ${ }^{11}$, Bengt Oxelman ${ }^{2,3}$, Bernard Pfeil ${ }^{3}$, Alexander Schliep ${ }^{12}$, Niklas Wahlberg ${ }^{13}$, Fernanda P. Werneck ${ }^{14}$, John Wiedenhoeft ${ }^{12,15}$, Sandi Willows-Munro ${ }^{16}$, Scott V. Edwards ${ }^{1,17}$

${ }^{1}$ Harvard University, Department of Organismic and Evolutionary Biology, Museum of Comparative Zoology, 26 Oxford St., Cambridge, MA 02138, USA.

${ }^{2}$ Gothenburg Global Biodiversity Centre, Box 461, SE-405 30 Göteborg, Sweden.

${ }^{3}$ University of Gothenburg, Department of Biological and Environmental Sciences, Box 461, 40530 Göteborg, Sweden.

${ }^{4}$ Gothenburg Botanical Garden, Carl Skottsbergs gata 22A, SE-41319 Göteborg, Sweden.

${ }^{5}$ Linköping University, Department of Computer and Information Science, SE-581 83 Linköping, Sweden.

${ }^{6}$ Swedish Museum of Natural History, Department of Bioinformatics and Genetics, Box 50007, 10405

Stockholm, Sweden.

${ }^{7}$ Université de Neuchâtel, Institut de Biologie, Rue Emile-Argand 11, Bureau D322, Neuchâtel,

Switzerland.

${ }^{8}$ University of Michigan, Department of Ecology and Evolutionary Biology, Ann Arbor, MI 48109, USA.

${ }^{9}$ University of Oslo, Centre for Ecological and Evolutionary Synthesis, P.O. Box 1066 Blindem, NO0316, Oslo, Norway.

${ }^{10}$ Institut de Biologie de 1'Ecole Normale Supérieure (IBENS), CNRS UMR 8197, INSERM U1024, Ecole Normale Supérieure, Paris Sciences et Lettres (PSL) Research University, F-75005 Paris, France.

${ }^{11}$ Rice University, Department of Computer Science, 6100 Main St. MS 132, Houston, TX 77005, USA.

${ }^{12}$ Chalmers University of Technology and University of Gothenburg, Department of Computer Science and Engineering, Computing Science Division, SE-412 96, Göteborg, Sweden.

${ }^{13}$ Lund University, Department of Biology, Sölvegatan 37, SE-223 62 Lund, Sweden.

${ }^{14}$ Instituto Nacional de Pesquisa da Amazônia, Coordenação de Biodiversidade, Programa de Coleções Científicas Biológicas, 69060-000 Manaus, AM, Brazil.

${ }^{15}$ Rutgers University, Department of Computer Science, 110 Frelinghuysen Rd. Piscataway, NJ 08854, USA.

${ }^{16}$ University of Kwazulu-Natal, School of Life Sciences, Pietermaritzburg, South Africa.

${ }^{17}$ Chalmers University of Technology and University of Gothenburg, Gothenburg Centre for Advanced Studies in Science and Technology, SE-412 96, Göteborg, Sweden.

*Corresponding author: Gustavo A. Bravo, E-mail: gustavo_bravo@,fas.harvard.edu

45

46

47 
50 Abstract

51 Building the Tree of Life (ToL) is a major challenge of modern biology, requiring advances in

52 cyberinfrastructure, data collection, theory, and more. Here, we argue that phylogenomics stands to

53 benefit by embracing the many heterogeneous genomic signals emerging from the first decade of large-

54 scale phylogenetic analysis spawned by high-throughput sequencing (HTS). Such signals include those

55 most commonly encountered in phylogenomic datasets, such as incomplete lineage sorting, but also those

56 reticulate processes emerging with greater frequency, such as recombination and introgression. Here we

57 focus specifically on how phylogenetic methods can accommodate the heterogeneity incurred by such

58 population genetic processes; we do not discuss phylogenetic methods that ignore such processes, such as

59 concatenation or supermatrix approaches or supertrees. We suggest that methods of data acquisition and

60 the types of markers used in phylogenomics will remain restricted until a posteriori methods of marker

61 choice are made possible with routine whole-genome sequencing of taxa of interest. We discuss

62 limitations and potential extensions of a model supporting innovation in phylogenomics today, the

63 multispecies coalescent model (MSC). Macroevolutionary models that use phylogenies, such as character

64 mapping, often ignore the heterogeneity on which building phylogenies increasingly rely and suggest that

65 assimilating such heterogeneity is an important goal moving forward. Finally, we argue that an integrative

66 cyberinfrastructure linking all steps of the process of building the ToL, from specimen acquisition in the

67 field to publication and tracking of phylogenomic data, as well as a culture that values contributors at

68 each step, are essential for progress.

69

70 


\section{1. Introduction}

72 Phylogenomics has been greatly enriched with the introduction of high-throughput sequencing (HTS) and

73 increased breadth of phylogenomic sampling, which have allowed researchers interested in the ToL to

74 scale up in several dimensions and placing both fields squarely in the era of 'big data'. Additionally,

75 conceptual advances and improvements of statistical models used to analyze these data are helping bridge

76 what some have perceived as a gap between phylogenetics and phylogeography (e.g., Felsenstein, 1988;

77 Huson, 2006; Edwards et al., 2016a). However, as datasets become larger, researchers are inevitably

78 faced with a plethora of heterogeneous signals across different genomic regions that often depart from a

79 dichotomously-branching phylogeny (Kunin, Goldovsky \& Darzentas, 2005; Jeffroy et al., 2006; Mallet,

80 Besansky \& Hahn, 2015). These signals cover an increasingly large array of biological processes at the

81 level of genes and genomes, as well as individual organisms and populations, including processes such as

82 recombination, hybridization, gene flow, and polyploidization; they can be thought of as conflicting, but

83 in truth, they are simply a record of the singular history that we commonly refer to as the ToL (King \&

84 Rokas, 2017). One of the grand challenges of evolutionary biology is deciphering this history, whether at

85 the level of genes, populations, species, or genomes, however, currently phylogenomicists have not yet

86 determined how to fully exploit the diverse signals in molecular data.

87 In this perspective piece, our goal is to highlight opportunities for the field of phylogenomics to

88 overcome conceptual and practical challenges as we navigate our way through the era of big data. We

89 argue that conceptually and analytically embracing heterogeneity generated by population-level processes

90 and associated with different histories across the genome will lead to increased insight into the ToL and

91 its underlying processes. Because major theoretical advances in phylogenomics and population genetics

92 resulting from the advent of genome-scale data have been reviewed elsewhere (e.g., Delsuc, Brinkmann

93 \& Philippe, 2005; Degnan \& Rosenberg, 2009; Ellegren \& Galtier, 2016; Payseur \& Rieseberg, 2016;

94 Hahn, 2018), here we focus on advances and challenges to phylogenomics specifically brought about by

95 population genetic processes, which inevitably leads us to focus on the major conceptual framework

96 dealing with such processes, the multispecies coalescent model (MSC). Likewise, advances in other 
97 methods such as supertrees (reviewed by Warnow, 2018), supermatrices (de Queiroz \& Gatesy, 2007 and

98 Philippe et al., 2017), and partitioned analyses (e.g., Lanfear et al., 2014; Kainier \& Lanfear, 2015) are

99 not central to the objectives of this perspective piece and further details on those topics can be found

100 elsewhere.

101 A key concept introduced by the scaling up from phylogeography to phylogenomics is the

102 continuum of processes and analytical methods, - the so-called phylogeography-phylogenetics continuum

103 (Edwards et al., 2016a). We argue here that bridging this continuum is critical for advancing

104 phylogenetics. This can be done by either developing phylogenomic approaches that acknowledge and

105 explicitly account for phylogeographic processes, or by determining the regions of parameter space (e.g.,

106 branch lengths in tree, level of gene flow) if any, where such within-species processes are not relevant.

107 For example, the choice of markers in a given phylogenomics project is currently guided more by

108 convenience and cost than by evaluating the biological properties and phylogenomic signals in those data;

109 but comparisons of signals across various types of markers (e.g., transcriptomes, noncoding regions)

110 reveal that marker choice is a critical step toward shedding light on the history of populations and

111 unraveling potential processes underlying such history (Rokas et al., 2003; Cutter, 2013; Jarvis et al.,

112 2014; Reddy et al., 2017). On the analysis side, we are in desperate need of methods that can handle the

113 increasingly large data sets being produced by empiricists, but at the same time there is a desire to include

114 increasingly diverse sources of signal in estimates of divergence times, biogeographic history, and models

115 of diversification (Delsuc, Brinkmann \& Philippe, 2005; Jeffroy et al., 2006; Kumar et al., 2012). Finding

116 the balance between breadth, depth, and computational feasibility in project design and statistical analysis

117 is crucial for the field today.

118 Additionally, we discuss ways in which data archiving and integration can benefit access to

119 phylogenomics data and the contributions of phylogenomics to society. Are the priorities that society

120 places on the many disciplines feeding into scientific efforts toward the ToL - fieldwork, museum

121 collections, databases - appropriate for this grand mission? Although we cannot possibly answer all of 
122 these questions within the scope of this perspective, we hope to at least spur discussion on the wide range

123 of field, laboratory, conceptual, and societal issues that allow phylogenomics to move forward.

124 We first describe the types of genomic data that researchers can generate to perform

125 phylogenomic analyses and how those are more or less suitable for phylogenomic and phylogeographic

126 analyses. We then discuss key concepts around the MSC and highlight the need to expand this model

127 beyond its current limitations. We then discuss how the interplay between phylogenomics and

128 macroevolution might strengthen our understanding of diversity patterns and offer suggestions as to how

129 the community can overcome limitations posed by current methods and models in both fields. Finally, we

130 discuss desired practices that, as a community, phylogenomicists, museum scientists, field biologists,

131 bioinformaticians, and other scientists can embrace toward the goal of assembling the ToL.

132

\section{2. Survey methodology}

134 During the 'Origins of Biodiversity Workshop' organized during May 15-19, 2017 by Chalmers

135 University of Technology and the University of Gothenburg, Sweden, under the auspices of the

136 Gothenburg Centre for Advanced Studies (GoCAS), we gathered scholars and students from several

137 countries and scientific backgrounds to discuss future perspectives in the fields of phylogenomics and

138 phylogeography. We spent one week sharing our recent experiences in these fields and outlining the

139 topics presented here and continued remotely to complete this review. Our goal is not to provide a

140 complete overview of phylogenomic and phylogeographic research, but rather present a number of

141 conceptual and practical aspects that we feel are essential to keep the momentum that these fields have

142 gained during recent times.

143

\section{3. Data generation and data types in phylogenomics}

\section{3.1. The need for large-scale phylogenomic data}


147 One of the fundamental challenges in evolutionary biology is to estimate a ToL for all species. The

148 potential impact of such large phylogenies is reflected in their publication in the highest impact journals,

149 but also in their broad contribution, which extends beyond big data, to methodological innovations, and

150 downstream understanding of macroevolutionary processes (e.g., coalescent methods of species tree

151 inference; accounting for hybridization and unsampled species or localities in datasets; understanding

152 community or genome evolution through large-scale phylogenetics). Hence, the phylogenomics

153 community is now placing a high priority on very large-scale trees, whether in terms of number of taxa,

154 number of genes, or both. The current need for large phylogenies and the high priority placed on them by

155 high-impact journals can also result in short-cuts, wherein extant species lacking any molecular data are

156 often placed in trees based on current taxonomy (Jetz et al., 2012; Zanne et al., 2014; Faurby \& Svenning,

157 2015), which can result in conflicts with more robust estimates based on actual data (Brown, Wang \&

158 Smith, 2017). At the same time, however, hypothesis-testing in areas such as macroevolution,

159 macroecology, biodiversity, and systematics require these large-scale trees, even as they present

160 challenges being built on high quality data. The phylogenetic knowledge on which we lay a foundation

161 for downstream analyses must be robust, and therefore it is essential that the input phylogenetic

162 hypotheses themselves are robust (Pyron, 2015). Indeed, the current bottlenecks in large-scale

163 phylogenomic data do not appear to be the sequencing, but rather the compilation of high quality, well-

164 curated genomic resources and the availability of adequate software and methods that can fuel

165 phylogenomics for the next century (e.g., Global Genome Initiative, www.mnh.si.edu/ggi/).

\section{3.2. Data quality}

168 Genome-scale data in the form of multiple alignments and other homology statements are the foundation

169 of phylogenomics. A major challenge is the difficulty of comprehensive quality checks of data, given that

170 HTS datasets are so large. As researchers collect datasets consisting of thousands of alignments across

171 scores of species and data quality is a serious concern that is left for detection and handling primarily by

172 computer algorithms. In addition to inherent systematic errors in the data (Kocot et al., 2017), several 
173 examples of errors in phylogenomic data sets have been reported in the literature, including the use of

174 unintended paralogous sequences in alignments (e.g., Struck, 2013); mistaking the genome sequence of

175 one species for another (Philippe et al., 2011); and inclusion of genome sequence from parasites into the

176 genome of the host (Kumar et al., 2013). However, the incidence of smaller errors in alignments that are

177 not easily discerned from natural allelic variation, such as base miscalls or misplaced indels, are probably

178 much more widespread than has been reported in the literature. Combined with the sensitivity of some

179 phylogenomic datasets to individual loci or Single Nucleotide Polymorphisms (SNP) within loci (Shen,

180 Hittinger \& Rokas, 2017), such errors could have damaging consequences for phylogenomic studies, for

181 the inference of topology and branch lengths of both gene phylogenies and species phylogenies

182 (Marcussen et al., 2014; Bleidorn, 2017). Furthermore, as phylogenomic datasets increase in size, it is

183 likely that the accumulation of errors due to the use of different sequencing chemistries and sequencing

184 depths (Quail et al., 2012; Goodwin, McPherson \& McCombie, 2016) will ultimately influence

185 phylogenetic inference. We predict that the impact of these errors will largely depend on the sampling

186 breadth and taxonomic scale of each study, and whether the species phylogeny is a tree or a network.

187 Sequencing high-quality samples from well-archived voucher specimens is a good first step to

188 increase reproducibility and alleviate issues related to sample identity (Peterson et al., 2007; Pleijel et al.,

189 2008; Chakrabarty, 2010; Turney et al., 2015; Troudet et al., 2018). For individual phylogenomic studies,

190 wholesale manual inspection of every locus is unsustainable (Irisarri et al. 2017), but spot checks of a

191 subset of the data (e.g., 5-10\% of the alignments) is a recommended best practice (Phillipe et al., 2011)

192 that is beginning to be encouraged in peer review and in published papers (Montague et al., 2014; Liu et

193 al., 2017). Such checking is important not only for new data generated by a given study, but also for data

194 downloaded from public repositories such as NCBI and Orthomam, which are well known to contain

195 errors (Wesche, Gaffney \& Keightley, 2004; Ranwez et al., 2007; Douzery et al., 2014). Because several

196 databases do not include the raw sequence data it is often impossible to evaluate whether oddities may

197 derive from poor sequencing. Robust pipelines for flagging poorly aligned sites or non-homologous

198 sequences, based on existing tools or novel scripts such as Gblocks (Castresana, 2000; Talavera \& 
199 Castresana, 2007) or TrimAl (Capella-Gutiérrez, Silla-Martínez \& Gabaldon, 2009) are gradually being 200 put into practice (Marcussen et al., 2014; He et al., 2016; Irisarri et al., 2017).

201 Coding regions, whether derived from transcriptomes or whole-genome data, are particularly

202 amenable to spot checking of alignments and to filtering out of low-quality data with bioinformatic

203 pipelines (e.g., Dunn et al., 2013; Blom, 2015). Coding regions have the advantage of allowing amino

204 acids to guide alignments, which is particularly useful for highly divergent sequences. Stop codons can

205 help flag errors or genuine pseudogenes. Examining gene tree topologies is also widely used to detect

206 paralogs in phylogenomic data (e.g., Betancur, Naylor \& Ortí, 2014). Examining gene trees for aberrantly

207 long branch lengths can also reveal misalignments (e.g., He et al., 2016); sensitivity analyses of methods

208 for indirectly detecting errors in alignments are sorely needed.

209

210 3.3. Data generation and marker development

211 3.3.1. Genome reduction methods

212 A growing number of genome reduction methods are now providing empiricists with the means to

213 generate genomic subsets suitable for phylogenetic and phylogeographic inference (reviewed by

214 McCormack et al., 2013; Leaché \& Oaks 2017; Lemmon \& Lemmon, 2013). For phylogenomics, most

215 prominently featured are sequence-capture, focusing on highly conserved regions (e.g., Faircloth et al.,

216 2012; Lemmon, Emme \& Lemmon, 2012; reviewed by Jones \& Good, 2016) and transcriptomes (e.g.,

217 Misof et al., 2014; Cohen et al., 2016; Fernández et al., 2014; Park et al., 2015; Simion et al., 2017;

218 Irisarri et al., 2017), but phylogenomic trees have also been constructed based on restriction-digest

219 methods that focus on single nucleotide polymorphisms or SNPs (Leaché, Chavez \& Jones, 2015; Harvey 220 et al., 2016) and analysis of transposable elements (e.g., Suh, Smeds \& Ellegren, 2015). This diversity of

221 marker types for phylogenetics should be celebrated, but each marker type brings with it a list of pros and 222 cons. For example, many questions in the higher level phylogenetics of animals and plants have so far 223 relied almost exclusively on transcriptome data. However, the uncritical use of transcriptomes in

224 phylogenetics is not without caveats. At high taxonomic levels, coding regions can exhibit extreme levels 
225 of among-taxon base composition, sometimes resulting in strong violations of phylogenetic models

226 (Romiguier et al., 2016; Romiguier \& Roux, 2017). Coding regions can exhibit reduced levels of

227 incomplete lineage sorting (ILS) compared to noncoding regions (Scally et al., 2012). Such reduced ILS

228 could in fact be helpful in building complex phylogenies with rapid radiations (Edwards, 2009a), but it

229 will certainly distort estimated branch lengths when coalescent methods, which assume neutrality, are

230 used. In addition to yielding abundant sequence variations and SNPs, transcriptome data also yields

231 information on the levels of expression of various genes, and in which tissue-specific genes are expressed.

232 However, using these aspects of transcriptome data are less likely to be of use to phylogeneticists,

233 precisely because specific genes are often tissue-specific and because expression data can exhibit high

234 levels of variation among individuals, populations and species in space and time (Todd, Black \&

235 Gemmell, 2016). Such variation will certainly pose limitations for long term phylogenomic endeavors

236 that will likely combine data collected originally for different purposes.

237 Although non-coding portions of the genome have been largely neglected in phylogenomics

238 because they are difficult to align and analyze, we are now making progress in understanding their

239 sequence evolution and how it might be informative for comparative purposes (Ulitsky, 2016; Edwards,

240 Cloutier \& Baker, 2017). For instance, studies on enhancer and promoter evolution in mammals have

241 shown that despite low levels of sequence conservation, there is conservation of regulatory function and

242 3D structure across species that carries information for comparative purposes (Villar et al., 2015;

243 Berthelot et al., 2018). The development of methods to infer and interpret the evolutionary history and

244 phylogenetic signal of non-coding elements and 3D genome structure is a critical priority.

245 SNPs have been advocated by some authors for higher level phylogenetics (Leaché \& Oaks,

246 2017), but the available methods for analyzing such data are still extremely limited. For example,

247 concatenation and two coalescent methods (SNAPP and SVD quartets: Bryant et al., 2012; Chifman \&

248 Kubatko, 2014) have recently been highlighted as the main methods available for phylogenomic analysis

249 of SNPs (Leaché \& Oaks, 2017). But each of these methods has its shortcomings. It is likely that

250 concatenation of SNPs will be misleading for many of the same reasons that concatenating genes can be 
251 misleading, due to different gene histories (see section 'Concepts and models in phylogenomics' for

252 further details; Kubatko and Degnan 2007). SNAPP, a coalescent method suitable for analysis of SNPs

253 (Bryant et al., 2012), works well only on relatively small data sets, and it is unclear how well SVD

254 quartets performs on some data sets (Shi \& Yang, 2018). Although SNPs do provide a helpful route

255 around the often-violated assumption in coalescent models of no recombination within loci (Bryant et al.,

256 2012), and are widely seen as excellent markers for phylogeography and population genetics, it remains

257 to be seen how powerful they are at higher phylogenetic levels.

258 Despite the diversity of marker types for phylogenomics, it remains unclear whether features

259 specific to each marker type can ultimately result in phylogenomic datasets that can strongly mislead. For

260 example, incongruence in the phylogeny of modern birds developed by Jarvis et al. (2014; 48 whole

261 genomes) and Prum et al. (2015; 259 anchored phylogenomics loci, 198 species) has recently been

262 attributed to differences in marker type rather than number of taxa (Reddy et al., 2017). Whereas Jarvis et

263 al. (2014) used primarily noncoding loci because they observed gross incongruence when using coding

264 regions, the loci used by Prum et al. (2015), although nominally focused on broadly "anchored"

265 conserved regions, came primarily from coding regions. Thus, at least one marker type is likely

266 inappropriate when applied across modern birds (ca. $100 \mathrm{Ma}$ ). These data type effects can stem from

267 multiple sources. Selection on exons might lead to localized differences in effective population size

268 across the genome, as previous studies have highlighted issues with base composition heterogeneity

269 within exons across taxa (Figuet et al., 2015; Scally et al., 2012). On the other hand, alignment quality of

270 introns and ultraconserved elements (UCEs) can sometimes be less than desired (Edwards, Cloutier \&

271 Baker, 2017). Clearly marker effects can potentially have substantial consequences on species tree

272 estimates and need to be further evaluated and compared side-by-side by the phylogenetic community

273 (Shen, Hittinger \& Rokas, 2017).

274

275 3.3.2. A priori versus a posteriori selection of loci for phylogenomics 
276 In an ideal world, phylogeneticists would have whole and fully annotated genomes of all taxa available,

277 allowing them to select loci for phylogenomics based on the relative merits of different loci. This $a$

278 posteriori (after data generation) selection would be carried out after assessing desired phylogenetic and

279 biological properties of a wide array of markers for which the data are already in hand. A posteriori

280 selection of loci for phylogenomics is clearly a long-term goal that will yield greater choice and

281 justification for specific loci. Today, the loci for phylogenomics are selected a priori (i.e., before data

282 generation) based primarily on cost and ease of collection and alignment, disregarding potentially useful

283 regions of the genome. Thus, an attractive aspect of whole-genome sequencing (WGS) for phylogenomics

284 is to have the opportunity to select markers a posteriori once genomes are in hand (e.g., Edwards,

285 Cloutier \& Baker 2017; Fig. 1). WGS is less prone to sequencing biases and also allows for further

286 expansion into different research fields and questions based on the same initial data (Lelieveld et al.,

287 2015). In contrast, a priori marker selection often limits the kinds of questions and methods that

288 researchers can apply and represents a real constraint for phylogenomics and other disciplines.

289 An important constraint for using WGS for downstream phylogenomic analyses is genome

290 quality. Obtaining high-coverage well-assembled and thoroughly annotated genomes is still very

291 expensive and time-consuming, and even low coverage genomes are still outside reach for large portions

292 of the scientific community. However, even low coverage genomes, which should be cautiously used for

293 maker selection due to potential problems caused by poor annotation and coverage, can sometimes yield a

294 modest number of markers for phylogenomics, and in the short term might even yield data sets allowing a

295 broader diversity of markers for analysis. Although we are fully aware of its constraints, we are

296 particularly excited about the potential that we see in routinely using WGS to produce phylogenomic data 297 sets.

299 3.3.3. More taxa versus more loci

300 The question of whether to add more genes or more taxa was a dominant theme in phylogenetics in the

301 1990s and early 2000s (e.g., Hillis, 1996; Kim, 1996), and remains a persistent question in phylogenomics 
302 today. After much debate in the literature (e.g., Hillis, 1996; Graybeal, 1998; Hillis, 1998; Poe, 1998;

303 Mitchell, Mitter \& Regier, 2000), the initial consensus view from the Sanger sequencing era of

304 phylogenetics, is that adding more taxa generally improves phylogenetic analysis more so than more

305 markers (e.g., Hillis, 1996; Graybeal, 1998; Poe, 1998). However, phylogenomics is adding a new twist to

306 this consensus, both from the standpoint of data acquisition and from theory (e.g., Rokas, 2005; Nabhan

$307 \&$ Sarkar, 2012; Xi et al., 2012; Patel, Kimball \& Braun, 2013). Amassing large data sets, both in terms of

308 more taxa and more loci, is still a guiding principle of phylogenomics. But with the ability now to bring

309 together many different types of markers in a single analysis, and to analyze them in ways that were not

310 previously available, the "more taxa vs. more genes" debate is becoming more nuanced (Nabhan \&

311 Sarkar, 2012). For example, recent work shows that this debate can be highly context-specific and model-

312 dependent (e.g., Baurain, Brinkmann \& Philippe, 2006; Dell Ampio et al., 2013; Edwards et al., 2016b).

313 Also, some phylogenetic methods, such as coalescent methods, appear to be more robust to limited taxon

314 sampling than traditional methods like concatenation (Song et al., 2012; Liu, Xi \& Davis, 2015). Some

315 researchers favor "horizontal" data matrices, wherein the number of loci far exceeds the number of taxa,

316 whereas other researchers favor "vertical" matrices, where many taxa are analyzed at just a few (1-5) loci.

317 Whereas the PCR era of phylogenetics was often dominated by vertical matrices, HTS is allowing data

318 matrices to become more horizontal (Fig. 2). It is important to note that as these more horizontal data

319 become more prevalent, they increase the amount of missing data and aligning problems that can

320 contribute to misleading or low phylogenetic resolution. At least in a coalescent framework, scaling up in

321 both dimensions will be crucial for improved phylogenies and the number of loci required to resolve a

322 given phylogenetic problem is often a function of the coalescent branch lengths in the phylogenetic tree

323 being resolved, with longer branches requiring fewer loci (Edwards et al., 2007; Huang et al., 2010). At

324 deeper time scales, increasing the number of loci have not proven particularly useful to resolve

325 problematic areas in the ToL (e.g.sister group to animals; King \& Rokas, 2017). Despite methodological

326 complications in the accurate estimation of population genetic parameters and computational limitations

327 for MCMC convergence at deep times in coalescent-based analyses, recalcitrant nodes likely represent 
328 true complexities in the diversification history of these groups and not necessarily reflect failures of 329 coalescent-based phylogenetics (Lanier \& Knowles, 2015).

330 To study how researchers have resolved challenges of balancing numbers of taxa versus numbers

331 of loci, we quantified trends in phylogenomic data set size and structure over the past 13 years, drawing

332 data from 164 data sets across diverse taxa (Supplementary Table S1). We found that, whereas the

333 number of species per paper has not increased significantly over time (Fig. 2A), there were significant

334 increases with time in number of loci (Fig. 2B), total length of sequence analyzed (Fig. 2C), as well as

335 total data set size, as measured by the product of species times locus number (Fig. 2E) or species times

336 total alignment length (Fig. 2F). These results mirror similar trends evaluated for the size of data sets in

337 phylogeography (Garrick et al., 2015). Surprisingly, we found no evidence for a tradeoff between the

338 number of species investigated and the number of loci analyzed (Fig. 2D); perhaps HTS data sets have

339 plateaued somewhat in terms of number of loci, whereas the number of species analyzed is more a

340 function of the questions being asked and the clade being investigated. Regardless, we suspect that, in

341 general, the number of loci and total alignment lengths in phylogenomic data sets are likely a function of

342 resources and sequencing effort. The era of whole genome sequencing in phylogenomics is still dawning,

343 given that most studies thus far have used targeted approaches for sampling loci (Supplementary Table

344 S1). We suspect that once whole genome sequencing on a clade-wide basis become routine (e.g., Genome

345 10K Community of Scientists, 2009; Grigoriev et al., 2014; Cheng et al., 2018), we will witness yet

346 another jump in the sizes of phylogenomic data sets.

\section{3.3.4. Filtering heterogeneous phylogenomic data sets}

349 Recent studies show that the addition of more loci and more taxa can result in higher levels of gene-tree

350 discordance (e.g., Smith et al., 2015; Shen, Hittinger \& Rokas, 2017). This is not unexpected - as the

351 number of taxa and loci increase, the greater the likelihood that the dataset will capture the heterogeneous

352 evolutionary history (e.g., incomplete lineage sorting [ILS], lateral gene transfer [LGT], hybridization,

353 gene duplication and loss [GDL]; See Table 1 for a definition of these concepts), misidentification of 
354 orthologs from paralogs, and patterns of molecular evolution (e.g., noise/lack of signal in the sequences,

355 and nonstationarity in base composition) that can contribute to gene tree discord. At the same time, the

356 variance in gene tree topologies could also have been caused by errors in gene tree estimation. Such

357 observations have been used to argue that the accuracy of gene tree inference should be maximized or at

358 least evaluated, but it is not clear what criteria should be used to filter sets of gene trees. For example,

359 filters can be based on rates of molecular evolution (Klopfstein, Massingham \& Goldman, 2017), levels

360 of phylogenetic informativeness (Fong et al., 2012), or on the cause of gene-tree discord itself, if known

361 (Huang et al., 2010). Chen, Liang \& Zhang (2015) found that selecting genes whose trees contained a

362 well-known uncontested and long branch in a given species phylogeny (long enough so as not to incur

363 substantial ILS) was a better way to improve phylogenomic signal than selecting genes based on

364 characteristics of sequence evolution. All of these methods are excellent suggestions and should be

365 explored further. Still, the effects of such culling on the distribution of gene trees, and whether it could

366 distort the distribution so that it departs from models like the multispecies coalescent, are unknown, and

367 potentially of concern (but see Huang et al., 2017). Aside from the use of some explicit methods for

368 detection of outlier genes (e.g., de Vienne, Ollier \& Aguileta, 2012), rogue taxa (e.g., Aberer, Krompas \&

369 Stamatakis, 2013), outlier long branches (e.g., Mai \& Mirarab, 2018), and tree space visualization (e.g.,

370 Huang et al., 2016; Jombart et al., 2017), an obvious way to alleviate potential effects of gene tree outliers

371 is a more balanced taxon sampling (Hedtke, Townsend \& Hillis, 2006). Nonetheless, we need further

372 studies on the effects of different types of phylogenomic filters on the properties of large-scale

373 phylogenomic datasets.

374

375 3.4. High throughput sequencing opens possibilities for new information and marker types

377 3.4.1. Heterozygosity and Intra-Individual Site Polymorphisms

378 Organisms with multiple ploidy levels are intra-individual polymorphisms and heterozygosity is, of

379 course, common in diploid and polyploid organisms. However, due to issues such as lack of sufficient 
380 read coverage and connectivity, confident identification of such polymorphism continues to be

381 challenging (Garrick, Sunnnucks \& Dyer, 2010; Lischer, Excoffier \& Heckel, 2014; Schrempff et al.,

382 2016) and many data sets do not permit statistical approaches, such as PHASE (Stephens, Smith \&

383 Donnelly, 2001) to robustly determine haplotypes of different alleles (Garrick, Sunnnucks \& Dyer, 2010).

384 Consequently, in phylogenetics, heterozygosity and intra-specific polymorphic sites are often

385 accommodated using UIPAC ambiguity codes or ignored entirely or by randomly selecting alleles (Iqbal

386 et al., 2012). In fact, most “one sequence per individual/species" phylogenomic data sets consists of

387 haplotypes that might not occur in nature because many methods, including de novo assemblies of

388 genomes, yield single haplotypes consisting of consensus or other haplotype summaries from diploid

389 organisms. The fact that HTS produces several reads of the same region allows for the identification of

390 heterozygosity and intra-specific polymorphic sites represents an untapped opportunity to incorporate

391 intra-individual variation in our phylogenetic estimates (Lischer, Excoffier \& Heckel, 2014; Schrempff et

392 al., 2016; Andermann et al., 2018). Recent models have been proposed to improve calling and sorting

393 such polymorphisms (De Maio, Schlötterer \& Kosiol, 2013; Lischer, Excoffier \& Heckel, 2014; Potts et

394 al., 2014; Schrempff et al., 2016) and, although results of different studies vary (Kubatko, Gibbs \&

395 Bloomquist, 2011; Lischer et al. 2014), estimation of individual, naturally occurring haplotypes has been

396 shown to improve phylogenomic reconstructions based on genome-scale data (Andermann et al., 2018).

397

398 3.4.2. Rare genomic changes

399 As noted above, molecular phylogenetics has primarily used alignments of sequence-level data for

400 phylogenetic inference. This bias is perhaps driven by the notion that genome evolution occurs by

401 aggregating small changes, such as point substitutions, over time, but more likely it is due to the

402 challenges of characterizing rare genomic changes, such as indels, transpositions, inversions, and other

403 large-scale genomic events (Rokas \& Holland, 2000; Boore 2006; Bleidorn 2017). This emphasis on

404 sequence data has produced a vast ecosystem of algorithms tailored to analyze such data, but most

405 phylogeneticists would agree that rare genomic changes would be a welcome addition to the toolkit of 
406 phylogenomics, because they are generally regarded as highly informative markers, providing strong

407 evidence of homology and monophyly (Boore 2006; Rogozin et al., 2008). With the increased availability

408 and affordability of WGS, our view of genome plasticity has changed drastically in recent years and we

409 are now capable of exploring other genomic features beyond the signals encapsulated in DNA or amino

410 acid sequences (e.g., Ryan et al., 2013). The question then arises of how to identify and utilize these rare

411 genomic markers, as well and assess their phylogenetic informativeness (Rokas \& Holland, 2000; King \&

412 Rokas, 2017). Genome-level characters will likely have different evolutionary properties than sequence-

413 based markers, suggesting that one of the biggest challenges we face for incorporating genomic changes

414 into phylogenetic analyses is to find informative evolutionary models and tools suited for these kinds of

415 data and assess how congruent or discordant they are with respect to other markers (e.g., Rota-Stabelli et

416 al., 2011). This will not only shed light on how phylogenetically informative different genomic changes

417 are, but also will broaden our understanding of the evolutionary intricacies across different genomic

418 regions (Rokas, 2011; Leigh et al., 2011).

419

420

\subsubsection{Gene order and synteny}

421 Computational algorithms to use gene order and rearrangements as markers in phylogenetics (Tang et al., 422 2004; Ghiurcuta \& Moret, 2014; Kowada et al., 2016) were spurred in part by the seminal paper by

423 Boore, Daehler \& Brown (1999) using mitochondrial gene rearrangements to understand the phylogeny of

424 arthropods. Initially, algorithms for making use of gene order and synteny were applied primarily to

425 microbial genomes, but recent efforts have extended such methods to the analysis of eukaryotes as well

426 (see Lin et al., 2013). Gene order and synteny appear most promising at high phylogenetic levels,

427 although we still do not know how informative gene order will be at many levels, such as within

428 mammals. Chromosomal rearrangements appear highly dynamic in some groups, such as mammals, and

429 further study of their use in phylogenomics is warranted (Murphy et al., 2005).

430

431 3.4.4. Indels and transpositions 
432 Indels and transpositions are two types of molecular characters that are underutilized in phylogenomics,

433 the former perhaps because standard methods of analysis often treat indels as missing data and the latter

434 because they are technically challenging to collect without whole genome data. Indels have been used

435 sporadically in phylogenomics and several have argued for their utility and informativeness, given

436 appropriate analytical tools (Jarvis et al., 2014; Ashkenazy et al., 2014; Roncal et al., 2016). Murphy et al.

437 (2007) used indels in protein-coding regions to bolster estimates of mammalian phylogeny and found that

438 the Atlantogenata hypothesis was supported after scrutinizing proteome-wide indels for spurious

439 alignments and orthology. The Avian Phylogenomics Project found that indels had less homoplasy than

440 SNPs and, despite showing high levels of ILS, was largely congruent with other markers across the avian

441 tree. Transposable elements arguably are even more highly favored by phylogenomics researchers, but are

442 much more difficult to isolate and analyze and have been used principally across various studies in

443 mammals and birds (Kaiser et al., 2007; Churakov et al., 2010; Kriegs et al., 2010; Suh et al., 2011; Baker

444 et al., 2014; Cloutier et al. 2018a). Whereas they are generally considered to have a low rate of

445 homoplasy, most researchers agree that they can in some circumstances exhibit insertional homoplasy.

446 Moreover, no marker is immune to the challenges of ILS, and transposable elements and indels are no

447 exception (Matzke et al., 2012; Suh, Smeds \& Ellegren, 2015). Still, the exceptional resolution afforded

448 by some studies employing transposable elements is exciting, and we expect this marker type to increase

449 in use as whole genomes are collected with higher frequency.

450

451 3.4.5. Copy Number Variations (CNV)

452 The 1000 Genomes Project estimates that in humans about 20 million base pairs are affected by structural

453 variants, including copy number variations (CNV) and large deletions (1000 Genomes Project

454 Consortium, 2015), suggesting that these types of mutations encompass a higher fraction of the genome

455 than do SNPs in humans. A CNV is a DNA segment of at least one kilobase $(\mathrm{kb})$ that varies in copy

456 number compared with a reference genome (Redon et al., 2006). CNVs appear as deletions, insertions,

457 duplications, and complex multi-site variants (Fredman et al., 2004). Such a profusion of CNVs across 
458 human genomes has proven useful in tracking population structure (Sjödin \& Jakobsson, 2012), but still

459 remains underappreciated in phylogenetics.

460 Newly available methods allow inference of $\mathrm{CNV}$ at high resolution with great accuracy

461 (Wiedenhoeft, Brugel \& Schliep, 2016). The frequency with which CNVs occur in animal and plant

462 populations raises the question of how informative they would be at higher phylogenetic levels, and

463 whether they would incur unwanted homoplasy that would obscure homology and phylogenetic

464 relationships. For example, some CNVs evolve so quickly that they can be used with success at the sub-

465 individual level, for example, in tracking clonal evolution of cancer cells using CNV-specific

466 phylogenetic methods (e.g., Schwartz \& Schäffer, 2017; Liang, Liao \& Zhu, 2017; Ricketts et al., 2018;

467 Urrutia et al., 2018). Moreover, their interspecific variation has been shown to correlate with the

468 phylogeny of some groups, such as the highly pathogenic and rapidly-evolving barley powdery mildews

469 (Frantzeskakis et al., 2018). However, such fast evolution may mean that these markers might be less

470 useful at higher levels of biological organization. Additionally, the adaptive nature of CNVs may or may

471 not facilitate clear phylogenetic signals. For example, a study in Arabidopsis thaliana (DeBolt, 2010)

472 showed that adaptation to novel environments, or to varying temperatures, is associated with mutations in

473 CNVs. If CNVs are to become a useful tool in phylogenomics or phylogeography, we must understand

474 their microevolutionary properties in greater detail. For example, the pattern of evolution of CNVs,

475 wherein deletions of genetic material may not easily revert, resulting in a type of Dollo evolution, might

476 help clarify the overall structure of the models applied to them (Rogozin et al., 2006; Gusfield, 2015).

477

478 3.5. Recent advances in the generation of high throughput sequence data and their impact on the

479 reconstruction of the Tree of Life

480 As sequencing technology rapidly moves forward (reviewed by Goodwin, McPherson \& McCombie,

481 2016), our ability to accurately identify the aforementioned marker types increases considerably. For

482 instance, the low per-base error rate of short-read sequencing technologies, such as the Illumina HiSeq X

483 Ten and NovaSeq (Illumina, San Diego, CA), allow for a significant reduction in the cost of sequencing 
484 which can result in data for more taxa at a higher coverage. This is certainly beneficial for the accurate

485 identification of SNPs, heterozygosity, and intra-individual site polymorphisms (Goodwin, McPherson \&

486 McCombie, 2016) and their use in a phylogenomic context. Moreover, single molecule real-time

487 sequencing technologies, such as Pacific Biosciences (Pacific Biosciences of California, Menlo Park, CA)

488 and Oxford Nanopore (Oxford Nanopore Technologies, ONT) produce reads that exceed $10 \mathrm{~kb}$ (Rhoads

$489 \& \mathrm{Au}, 2015 ; \mathrm{Lu}$, Giordano \& Ning, 2016). The advent of these technologies has led to improved and

490 more efficient assembly methods that allow accurate identification of structural changes (e.g., Khost,

491 Eickbush \& Larracuente, 2017; Merker et al., 2018). When combined with data resulting from short-read

492 sequencing, they represent a powerful tool to correctly identify and use a wide array of genomic markers

493 for numerous purposes. These technical advances, which include portable devices that can be carried into

494 the field (i.e., Oxford Nanopore; Johnson et al., 2017), will certainly yield an increase in the genomic loci

495 and taxa available for genomic and phylogenomic studies.

496

\section{4. Concepts and models in phylogenomics}

498 For decades, phylogenetics has struggled with how best to translate evolutionary changes in DNA 499 sequences and other characters into phylogenies, and genomic data are no exception to this trend.

500 Phylogenomics is still in a developing stage of formulating models that effectively represent the

501 underlying mechanisms for genome-scale variation while remaining efficient and within reasonable

502 analytical and bioinformatic capacities. The current focus on models and evolutionary forces generating

503 the patterns that we recover as branching and reticulation events in our phylogenetic reconstructions is a

504 healthy one and can be extended to other important topics in phylogenomics, such as species delimitation, 505 character mapping, and trait evolution (e.g., Yang and Rannala 2014). All of these areas are developing

506 rapidly and are in need of updated models and bioinformatics applications to cope with the heterogeneity

507 brought by genome-scale data.

508

509 4.1. The multispecies coalescent model 
510 One of the key practical advances in molecular phylogenetics has been the incorporation of gene tree

511 stochasticity into the inference of species phylogenies, via the multispecies coalescent model (MSC:

512 Rannala \& Yang, 2003; Liu \& Pearl, 2007; Heled \& Drummond, 2010). The MSC allows gene trees to be

513 inferred with their own histories, including coalescent-appropriate branching models, but contained

514 within independent yet connected lineages within a species phylogeny, with speciation-appropriate

515 branching models (Degnan \& Rosenberg, 2009). The main conceptual advance has been to understand

516 and separately manage the variation at different levels of biological organization - an advance that began

517 years ago (Doyle 1992; Maddison, 1997; Pamilo and Nei 1988), but has only recently been widely

518 embraced and put into practice (Edwards, 2009b). Given its ability to accommodate heterogeneous

519 histories across loci scattered throughout the genome, the MSC lays at the core of the conceptual

520 framework to deal with genome-scale data (e.g., Rannala \& Yang, 2008; Liu et al., 2015). In the few

521 instances in which model comparison and fit has been evaluated (Liu \& Pearl 2007; Edwards et al. 2007),

522 the MSC vastly outperforms concatenation. This of course does not mean that the MSC is the correct, or

523 even an adequate, model for phylogenomic data (Reid et al., 2014). Despite concerns regarding some of

524 its implementations when dealing with genomic data (e.g., Springer \& Gatesy, 2016), the MSC is a

525 powerful theoretical model for phylogenomics and there is room for refinement and improvement for its

526 applications (e.g., Edwards et al., 2016b, Xu \& Yang, 2016).

527

528 4.2. Bypassing full likelihood models by relying on summaries of the coalescent process

529 Given the huge computational resources required for modelling all the complexities of evolutionary

530 processes in a statistical framework, there is interest in methods that will accommodate genome-scale data

531 for large numbers of species within a coalescent framework. The utility of such methods cannot be

532 overstated: the rapid rise of large-scale genomic data sets has clearly outstripped theoretical and

533 computational methods required to analyze them. For example, although progress is being made

534 regarding scalability of full Bayesian methods of species phylogeny inference (e.g., Ogilvie, Bouckaert \&

535 Drummond, 2017), they are still unable to accommodate large phylogenomic datasets, which often consist 
536 of hundreds of species for thousands of loci (Supplementary Table S1). A common approach to speeding

537 up species phylogeny inference consists of 'two-step' methods, wherein gene trees are estimated first and

538 separately from the species phylogeny; then, using various summaries of the coalescent process for

539 collections of gene trees, a species phylogeny is estimated. Many useful methods for estimating species

540 phylogenies in this way have been proposed (see Marcussen et al., 2014; Liu, Wu \& Yu, 2015; Mirarab \&

541 Warnow, 2015; Mirarab, Bayzid \& Warnow, 2016), taking advantage of summary statistics of the

542 coalescent process, such as the average ranks of pairs of species in the collection of gene trees (e.g.,

543 STAR: Liu et al., 2009; ASTRAL-II: Mirarab \& Warnow, 2015) or the distribution of gene trees

544 containing triplets of species (e.g., MP-EST; Liu, Yu \& Edwards, 2010). Some of these two-step

545 methods, while approximate, nonetheless allow for statistical testing in a likelihood framework. For

546 example, MP-EST can evaluate the (pseudo)likelihood of two proposed species phylogenies given a

547 collection of gene trees and the difference in likelihood can be used to evaluate two proposed species

548 phylogenies against each other. However, such statistical approaches have rarely been used thus far, and

549 bootstrapping or approximate posterior probabilities on branches are by far the most common statistics

550 applied to species phylogenies (Sayyari \& Mirarab, 2016). Speeding up the estimation process using two-

551 step methods can be effective, but it can also accumulate errors or misallocate sources of variance which

552 cannot be corrected at later stages (Xu \& Yang, 2016). If gene trees are biased or uninformative, then

553 downstream analyses for species phylogeny estimation or species delimitation may similarly be

554 compromised (e.g., Olave, Sola \& Knowles, 2014). For example, MP-EST can sometimes perform poorly

555 when PhyML (Guindon et al., 2010) is used to build low-information gene trees because PhyML may

556 produce biased gene trees when the alignments contain very similar sequences (Xi, Liu \& Davis, 2015).

557 This may account for the lower performance of MP-EST compared to ASTRAL in some simulation

558 conditions, because ASTRAL resolves input polytomies and zero-length branches in gene trees more

559 appropriately. This difference between MP-EST and ASTRAL is eliminated when RAxML (Stamatakis,

5602014 ) is used to build gene trees (Xi, Liu \& Davis, 2015). 


\section{4.3. Beyond the multispecies coalescent model}

\section{4.3.1. Reticulation at multiple levels challenges the standard multispecies coalescent model}

564 The phylogenetic processes of branching and reticulation can operate at several levels of organization,

565 including within genes, within genomes, and within populations or species (Figs. 3, 4 and 5). For

566 example, recombination can cause reticulations within genes, allopolyploidization can cause reticulations

567 at the level of whole genomes, and introgression and hybridization can cause reticulations at the level of

568 populations. These levels are nested so that branching processes (and in part reticulations) acting at a

569 higher level will cause correlated branching patterns at lower levels. At the same time, reticulations at

570 lower levels, such as recombination acting within genes, will cause inference problems at higher levels,

571 such as estimating population histories. Crucially, however, it is only recombination that will break one

572 key element driving many recent models of phylogenetics and population histories, namely dichotomous

573 gene trees. Reticulations at levels of organization higher than the genome, such as the fusing of

574 populations, as well as gene duplication, will still yield collections of dichotomous gene trees, even if the

575 higher-level history is reticulated. Ultimately, the additive effects of these reticulate processes result in

576 our observed phylogenetic reconstructions, and we expect all of these scenarios to produce bifurcating,

577 dichotomous gene trees. From a modelling point of view, another key distinction is whether at the species

578 level, we still have a phylogeny that is tree-like, or whether a network is needed. The process whereby

579 two populations jointly produce a third requires a network to model properly. Allopolyploidy is another

580 situation requiring a network. There are several statistical methods for inferring homoploid networks (Yu

581 et al., 2014; Solís-Lemus \& Ané, 2016; Wen, Yu \& Nakhleh, 2016; Wen \& Nakhleh, 2018), species

582 histories under allopolyploidy (Jones, Sagitov \& Oxelman, 2013), and some two-step methods such as

583 PADRE (Huber et al., 2006; Lott et al., 2009). In general, dealing with multiple simultaneous violations

584 of the MSC, such as introgression and allopolyploidy, remains challenging (Degnan, 2018). It is likely

585 that the history of many radiations involves parts of the genome with a dichotomous history and parts that

586 exhibit reticulation, demanding methods that accommodate both scenarios. Alternatively, rather than

587 trying to accommodate multiple processes in our methods for phylogenetic inference, we might instead 
588 focus our attention on subsets of loci that would not violate the MSC (e.g., Knowles et al., 2018). In cases

589 where processes other than incomplete lineage sorting contribute to gene tree discord (i.e., the distribution

590 of trees is statistically inconsistent with expectations under the MSC; see Smith et al., 2015), loci

591 consistent with the MSC model can be identified (e.g., separated from loci with horizontal gene transfer)

592 using CLASSIPHY (Huang et al., 2017). It has also been suggested that in order to distinguish violations

593 of the MSC, the MSC can be used as a null model to be compared with increasingly complex models that

594 would invoke processes such as hybridization and recombination using networks (Degnan, 2018). To

595 follow this promising approach, further research must be conducted to not only model specific processes,

596 but also distinguish them.

597 Models accommodating dichotomous divergence with gene flow are somewhat limited. For

598 example, in IMa2 (Hey \& Nielsen, 2004; Hey \& Nielsen, 2007; Hey, 2010) the species phylogeny must

599 be known and fairly small; in the method of Dalquen, Zhu \& Yang (2017), both the species phylogeny

600 and gene trees are restricted to three tips. Looking forward, it may be useful to deal with two sub-

601 problems: The first is estimating the species phylogeny despite migration, for example by identifying

602 which loci are interfering with the species phylogeny inference or causing reticulations in the form of

603 gene flow. The second sub-problem is to incorporate a gradual speciation process (Fig. 6), where gene

604 flow after speciation slowly declines, perhaps according to some simple function like an exponential.

605 Such a model would capture what is thought to be a more common speciation process than the

606 instantaneous process modelled by the MSC (Jones, 2018).

607 In some cases, it is possible to model one situation with either a species network or a tree with

608 gene flow. Long (1991) discussed two models of admixture: Intermixture and gene flow (Fig. 7). The

609 phylogenetics community has mainly focused on methods for inference under the intermixture model

610 (e.g., the multispecies network coalescent; Yu et al., 2014, whereas the population genetics community

611 has focused more on models including gene flow (e.g., IM, admixture graphs, G-PhoCS, Phrapl). While

612 some initial work to test inference based on one of these models on data generated by the other has

613 recently appeared (Wen \& Nakhleh, 2018; Solís-Lemus et al., 2017; Blischak et al., 2018; Zhang et al., 
614 2018), much more work is needed to bring together these two lines of work. Simulations and comparisons

615 of observed and expected summary statistics, such as the site-frequency spectrum (Excoffier et al., 2013),

616 have proven especially useful in distinguishing such scenarios (Fig. 7).

617 Reticulation in the form of gene flow or introgression is probably the most difficult violation of

618 the MSC to address (but see Hibbins \& Hahn, 2018 for a model that estimates the timing and direction of

619 introgression based on the multispecies network coalescent), in part because the number of potential trees

620 accommodating a reticulating network is even higher than the already high number of trees for a given

621 number of taxa. There is at least one issue where reticulation presents an opportunity as well as a

622 challenge. Any kind of gene flow/hybridization means that there is the possibility of inferring the

623 existence of extinct species, because extinct species contribute novel alleles that exceed the coalescence

624 time of most alleles in the focal species under study (Hammer et al., 2011). Well-known examples are the

625 documented presence of Neanderthal genes in most human genomes due to introgression (e.g., Meyer et

626 al., 2012) and the presence of genomes derived from now-extinct diploids in extant allopolyploids (i.e.

627 meso-allopolyploids; e.g., Mandáková et al., 2010; Marcussen et al., 2015). Some current models can

628 explain the data as containing genetic information from extinct species, but they do not model the full

629 species phylogeny: such a generalized approach seems a promising avenue to explore.

630

631 4.3.2. Polyploidy and the challenges of analyzing gene duplication and loss

632 The MSC model describes well allelic lineages and the mutations they accumulate (Fig. 3; Degnan \&

633 Rosenberg, 2009; Liu, Xi \& Davis, 2015). The simple MSC model is challenging to apply to evolutionary

634 events in which the evolving entities (genes or paralogs) duplicate and occasionally go extinct during the

635 evolutionary history of the populations/species and thus cannot be sampled in contemporary population or

636 species. Estimating the existence and number of these "ghost" lineages remains challenging. For example,

637 how can we detect duplication events if one of the duplicated loci is lost in descendant lineages? In the

638 case of polyploidy, two (or more) genomes having separate evolutionary histories end up together in a 
639 single individual. What consequences for evolutionary history do genomic conflicts and dosage variation

640 in gene expression impose? Polyploidy also raises technical issues, such as whether or not homoeologous

641 sequences are recovered in standard genomic surveys.

642 The complication that gene duplication and loss (GDL) brings to the inference of species

643 phylogenies has long been recognized (Fitch, 1970). It is therefore surprising that practical solutions to

644 the problem of GDL are almost non-existent, with empirical examples usually based on ad hoc methods

645 and deductions. Ancient duplications where most additional copies are retained in descendent species can

646 be fairly easy to diagnose based on phylogeny (Oxelman et al., 2004; Pfeil et al., 2004). However,

647 resolving duplications becomes more difficult when copy number changes quickly (Ashfield et al., 2012),

648 or when duplications are recent and copy loss is complete or nearly so, thus returning the locus to a

649 single-copy state (Ramadugu et al., 2013). In the latter case, the phylogenetic pattern can mimic that of

650 ILS and become indistinguishable from it (Sousa et al., 2017), generally leaving no trace at all of the loss.

651 Why is GDL so challenging to implement in theory? The topological and coalescent-time

652 similarities between ILS and GDL complicates extending the MSC to include both processes, unless copy

653 number exceeds one in at least some samples (Fig. 4). Assuming that allelic and homoeologous variation

654 is not confused with the copy number of independently duplicated genes, at the very least, duplicated

655 genes could be handled as independent loci with missing data for some samples with MSC inference.

656 When copy loss is complete, or when the duplication is so recent so as to conflate allelic versus copy

657 variation, these GDL loci have little effect on species phylogeny inference and divergence times,

658 especially if the algorithms used employ averages over coalescence times or other parameters across

659 many gene trees (Liu et al., 2009; Sousa et al., 2017). At high proportions, though, they may cause serious

660 issues for phylogenetic reconstruction, because the unexpected positions of gene duplications in a species

661 phylogeny, coupled with random copy loss, means that no specific pattern is expected among the affected

662 gene trees (Fig. 4). This scenario contrasts with the retention of ancestral polymorphisms, where we know

663 that branches in short species phylogenies (in coalescent units) are the cause (Rosenberg \& Nordborg,

664 2002). Thus, we expect deeply coalescing lineages to occur in specific parts of a species phylogeny with a 
665 limited number of topological outcomes and branch lengths limited by effective population size, which is 666 not the case for duplicated genes. A recent approach to identifying genes that are single copy, but have 667 nonetheless been affected by GDL, was made using the genomic location of the loci (Sousa et al., 2017), 668 and could prove useful for distinguishing GDL and ILS.

669

670 4.3.3. Recombination

671 All existing methods for coalescent estimation of species trees and networks make two important 672 assumptions, namely that (1) there is free recombination between loci, and (2) there is no recombination 673 within a locus. These two assumptions address a key concept distinguishing MSC models from 674 concatenation or supermatrix models: it is the conditional independence of loci, mediated by 675 recombination between loci, and not the ability to address ILS or discordance among genes per se. 676 Moving forward, three important questions to address are: (1) How robust are methods to the presence of 677 recombination within loci and/or to the violation of independence among loci? (2) How should we model 678 recombination within the species phylogeny inference framework? and (3) How do we detect it and 679 differentiate recombination-free loci?

680 Researchers have started to examine the first question and found a detectable effect of 681 recombination only under extreme levels of ILS and gene tree heterogeneity (e.g., Lanier \& Knowles, 682 2012). However, more analyses and studies are still needed to explore a wider range of factors and 683 parameters that could affect phylogenetic inference when the assumption of recombination-free loci is 684 violated (e.g., Li et al., 2018). For answering the second question, one approach involves combining the 685 multispecies coalescent with hidden Markov models (e.g., Hobolth et al., 2007). These methods suffer 686 from the "state explosion problem", where individual states are needed for the different coalescent 687 histories, and they increase rapidly with the number of taxa in the dataset, making them infeasible except 688 for very small ( $\sim 4$ taxa) datasets. New methods that scale to larger datasets are needed if such approaches 689 are to be useful in practice. A different direction is to devise novel methods for inferring species 
690 phylogeny while assuming that the genealogies of the individual loci could take the form of an ancestral

691 recombination graph (ARG: Griffiths \& Marjoram, 1996; Siepel, 2009; Rasmussen et al., 2014).

692 Extending these approaches to address recombination would require the development of new

693 models that significantly extend the multispecies coalescent to account for ARGs within the branches of a

694 species phylogeny. For two-step species tree methods, this entails developing new methods that infer

695 ARGs for the individual loci and methods that infer species phylogenies from collections of ARGs. For

696 single-step Bayesian methods, novel developments are needed to sample species phylogenies, locus-

697 specific ARGs, and their related parameters. It will also be important to better understand the conditions

698 under which ignoring recombination will still yield reasonable estimates of phylogeny. Extending the

699 theory to accommodate ARGs may be of intrinsic interest, but if the parameter space in which

700 recombination is relevant is very small, then practitioners may be able to ignore recombination.

701

\section{4.4. Species concepts and delimitation}

703 Coalescent methods have played an important role in the development and critical evaluation of species

704 delimitation methods because they provide hypotheses for species boundaries based on genetic data and

705 be integrated with phenotypic data (e.g., Solís-Lemus et al., 2015). Irrespective of traditional species

706 concepts, it is essential that the entities at the tips of the species tree do not violate the assumptions of the

707 MSC, wherein species are defined mathematically (e.g., Rannala \& Yang, 2003, Degnan \& Rosenberg,

708 2009): the branches of the species tree constitute species or populations that do not exchange genes.

709 However, the MSC model also carries strict assumptions about the divergence process if the delimited

710 units are to be interpreted as species. Specifically, it is important to emphasize that in the "standard" MSC

711 model, these species represent populations that, immediately after divergence, no longer experience gene

712 flow. Therefore, the species of the MSC model do not necessarily correspond with species as a taxonomic

713 rank, defined by traditional species concepts (Heled \& Drummond, 2010): "MSC" species could simply

714 be populations by other criteria, so long as they have ceased to exchange genes, even for a short period of

715 time. In other words, a species tree built under the MSC might then be interpreted as a depiction of the 
716 history of the barriers to gene flow among diverging structured populations and this may be particularly

717 true when there is dense spatial and genomic sampling across individuals (Sukumaran \& Knowles, 2017).

718 Therefore, in those species tree methods requiring a priori assignments of individuals to species, such

719 assignments may strongly influence the inferred species phylogeny, in the same way that hybridization

720 will have serious consequences on an estimated species phylogeny (Leaché et al., 2014).

721 Recently, several MSC-based methods that have the ability to simultaneously perform species

722 delimitation and estimate the species phylogenies have been developed and implemented (e.g., Yang \&

723 Rannala, 2014; Jones, Aydin, \& Oxelman, 2015; Jones, 2017). These methods seem to consistently

724 recover the correct number of "MSC species" given the assumptions of the model. However, it is

725 probable that the assumption of no gene flow between the descendant populations is often violated and

726 that most reproductive isolation processes are gradual or episodic rather than sudden and permanent (e.g.,

727 Rosindell et al., 2010). There is thus need for methods that perform simultaneous species phylogeny

728 estimation and assignment of individuals to species while considering the limitations of the MSC (Jones,

729 Aydin, \& Oxelman, 2015).

730 If one prefers a species concept that affirms that most recently diverged populations are

731 necessarily reproductively isolated, current methods will overestimate the number of species as defined

732 by traditional species concepts and will likely reveal instead intraspecific population structure

733 (Sukumaran \& Knowles, 2017). Toprak et al. (2016) used DISSECT (Jones, Aydin \& Oxelman, 2015)

734 but also employed checks as to the integrity of various hypotheses of species boundaries suggested by the

735 data. From a computational point of view, any species delimitation method will need an operational

736 definition of species. Therefore, a possible development of MSC-based species delimitation methods

737 could be allowing migration and assuming that speciation is complete when a certain proportion of the

738 migrations is reached or when the migration rate is sufficiently low. However, this solution will not be

739 suited for the protracted speciation model because other kinds of information besides the movement of

740 genes will still be needed to identify when a clade becomes reproductively isolated. Possibly the best way

741 to avoid confusion is to restrict the word "species" to taxonomy and base it on multiple sources of 
742 information which are synthesized in an integrative fashion (Dayrat, 2005; Will, Mishler \& Wheeler,

743 2005; Bacon et al., 2012; Solís-Lemus, Knowles \& Ané, 2015), and refer to the reproductively isolated

744 units of MSC analysis as "MSC units" or "MSC taxa".

745

746 5. Models at the intersection of phylogenomics and macroevolution

747 At the intersection of phylogenomics and macroevolution, phylogeneticists aim at shedding light on how

748 patterns of organismal diversity have been generated and maintained through time. The former focuses

749 primarily on building phylogenies, whereas the latter uses them to study the tempo and mode of

750 diversification over time. In many important respects, these two sub-disciplines have remained distinct

751 and non-communicative. On the one hand, phylogenomics and phylogeography have not exhaustively

752 aimed to address the type of questions - related to diversification and trait evolution - that macroevolution

753 focuses on. On the other hand, macroevolution ignores many kinds of complexities inherent to the

754 phylogeny building process that phylogenomics has recently begun to address.

755

Macroevolutionary models focus on long-term processes, in terms of both species richness and

756 phenotypic diversity. They rely on two types of models: birth-death models of diversification aimed at understanding how and why speciation and extinction rates vary through time and across lineages (Hey 1992; Nee, Mooers \& Harvey, 1992; see Stadler, 2013 and Morlon, 2014 for review) and models of trait evolution aimed at understanding the mode and tempo of phenotypic evolution (Felsenstein, 1973; see Pennell \& Harmon, 2013 and Manceau, Lambert \& Morlon, 2017 for reviews). These models are typically constructed at the level of species, ignoring the populations or individuals that constitute these species (but see Manceau, Lambert \& Morlon, 2015 and Rosindell, Harmon \& Etienne, 2015 for exceptions). As a consequence, microevolutionary processes such as coalescence have informed phylogenetic methods for building phylogenies more so than have macroevolutionary methods that use them. For example, the most widely used phylogenetic dating methods generally do not acknowledge the critical distinction between speciation times, which are usually of primary interest, and coalescence times,

767 which are often assumed to represent speciation times but in fact represent events older than the 
768 divergence of the species concerned (Edwards \& Beerli, 2000; dos Reis, Donoghue \& Yang, 2016;

769 Angelis \& dos Reis 2015). In addition, macroevolutionary models are fit to species phylogenies

770 (diversification models) or a combination of species phylogenies and phenotypic data (trait evolution

771 models), most often assuming that evolution is best represented by a species tree, not a network (but see

772 Jhwueng \& O'Meara, 2015; Bastide et al., 2018; Solís-Lemus et al., 2017 for models of trait evolution on

773 networks), and that the species phylogeny is known. Nearly all models that use phylogenies to study

774 character evolution assume a single underlying species phylogeny on which characters evolve. But it has

775 become evident recently that different characters in principle have different phylogenies, for the same

776 reason that genes themselves might have different phylogenies (Hahn \& Nahkleh, 2016). Analyzing

777 incongruences between character evolution inferred from the species tree versus from gene trees that are

778 more directly linked to the character under study would provide a refined understanding of character

779 evolution. Recent work on the phylogeny of quantitative characters may be helpful in this endeavor

780 (Felsenstein, 2012).

781 Developing research projects that integrate the heterogeneity inherent in phylogenomics and

782 macroevolution will bring important new insights into the evolutionary process. For example, developing

783 diversification and phenotypic evolution models to be fit to networks rather than dichotomous trees will

784 allow estimates of rates of hybrid speciation and phenotypic evolution as well as a better understanding of

785 factors influencing such rates (Bastide et al., 2018). Embracing genetic heterogeneity and the

786 incongruence between gene trees and species phylogenies when applying macroevolutionary models

787 could help us to better understand how speciation proceeds, and also to analyze the coupling between

788 genetic and phenotypic evolution (e.g., is phenotypic convergence coupled or not with genetic

789 convergence in relevant genes?). Developing macroevolutionary models accounting for within-species

790 heterogeneity linked to biogeography could help us understand how biogeographic structuring influences

791 speciation, extinction, and phenotypic evolution.

792 More generally, evolutionary biologists have yet to thoroughly explore the type of new questions

793 that we are going to be able to address if we are given genomic data at the tips of all species from a 
794 phylogeny. Such data could allow us to gain an integrative understanding of three fundamental aspects of

795 evolution: evolution at the molecular level, at the phenotypic level, and at the clade level, as well as the

796 links among them. Are rates of evolution at these three levels correlated? If so, how? Do features of

797 genomes or of genome evolution, such as quantity of transposable elements, substitution rates, number of

798 gene duplications, influence rates of diversification and phenotypic evolution? Clearly, we are only at the

799 beginning of exploring these new possibilities.

800

801 5.1. Mapping trait evolution on heterogeneous genomic datasets

802 Mapping the genomic basis of phenotypic traits is a major trend in evolutionary biology today (Elmer \&

803 Meyer, 2011; Hoban et al., 2016). Such mapping can be conducted in the context of populations of a

804 single species or, increasingly, via comparisons of species on a phylogeny (e.g., Hiller et al., 2012;

805 Marcovitz, Jia \& Bejerano, 2016). Phylogenetic genome-wide association studies ("PhyloGWAS")

806 methods identify genomic features in coding or non-coding DNA that exhibit unusual patterns of

807 evolution on branches concerned with repeated evolution of phenotypes, thereby drawing connections

808 between the genomic and phenotypic levels (Pease et al., 2016). Such phylogenomic mapping usually

809 assumes a single phylogeny, the species phylogeny, as a framework for analysis, and therefore ignores

810 genomic heterogeneity. To make phyloGWAS mapping most efficient it might be more appropriate to use

811 the local topology in the genome for inference and estimation of ancestral states. Estimating genotype-

812 phenotype associations solely on the species phylogeny might yield misleading results regarding the

813 origin and evolution of phenotypic traits (Hahn \& Nakleh, 2016; Mendes, Hahn \& Hahn, 2016; Guerrero

$814 \&$ Hahn, 2018). Heterogeneity across gene histories has been traditionally considered as "biological

815 noise" when using comparative genomics to map traits, but of course such heterogeneity is the focus of

816 gene mapping efforts at lower taxonomic levels. A recently proposed application of the MSC for

817 quantitative traits, accounting for genealogical heterogeneity improves downstream estimates of mean

818 trait values, phylogenetic signal, and evolutionary rates of traits (Mendes et al., 2018). Furthermore,

819 genome-wide or gene-specific selective sweeps associated with the evolution of a particular phenotypic 
820 trait are a major source of genetic heterogeneity among closely related populations or species, and can be

821 captured using outlier statistics, such as Fst or Dxy (Pease et al., 2016). Such selective sweep mapping of

822 genes with large phenotypic effect can now be accomplished with high resolution and precision in

823 genomically poorly studied organisms (Lamichhaney et al., 2015). Apart from providing valuable

824 knowledge on the genetic basis of trait diversification, such data are providing increasing support to the

825 fact that cases of genetic heterogeneity can be profitably used in the effort to understand and resolve

826 evolutionary history, rather than considering it "biological noise." Such thinking needs to be incorporated

827 into comparative genomics more frequently (e.g., Mendes et al., 2018).

828

\section{5.2. Tree-free methods of character evolution}

830 We have seen that incorporating phylogenetic heterogeneity is a challenge for macroevolutionary models

831 of character evolution. At the other end of the spectrum are a class of methods (so called "tree-free

832 methods") that attempt to draw inferences and principles about trait evolution without assuming a

833 particular phylogeny. The common situation when analyzing character or trait data correlated by a

834 phylogeny is to assume a stochastic process for the trait, commonly a variation of the Brownian motion

835 (BM; Felsenstein, 1985) or Ornstein-Uhlenbeck (OU; Hansen, 1997) processes. Then, using the estimated

836 phylogeny and measured trait data for each species, the parameters of various evolutionary processes -

837 trait variation, patterns and rates of change, etc. - are estimated, often using maximum-likelihood or

838 Bayesian approaches (see Pennell \& Harmon, 2013 and Manceau, Lambert \& Morlon, 2017 for reviews).

839 However, given the various logistical and technical challenges of inferring robust phylogenies, exploring

840 tree-free methods might represent a useful mechanism for guiding the study of character evolution for

841 certain groups.

842 Tree-free comparative methods work by integrating over the space of trees (under a given

843 branching process model). For example, under a pure birth model and with enough tip measurements, the

844 optimum value of the OU process can be estimated as the sample average (Bartoszek \& Sagitov, 2015a).

845 Similar results have now been derived for other models of tree growth that include extinction (Adamczak 
846 and Miłoś, 2014; 2015; Ané, Ho \& Roch, 2017). Similarly, the rate of adaptation under the OU process,

847 often modeled as the stationary variance - the ratio of the squared "rate of evolution" (sigma parameter in

848 the OU model) and twice the "rate of adaptation" (the alpha parameter) can be estimated as the sample

849 variance (Bartoszek \& Sagitov, 2015a). Teasing sigma and alpha apart, however, requires a tree. The key

850 parameter of the BM model, the rate of evolution, is similarly estimable directly from the trait sample

851 (Bartoszek \& Sagitov, 2015b; Crawford \& Suchard, 2013), whereas the root state cannot be consistently

852 estimated without a tree (Ané, 2008; Sagitov \& Bartoszek, 2012). In addition to providing tree-free

853 estimators of some model parameters, the studies mentioned above also derived Central Limit Theorems

854 that allow computing confidence intervals around these point estimates as well as the sample sizes needed

855 to obtain reliable estimates.

856

\section{5.3. Extinct and unsampled species}

858 A notable case when phylogenomics and macroevolution do meet is in the treatment of extinct or unsampled species in phylogenetic reconstruction and dating. Despite the avalanche of genomic data for an increasing number of species, we still lack sequence data for most species, making it difficult to place

861 them in a phylogeny. Some researchers (e.g., Jetz et al., 2012; Tonini et al., 2016) have used a combination of consensus trees and current taxonomic classifications to impute the phylogenetic relationships of unsampled species. In this case, polytomies are often resolved by using distributions of branching times obtained from macroevolutionary birth-death models (Kuhn, Mooers \& Thomas, 2011).

865 While we appreciate the value of these approaches given the real logistic difficulties researchers face as

866 they attempt to obtain samples from around the globe and that methods are now easily applicable, such

867 approaches have generated well-founded concerns about biases in our inferences (Davies et al., 2012;

868 Rabosky, 2015) and the extent of these biases remain largely unknown (Pennell, FitzJohn, \& Cornwell,

869 2016). Nonetheless, there are methods that can objectively alleviate issues arising from using incomplete

870 phylogenies in downstream phylogenetic comparative analyses. For example, recent results using

871 conditioned birth-death processes (e.g., Gernhard, 2008a; b; Sagitov \& Bartoszek, 2012) show that under 
872 constant rate processes the size of the clade contributes information on the height of the tree and also on

873 the coalescence times. Such results can be used to improve the calibration and node dating of the

874 phylogeny when some species are not sampled. One would expect that ignoring the non-sequenced

875 species would incur a bias resulting in shorter tree heights, because less time is usually required to

876 generate fewer tips. Conditioned branching process models can help alleviate this bias. Also,

877 macroevolutionary birth-death models are used as branching process priors in Bayesian molecular dating.

878 The availability of likelihood expressions for incompletely sampled phylogenies (Stadler 2009; Stadler \&

879 Steel 2012; Morlon, Parsons \& Plotkin, 2011) thus allow to date phylogenies while accounting for the

880 fact that we have observed only a certain fraction of unsampled species.

881 An important source of genetic data for extinct and unsampled species comes from ancient DNA.

882 Current methods now allow sequencing ancestral DNA and incorporating it into phylogenomic,

883 phylogeographic, and population genetic analyses (reviewed by Leonardi et al., 2017), and even obtaining

884 whole-genomes from various samples dating back up to a few thousand years (e.g., Lynch et al., 2015;

885 Cloutier et al., 2018b). The paleontological and paleobiological records represent another source of

886 extinct species for which genomic data is out of reach. Having the opportunity of integrating the temporal

887 and phylogenetic information of extinct data provided by fossils into phylogenomic estimates of extant

888 diversity is a crucial task toward a complete ToL (reviewed by Hunt \& Slater, 2016). Besides the

889 possibility of placing fossil data into phylogenetic trees, a growing field of development is that of time-

890 scaling phylogenies using fossil data. Traditionally, node-dating methods have used fossils to bound the

891 minimum age of nodes at the base of extant clades in which fossils likely belong based on morphological

892 comparisons (reviewed by Ksepka et al., 2011) or estimated fossil ages have been used to post-hoc-scale

893 branch lengths (Sanderson, 1992; Smith \& O’Meara, 2012; Bapst, 2014). However, there is an increasing

894 interest in simultaneously performing phylogenetic inference and time-scaling phylogenies (Pyron, 2011;

895 Ronquist et al., 2012; Heath, Huelsenbeck \& Stadler, 2014). These methods, known as tip-dating, have

896 the advantage of accommodating phylogenetic uncertainty implemented in a Bayesian model-based

897 framework (Hunt \& Slater, 2016) and have been implemented in several groups spanning a wide temporal 
898 scale (e.g., Pyron, 2011; Pyron \& Burbrink, 2012; Ronquist et al., 2012; Heath, Huelsenbeck \& Stadler,

899 2014; Slater, 2015; Larson-Johnson, 2016; Matzke \& Wright, 2016). Lastly, these phylogenies containing

900 both extinct and extant diversity serve as framework to conduct robust diversification and trait evolution

901 studies (Hunt, 2013; Pennell \& Harmon, 2013; Pyron, 2015).

902

903 6. Building, updating and sustaining the Tree of Life

904 6.1. Scalability challenges

905 Inferring the phylogeny of all living organisms represents a different challenge than inferring the

906 relationships of just a few terminals; often the scale at which new methods are developed and tested is on

907 this latter scale. For instance, for eukaryotes alone, recent conservative estimates indicate that there are

$908 \sim 8.7$ million species on Earth and only 9-14\% of them have been formally described (Mora et al., 2011).

909 Furthermore, out of 2.6 million taxa currently represented in the Open Tree of Life

910 (https://tree.opentreeoflife.org; Hinchliff et al., 2015), only 55,000 were gathered from hard-data

911 phylogenies, whereas phylogenetic affinities of the rest were inferred from current taxonomic

912 classifications (McTavish et al., 2015; 2017). These observations suggest that the vast majority of taxa on

913 Earth still await formal taxonomic description and placement in the ToL (Mora et al., 2011; McTavish et

914 al., 2017). As mentioned above, one common challenge that phylogeneticists encounter is the difficulty in

915 accessing samples from rare, endangered, or extinct taxa, particularly in countries where collecting and

916 exporting is difficult. Recent genomic techniques now allow successful results in obtaining valuable

917 ancient DNA data from museum specimens (e.g., Staats et al., 2013; Hykin, Bi \& McGuire, 2015;

918 McCormack, Tsai \& Faircloth, 2016; McCormack et al., 2017; Ruane \& Austin, 2017), and here, we

919 advocate for routine use of these resources to improve taxon sampling, enhance research in

920 phylogenomics and phylogeography, and increase awareness and usefulness of natural history collections.

921 Despite the great increase in the generation of genomic data across organisms, we are often

922 limited to fast and efficient but simpler, less realistic phylogenetic methods and assumptions, such as IQ-

923 Tree (Nguyen et al., 2015), PhyloBayes (Lartillot et al., 2013), and ExaML (Kozlov, Aberer \& 
924 Stamatakis, 2015), to deal with large, heterogeneous datasets. The main downside of these options is that

925 they are not a full coalescent framework and thus far rely on data concatenation. Fully coalescent

926 methods, such as the popular phylogenetic software program *BEAST (Heled \& Drummond, 2010), are

927 not capable of dealing with more than a few hundred taxa and some dozen loci at a time for a common

928 analysis, and only recently the release of StarBeast2 allows for the use of thousands of loci for tens of

929 taxa (Ogilvie, Bouckaert \& Drummond, 2017). To tackle this problem, we encourage the continuing

930 development of methods that are fully scalable and ideally only increase analytical time linearly rather

931 than exponentially with the number of taxa and loci. Phylogenetic methods should also be fully

932 parallelizable (in order to run natively in computer clusters) and contain checkpoints, i.e., be able to

933 resume the analyses from the latest logged file in case an analysis crashes or the user wishes to evaluate

934 partial results. Another point of possible improvement is in dealing with new sequences to be added to a

935 previously large dataset: should the analysis start from scratch, or could there be substantial time gains by

936 letting those sequences find their placement in the phylogeny 'on the fly' (e.g., Siu-Ting et al., 2014).

937 Large scale phylogenies should ideally be based on the best (or most comprehensive) available

938 datasets in terms of taxonomic and molecular sampling and be constructed from the data itself. However,

939 even supermatrix inference conducted under a single analysis can add bias on tree heights and

940 coalescence times when performed across unbalanced sampled clades (a very common case for species-

941 rich clades or understudied taxa), and therefore affect downstream analyses that rely on these parameters

942 (e.g., biogeography, trait evolution, diversification rates). Computing optimally populated datasets that

943 combine the largest number of taxa and loci simultaneously is a complex mathematical problem, but

944 recent approaches (e.g., SUPERSMART - Antonelli et al., 2017; PyPHLAWD - Smith \& Brown, 2018)

945 attempt to overcome it objectively, such as applying the knapsack problem to phylogenetics by packing

946 the optimal choice of species and suitable alignments into a minimally sparse supermatrix.

947

\section{6.2. Community initiatives}


949 Building the ToL is a grand challenge in molecular phylogenetics, and one that cannot be accomplished

950 by a single person or institution's efforts. Several initiatives have been developed in recent years to

951 coordinate efforts and provide the research community with synthetic information. A prominent project is

952 the Open Tree of Life (https://tree.opentreeoflife.org/; Hinchliff et al., 2015). This project provides a

953 synthesis of previously published phylogenies merged through supertree and other grafting methods. One

954 issue faced by the initiative is that it relies on authors uploading their phylogenetic trees to open data

955 repositories, such as Dryad Data Repository (http://datadryad.org/pages/organization; Vision, 2010) or

956 TreeBase (Sanderson et al., 1994; Piel et al., 2009), which at least until recently only occurred in about

$95717 \%$ of cases (Drew, 2013). Substantial curatorial efforts are also critical to facilitate reusability of

958 deposited trees (McTavish et al., 2015). A different approach was taken by Antonelli et al. (2017), who

959 developed a framework for continuously inferring time-calibrated large phylogenies from raw sequence

960 data deposited in GenBank (Clark et al., 2016) in a multi-step method. Similarly, various tools have been

961 developed to make information contained in the ToL available for the general public (e.g., Rosindell \&

962 Harmon, 2012; Harmon et al., 2013).

963

964 6.3. Mapping the Tree of Life

965 While progress has been made in mapping species distributions at the large scale aiming for improved 966 conservation practices (e.g., the Map of Life collaborative project; https://mol.org/), most initiatives do 967 not map the tips of phylogenetic trees directly onto the geographic space, and therefore are limited by 968 current taxonomic knowledge. As spatial variation in biodiversity results from interactions between 969 evolutionary history and environmental factors, explicit connections between the tips of the ToL and 970 geographic ranges will greatly improve biogeographic inferences (Quintero et al., 2015) and our

971 understanding of biodiversity patterns and future trends. Advances in mapping the ToL through earth

972 history using genomic-based phylogenetic inferences over broad scales and explicit spatial models (e.g.,

973 geophylogenies and continuous diffusion models: Kidd, 2010) depend directly on locality data that should

974 be made available in raw and ready-to-use formats. Data sharing policies for associated data, such as 
975 geographic coordinates and voucher information, is not well established among journals. We argue that

976 editorial boards should try as best as possible to establish data policies that value and encourage the

977 deposit of geographic data associated to vouchered specimens and other associated information available

978 for future reference.

979

980 6.4. Best practices for building the Tree of Life

981 6.4.1. Data must be well curated in databases and publicly available

982 As we are now in the era of big data in biological sciences, adequate reproducibility must be a

983 fundamental endeavor of biodiversity research. Therefore, data publication in open access repositories

984 represents a powerful tool that not only ensures long-term storage and public availability for future

985 research, but also serves as a vehicle for clarifying intellectual rights and scientific merits (Costello \&

986 Wieczorek, 2014). Biocuration, the activity of organizing, representing, and making biological

987 information accessible to both biologists and bioinformaticians, has now become an important

988 consideration in building, updating, and sustaining the ToL (McTavish et al, 2017). The exponential

989 growth in the amount of genomic scale data and the increased dependence on the availability of each

990 other's' data to answer complex biological questions means that there is a need for improved data

991 management, analysis, and accessibility. GenBank has been the main open access repository for annotated

992 collections of publicly available molecular data. Although the data stored in this database usually lists

993 information such as organism of origin and publication details, the utility of molecular data in this

994 database to answer multiple biological questions, such as biogeographic patterns of biodiversity, is often

995 hampered by lack of associated information such as collection locality or (Scotch et al., 2011; Gratton et

996 al., 2017) attachment to a specific voucher specimen. Moreover, recent surveys have shown that fewer

997 than $20 \%$ of phylogenetic studies provide access to phylogenetic data (i.e., alignments and phylogenies)

998 and when they do, critical biological information such as complete taxon names is missing (Drew et al.,

999 2013; Magee, May \& Moore, 2014). 
1001 submit molecular data that is linked to voucher specimens deposited in recognized scientific collection

1002 and museums. Second, authors, journals, and curators should encourage all molecular data submitted to

1003 include information such as collection locality and details of voucher specimens. In this regard, other

1004 global initiatives such as the International Barcode of Life Project (iBOL; http://www.ibolproject.org)

1005 have had great success linking molecular data with morphological and distributional data. When all the

1006 data produced or published are curated to high standards and made accessible as soon as available,

1007 biological research will be able to process massive amounts of complex data much more quickly.

1008 Submitting sequence and tree data during publication is now routine. However, making available

1009 all analytical methods such as software and code used to process and analyze data is less widely

1010 employed by the phylogenetic community. Facilities such as TreeBase, Dryad Digital Repository, and

1011 Github (https://github.com/) provide a platform for the curated storage of the data and bioinformatic

1012 pipelines underlying the scientific literature (see McTavish et al., 2015; 2017). Authors and journals

1013 should require all published research to include links to raw data, processed data, and all analytical

1014 methods used to produce the results presented. In general, we advocate for following best practices of

1015 data management and publication to ensure the quality and utility of phylogenomic data and their

1016 associated biological information (Stoltzfus et al., 2012; Drew et al., 2013; Costello \& Wieczorek, 2014).

1017 In putting together Figure 2, for example, we found that basic information on a given phylogenomic

1018 study, such as the number of species or sequences analyzed, or the total number of base pairs in an

1019 alignment, were often not reported or difficult to recover; including such information in easy-to-access

1020 tables prior to article acceptance would greatly facilitate meta-analyses and syntheses as the number of

1021 studies grows (Supplementary Table S1).

1022

1023 6.4.2. The need of adequate curation of analytical tools

1024 In the same way that data must be adequately stored and curated, analytical tools must be available for

1025 future use and should guarantee proper reproducibility (Wilson et al., 2014; Darriba, Flouri \& Stamatakis, 
1026 2018). One of the reasons behind the dramatic increase in the number of phylogeographic and

1027 phylogenetic studies during the last 20 years is the proliferation of software and bioinformatic tools to

1028 process and analyze these data. Thanks to these new methods, it is now possible to implement a wide

1029 array of theoretical models that sustain the fields of phylogenomics and phylogeography. As stated above,

1030 genome-wide data have notoriously increased the necessity to expand our analytical models, ultimately

1031 leading to a stronger demand for computing resources (Darriba, Flouri \& Stamatakis, 2018). Given their

1032 key role in phylogenomic research, it is advisable that software development, documentation, and

1033 availability follow the best possible practices (e.g., Leprevost et al., 2014; Wilson et al., 2014; Guang et

1034 al., 2016; Darriba, Flouri \& Stamatakis, 2018). Having both data and analytical tools adequately stored

1035 and accessible to the public not only will ensure high reproducibility of previous studies, but, more

1036 importantly, will facilitate continuing the construction of the ToL (McTavish et al., 2017).

1037

1038 6.4.3. All contributions toward building the Tree of Life must be properly recognized

1039 Some current publishing practices in the scientific community may unintentionally represent hurdles

1040 toward the ultimate end of collecting and disseminating phylogenetic data on which to build a ToL. For

1041 instance, the increasing need in many countries and communities for publishing high-impact papers

1042 understandably often discourages researchers from releasing their data until their studies are complete and

1043 have passed the peer-review process. This is partially explained by the heavy emphasis of top journals on

1044 unusually novel and flashy findings as compared to those studies that represent more modest, but just as

1045 critical, advances in the understanding of the phylogenetic relationships of the groups. Similarly, this urge

1046 to publish high-impact papers often impedes adequate long-term studies that could potentially generate a

1047 wider variety of basic data. With the cultural emphasis on impact and numbers and rates of publication, in

1048 practice there is often a penalty for long-term studies. Our current climate often values novel results

1049 produced in the short term. Consequently, as a community, we must reach an equilibrium between short-

1050 and long-term scientific production in a way that values both, encouraging high impact studies bringing 
1051 radical reorganizations of the ToL, without hurting lower impact research and the ongoing search for

1052 innovation.

1053 Moreover, because building the ToL is a slow and daunting task, it is important that, as a

1054 scientific community, all contributors to the process receive proper recognition for their contributions,

1055 thereby keeping motivation high and retaining our best talent. Unfortunately, some contributors, both

1056 institutions and roles within them, receive less recognition in this grand task than others. For example,

1057 field biologists that obtain basic natural history information and specimens used for building the ToL

1058 (Suarez \& Tsutsui, 2004), and the natural history museums that house those specimens, are often not

1059 recognized sufficiently. As a community, we have been following a trend in which, perhaps inadvertently,

1060 we do not value as much the production of basic biological and natural history data. This can certainly be

1061 recognized in our national funding practices, which often do not support basic taxonomic or natural

1062 history fieldwork at the expense of flashier end-uses of biological specimens. Specimens are the

1063 foundation of most phylogenomic and phylogeographic studies, and we should find standard mechanisms

1064 not only to acknowledge, but also to encourage the production of these data in an integrative framework.

1065 It is time to strengthen those initiatives aimed at recognizing scientific production beyond citations of

1066 peer-reviewed literature (e.g., ORCID; https://orcid.org) by giving also credit to the production and

1067 impact of basic biology datasets and collected specimens. Providing credit for depositing and generating

1068 data by tracking, for example, number of access and downloads or number of studies using genetic data

1069 associated to specimens, could represent a formal recognition of the importance of producing and sharing

1070 basic biological data could help bridge the gap between naturalists, taxonomists, empiricists, and

1071 mathematicians invested on the study of life history.

1072 It will be exciting to have objective estimates that allow tracking the direct and indirect impact of

1073 how these data and samples are being used. We are confident that such initiatives will highlight the

1074 importance of continuing field- and museum-based research in various fields of biological research

1075 (Buerki \& Baker, 2016). Furthermore, such cultural shifts will undoubtedly encourage discerning young 
1076 minds to embrace basic biological research in their academic endeavors, rather than embracing more

1077 lucrative and societally appreciated applied fields.

1078

1079 7. Conclusions

1080 In this perspective, we have attempted to cover ground in the vast arena of issues facing modern

1081 phylogenomics today. In Table 2, we summarize some of the most pressing challenges that the field of

1082 phylogenomics is experiencing as we use coalescent-based methods toward building the ToL. We have

1083 seen how genome-scale phylogenomics, currently on a strong footing as a result of the multispecies

1084 coalescent model, is increasingly improved by models that recognize reticulate processes, such as

1085 recombination and introgression. In contrast, macroevolutionary models that use phylogenies have yet to

1086 embrace the heterogeneity that currently drives many theoretical innovations in phylogenetic

1087 reconstruction itself. We have emphasized the need for the phylogenomics community to embrace high

1088 standards of data quality, curation and accessibility in its long-term pursuit of the ToL. Such a grand

1089 mission requires value and recognition placed not only on the end products of the process, such as

1090 publications and trees, but also on the natural history specimens on which phylogenies are based and

1091 which are cared for by the community of natural history museums. Building the ToL will require

1092 contributions from all sectors of biological and related sciences - from field biology to theory and

1093 everything in between - and robust cyberinfrastructures to integrate these diverse and increasingly

1094 massive data streams.

1095

\section{ACKNOWLEDGEMENTS}

1097 This paper is a product of the 'Origin of Biodiversity Workshop' organized by Chalmers University of

1098 Technology and the University of Gothenburg, under the auspices of the Gothenburg Centre for

1099 Advanced Studies (GoCAS). We are particularly grateful to the GoCAS organizers and facilitators, in

1100 particular Karin Hårding, Mattias Marklund, Bernt Wennberg, Sandra Johansson, and Lotta Fernström.

1101 We thank Johnathan Clark, Alison Cloutier, Phil Grayson, Kathrin Näpflin, Flavia Termignoni, Jonathan 
1102 Schmitt, Simon Sin, João Tonini, and Pengcheng Wang for help compiling Supplementary Table 1.

1103 Thomas Couvreur, Tobias Andermann, Prosanta Chakrabarty, Alex Pyron, Claire Morgan, Chris Creevey,

1104 and one anonymous reviewer provided useful comments that improved the contents of this manuscript.

1105

1106 REFERENCES

11071000 Genomes Project Consortium. 2015. A global reference for human genetic variation. Nature 526:

$1108 \quad 68-74$.

1109 Aberer, A. J., Krompas, D., Stamatakis, A. 2013. Pruning Rogue Taxa Improves Phylogenetic Accuracy:

$1110 \quad$ An Efficient Algorithm and Webservice. Systematic Biology 62: 162-166.

1111 Adamczak, R., Miloś, P. 2014. U-statistics of Ornstein-Uhlenbeck branching particle system. Journal of

1112 Theoretical Probability 27: 1071-1111.

1113 Adamczak, R., Miloś, P. 2015. CLT for Ornstein-Uhlenbeck branching particle system. Electronic

$1114 \quad$ Journal of Probability 20: 1-35.

1115 Ané, C. 2008. Analysis of comparative data with hierarchical autocorrelation. Annals of Applied

$1116 \quad$ Statistics 2: 1078-1102.

1117 Ané, C., Ho, L. S. T., Roch, S. 2017. Phase transition on the convergence rate of parameter estimation

1118 under an Ornstein-Uhlenbeck diffusion on a tree. Journal of Mathematical Biology 74: 355-385.

1119 Andermann, T., Fernandes, A. M., Olsson, U., Topel, M., Pfeil, B., Oxelman, B., Aleixo, A., Faircloth,

1120 B. C., Antonelli, A. 2018. Allele Phasing Greatly Improves the Phylogenetic Utility of

1121 Ultraconserved Elements. Systematic Biology syy039, https://doi.org/10.1093/sysbio/syy039

1122 Angelis, K., dos Reis, M. 2015. The impact of ancestral population size and incomplete lineage sorting on

1123 Bayesian estimation of species divergence times. Current Zoology 61:874-885.

1124 Antonelli, A., Hettling, H., Condamine, F. L., Vos, K., Nielsson, R. H., Sanderson, J., Sauquet,

1125 H., Scharn, R., Silvestro, D., Töpel, M., Bacon, C.D., Oxelman, B., Vos, R. A. 2017. Towards a Self-

1126 Updating Platform for Estimating Rates of Speciation and Migration, Ages, and Relationships of

1127 Taxa. Systematic Biology 66:152-166. 
1128 Ashfield, T., Egan, A. N., Pfeil, B. E., Chen, N. W. G., Podicheti, R., Ratnaparkhe, M. B., Ameline-

1129 Torregrosa, C., Denny, R., Cannon, S., Doyle, J. J., Geffroy, V., Roe, B. A., Saghai-Maroof, M. A.,

1130 Young, N. D., Innes, R. W. 2012. Evolution of a complex disease resistance gene cluster in diploid

1131 Phaseolus and tetraploid Glycine. Plant Physiology 159: 336-354.

1132 Ashkenazy, H., Cohen, O., Pupko, T., Huchon, D. 2014. Indel Reliability in Indel-Based Phylogenetic

1133 Inference. Genome Biology and Evolution 6: 3199-3209.

1134 Bacon, C. D., McKenna, M. J., Simmons, M. P., Wagner, W. L. 2012. Evaluating multiple criteria for

1135 species delimitation: an empirical example using Hawaiian palms (Arecaceae: Pritchardia). BMC

1136 Evolutionary Biology 2012: 12-23.

1137 Baker, A. J., Haddrath, O., McPherson, J. D., Cloutier, A. 2014. Genomic Support for a Moa-Tinamou

1138 Clade and Adaptive Morphological Convergence in Flightless Ratites. Molecular Biology and

$1139 \quad$ Evolution 31: 1686-1696.

1140 Bapst, D. W. 2014. Assessing the effect of time-scaling methods on phylogeny-based analyses in the

1141 fossil record. Paleobiology 40: 331-351.

1142 Bartoszek, K., Sagitov, S. 2015a. Phylogenetic confidence intervals for the optimal trait value. Journal of

$1143 \quad$ Applied Probability 52: 1115-1132.

1144 Bartoszek, K., Sagitov, S. 2015b. A consistent estimator of the evolutionary rate. Journal of Theoretical

$1145 \quad$ Biology 371: 69-78.

1146 Bastide, P., Solís-Lemus, C., Kriebel, R., Sparks, K. W., Ané, C. 2018. Phylogenetic Comparative

1147 Methods on Phylogenetic Networks with Reticulations. Systematic Biology 67: 800-820.

1148 Baurain, D., Brinkmann, H., Philippe, H. 2006. Lack of Resolution in the Animal Phylogeny: Closely

1149 Spaced Cladogeneses or Undetected Systematic Errors? Molecular Biology and Evolution 24: 6-9.

1150 Berthelot, C., Villar, D., Horvath, J. E., Odom, D. T., Flicek, P. 2018. Complexity and conservation of

1151 regulatory landscapes underlie evolutionary resilience of mammalian gene expression. Nature

$1152 \quad$ Ecology and Evolution 2: 152-163.

1153 Betancur, R., Naylor, G. J. P., Ortí, G. 2014. Conserved genes, sampling error, and phylogenomic 
1154 inference. Systematic Biology 63: 257-262.

1155 Bleidorn, C. 2017. Sources of Error and Incongruence in Phylogenomic Analyses. In: Phylogenomics.

1156 Cham: Springer International Publishing, 173-193.

1157 Blom, M. P. K. 2015. EAPhy: A Flexible Tool for High-throughput Quality Filtering of Exon-alignments 1158 and Data Processing for Phylogenetic Methods. PLoS ToL.

1159 Boore, J. L. 2006. The use of genome-level characters for phylogenetic reconstruction. Trends in Ecology $1160 \quad$ and Evolution 21:439-446.

1161 Boore, J. L., Daehler, L. L., Brown, W. M. Complete sequence, gene arrangement, and genetic code of 1162 mitochondrial DNA of the cephalochordate Branchiostoma floridae (Amphioxus). 1999. Molecular $1163 \quad$ Biology and Evolution 16: 410-418.

1164 Brown, J. W., Wang, N., Smith, S. A. 2017. The development of scientific consensus: Analyzing conflict 1165 and concordance among avian phylogenies. Molecular Phylogenetics and Evolution 116: 69-77.

1166 Bryant, D., Bouckaert, R., Felsenstein, J., Rosenberg, N. A., RoyChoudhury, A. 2012. Inferring species

1167 trees directly from biallelic genetic markers: bypassing gene trees in a full coalescent analysis.

1168 Molecular Biology and Evolution 29: 1917-1932.

1169 Buerki, S., Baker, W. J. 2016. Collections-based research in the genomics era. Biological Journal of the $1170 \quad$ Linnean Society 117: 5-10.

1171 Burbrink, F. T., Pyron, R. A. 2011. The Impact of Gene-Tree/Species-Tree Discordance on

1172 Diversification-Rate Estimation. Evolution 65: 1851-1861.

1173 Capella-Gutierrez, S., Silla-Martinez, J. M., Gabaldon, T. 2009. trimAl: a tool for automated alignment 1174 trimming in large-scale phylogenetic analyses. Bioinformatics 25: 1972-1973.

1175 Castresana, J. 2000. Selection of conserved blocks from multiple alignments for their use in phylogenetic 1176 analysis. Molecular Biology and Evolution 17: 540-552.

1177 Chakrabarty, P. 2010. Genetypes: a concept to help integrate molecular phylogenetics and taxonomy. $1178 \quad$ Zootaxa 2632: 67-68.

1179 Chen, M. Y., Liang, D., Zhang, P. 2015. Selecting Question-Specific Genes to Reduce Incongruence in 
1180 Phylogenomics: A Case Study of Jawed Vertebrate Backbone Phylogeny. Systematic Biology 64:

$1181 \quad 1104-1120$.

1182 Cheng, S., Melkonian, M., Smith, S. A., Brockington, S., Archibald, J. M., Delaux, P-M., Li, F-W.,

1183 Melkonian, B., Mavrodiev, E. V., Fu, W. S. Y., Yang, H., Soltis, D. E., Graham, S. W., Soltis, P. S.,

1184 Liu, X., Xu, X., Wong, G. K-S. 2018. 10KP: A phylodiverse genome sequencing plan. GigaScience

$1185 \quad 7: 1-9$.

1186 Chifman, J., Kubatko, L. 2014. Quartet inference from SNP data under the coalescent model.

1187 Bioinformatics 30: 3317-3324.

1188 Churakov, G., Sadasivuni, M. K, Rosenbloom, K. R., Huchon, D., Brosius, J., Schmitz, J. 2010. Rodent

1189 Evolution: Back to the Root. Molecular Biology and Evolution 27: 1315-1326.

1190 Clark, K., Karsch-Mizrachi, I., Lipman, D. J., Ostell, J., Sayers, E.W. 2016. GenBank. Nucleic Acids

$1191 \quad$ Research 44: D67-D72.

1192 Cloutier, A., Sackton, T. B., Grayson, P., Clamp, M., Baker, A. J., Edwards, S. V. 2018a. Whole-genome

1193 analyses resolve the phylogeny of flightless birds (Palaeognathae) in the presence of an empirical

1194 anomaly zone. bioRxiv https://doi.org/10.1101/262949.

1195 Cloutier, A., Sackton, T. B., Grayson, P., Edwards, S. V., Baker, A. J. 2018b. First nuclear genome

1196 assembly of an extinct moa species, the little bush moa (Anomalopteryx didiformis). bioRxiv doi:

1197 https://doi.org/10.1101/262816.

1198 Cohen, O., Doron, S., Wurtzel, O., Dar, D., Edelheit, S., Karunker, I., Mick, E., Sorek, R. 2016.

1199 Comparative transcriptomics across the prokaryotic Tree of Life. Nucleic Acids Research 44: W46-

$1200 \quad$ W53.

1201 Costello, M. J., Wieczorek, J. 2014. Best practice for biodiversity data management and publication.

1202 Biological Conservation 173: 68-73.

1203 Crawford, F. W., Suchard, M. A., 2013. Diversity, disparity, and evolutionary rate estimation for

1204 unresolved Yule trees. Systematic Biology 62: 439-455.

1205 Cutter, A. D. 2013. Integrating phylogenetics, phylogeography and population genetics through genomes 
1206 and evolutionary theory. Molecular Phylogenetics and Evolution 69: 1172-1185.

1207 Dalquen, D. A., Zhu, T., Yang, Z. 2017. Maximum Likelihood Implementation of an Isolation-with-

1208 Migration Model for Three Species. Systematic Biology 66: 379-398.

1209 Darriba, D., Flouri, T., Stamatakis, A. 2018. The state of software for evolutionary biology. Molecular $1210 \quad$ Biology and Evolution 35: 1037-1046.

1211 Davies, T. J., Kraft, N. J. B., Salamin, N., Wolkovich, E. M. 2012. Incompletely resolved phylogenetic

1212 trees inflate estimates of phylogenetic conservatism. Ecology 93: 242-247.

1213 Dayrat, B. 2005. Towards integrative taxonomy. Biological Journal of the Linnean Society 85: 407-415.

1214 de Queiroz, A., Gatesy, J. 2007. The supermatrix approach to systematics. Trends in Ecology and

1215 Evolution 22: 34-41.

1216 de Vienne, D. M., Ollier, S., Aguileta, G. 2012. Phylo-MCOA: a fast and efficient method to detect

1217 outlier genes and species in phylogenomics using multiple co-inertia analysis. Molecular Biology and

1218 Evolution 29: 1587-1598.

1219 De Maio, N., Schlötterer, C., Kosiol, C. 2013. Linking Great Apes Genome Evolution across Time Scales

1220 Using Polymorphism-Aware Phylogenetic Models. Molecular Biology and Evolution 30: 2249-

$1221 \quad 2262$.

1222 DeBolt, S. 2010. Copy Number Variation Shapes Genome Diversity in Arabidopsis Over Immediate

1223 Family Generational Scales. Genome Biology and Evolution 2: 441-453.

1224 Degnan, J. H. 2018. Modeling Hybridization Under the Network Multispecies Coalescent. Systematic

1225 Biology 67: 786-799.

1226 Degnan, J. H., Rosenberg, N. A. 2009. Gene tree discordance, phylogenetic inference and the

1227 multispecies coalescent. Trends in Ecology \& Evolution 24: 332-340.

1228 Dell Ampio, E., Meusemann, K., Szucsich, N. U., Peters, R. S., Meyer, B., Borner, J., Petersen, M.,

1229 Aberer, A. J., Stamatakis, A., Walzl, M. G., Minh, B. Q., Haeseler, von A., Ebersberger, I., Pass, G.

1230 N., Misof, B. 2013. Decisive Data Sets in Phylogenomics: Lessons from Studies on the Phylogenetic

1231 Relationships of Primarily Wingless Insects. Molecular Biology and Evolution 31: 239-249. 
1232 Delsuc, F., Brinkmann, H., Philippe, H. 2005. Phylogenomics and the reconstruction of the Tree of Life.

$1233 \quad$ Nature Reviews Genetics 6: 361-375.

1234 dos Reis, M., Donoghue, P. C. J., Yang, Z. 2016. Bayesian molecular clock dating of species divergences 1235 in the genomics era. Nature Reviews Genetics 17:71-80.

1236 Douzery, E. J. P., Scornavacca, C., Romiguier, J., Belkhir, K., Galtier, N., Delsuc, F., Ranwez, V. 2014.

1237 OrthoMaM v8: A Database of Orthologous Exons and Coding Sequences for Comparative Genomics 1238 in Mammals. Molecular Biology and Evolution 31:1923-1928.

1239 Doyle, J. J. 1992. Gene trees and species trees: molecular systematics as one-character taxonomy.

$1240 \quad$ Systematic Botany 17: 144-163.

1241 Drew, B. T. 2013. Data deposition: Missing data mean holes in Tree of Life. Nature 493: 305.

1242 Drew, B. T., Gazis, R., Cabezas, P., Swithers, K. S., Deng, J., Rodriguez, R., Katz, L. A., Crandall, K. A.,

1243 Hibbett, D. S., Soltis, D. E. 2013. Lost Branches on the Tree of Life. PLoS Biology 11:e1001636.

1244 DOI: 10.1371/journal.pbio.1001636.

1245 Dunn, C. W., Howinson, M., Zapata, F. 2013. Agalma: an automated phylogenomics workflow. BMC $1246 \quad$ Bioinformatics 14: 330.

1247 Edwards, S. V. 2009a. Natural selection and phylogenetic analysis. Proceedings of the National Academy 1248 of Sciences of the United States of America 106: 8799-8800.

1249 Edwards, S. V. 2009b. Is a new and general theory of molecular systematics emerging? Evolution 63:1$1250 \quad 19$.

1251 Edwards, S. V., Beerli, P. 2000. Perspective: gene divergence, population divergence, and the variance in 1252 coalescence time in phylogeographic studies. Evolution 54: 1839-1854.

1253 Edwards, S. V., Cloutier, A., Baker, A. J. 2017. Conserved Nonexonic Elements: A Novel Class of 1254 Marker for Phylogenomics. Systematic Biology 66: 1028-1044.

1255 Edwards, S. V., Liu, L., Pearl, D. K. 2007. High-resolution species trees without concatenation.

1256 Proceedings of the National Academy of Sciences USA 104: 5936-5941.

1257 Edwards, S. V., Potter, S., Schmitt, C. J., Bragg, J. G., Moritz, C. 2016a. Reticulation, divergence, and the 
1258 phylogeography-phylogenetics continuum. Proceedings of the National Academy of Sciences USA

$1259 \quad 113: 8025-8032$.

1260 Edwards, S. V., Xi, Z., Janke, A., Faircloth, B. C., McCormack, J. E., Glenn, T. C., Zhong, B., Wu, S.,

1261 Lemmon, E. M., Lemmon, A. R., Leaché, A. D., Liu, L., Davis, C. C. 2016b. Implementing and

1262 testing the multispecies coalescent model: A valuable paradigm for phylogenomics. Molecular

1263 Phylogenetics and Evolution 94: 447-462.

1264 Elmer, K. R., Meyer, A. 2011. Adaptation in the age of ecological genomics: insights from parallelism

1265 and convergence. Trends in Ecology and Evolution 26: 298-306.

1266 Ellegren, N., Galtier, N. 2016. Determinants of genetic diversity. Nature Reviews Genetics 17: 422-433.

1267 Excoffier, L., Dupanloup, I., Huerta-Sánchez, E., Sousa, V. C., Foll, M. 2013. Robust demographic

1268 inference from genomic and SNP data. PLoS Genet 9: e1003905.

1269 Faircloth, B. C., McCormack, J. E., Crawford, N. G., Harvey, M. G., Brumfield, R. T., Glenn, T. C. 2012.

1270 Ultraconserved Elements Anchor Thousands of Genetic Markers Spanning Multiple Evolutionary

1271 Timescales. Systematic Biology 61: 717-726.

1272 Faurby, S., Svenning, J. C. 2015. A species-level phylogeny of all extant and late Quaternary extinct

1273 mammals using a novel heuristic-hierarchical Bayesian approach. Molecular Phylogenetics and

$1274 \quad$ Evolution 84: 14-26.

1275 Felsenstein, J. 1973. Maximum-likelihood estimation of evolutionary trees from continuous characters.

1276 American Journal of Human Genetics 25:471-492.

1277 Felsenstein, J. 1985. Phylogenies and the comparative method. American Naturalist 125: 1-15.

1278 Felsenstein, J. 1988. Phylogenies from molecular sequences: inference and reliability. Annual Review of

$1279 \quad$ Genetics 22: 521-565.

1280 Felsenstein, J. 2012. A comparative method for both discrete and continuous characters using the

1281 threshold model. American Naturalist 179: 145-156.

1282 Fernández, R, Laumer C. E., Vahtera, V., Libro, S., Kaluziak, S., Sharma, P. P., Pérez-Morro, A. R.,

1283 Edgecombe, G. D., Giribert, G. 2014. Evaluating Topological Conflict in Centipede Phylogeny 
$1284 \quad$ Using Transcriptomic Data Sets. Molecular Biology and Evolution 31: 1500-1513.

1285 Figuet, E., Ballenghien, M., Romiguier, J., Galtier, N. 2015. Biased Gene Conversion and GC-Content

1286 Evolution in the Coding Sequences of Reptiles and Vertebrates. Genome Biology and Evolution 7:

$1287 \quad 240-250$.

1288 Fitch, W. M. 1970. Distinguishing homologous from analogous proteins. Systematic Zoology 19: 99-113.

1289 Fong, J. J., Brown, J. M., Fujita, M. K., Boussau, B. 2012. A Phylogenomic Approach to Vertebrate

1290 Phylogeny Supports a Turtle-Archosaur Affinity and a Possible Paraphyletic Lissamphibia. PLoS

1291 ONE 7: e48990-14.

1292 Frantzeskakis, L., Kracher, B., Kusch, S., Yoshikawa-Maekawa, M., Bauer, S., Pedersen, C., Spanu, P.

1293 D., Maekawa, T., Schulze-Lefert, P., Panstruga, R. 2018. Signatures of host specialization and a

1294 recent transposable element burst in the dynamic one-speed genome of the fungal barley powdery

1295 mildew pathogen. BMC Genomics 19: 381.

1296 Fredman, D., White, S. J., Potter, S., Eichler, E. E, Dunnen, J. T. D., Brookes, A. J. 2004. Complex SNP-

1297 related sequence variation in segmental genome duplications. Nature Genetics 36:861-866.

1298 Garrick, R. C., Sunnucks, P., Dyer, R. J. 2010. Nuclear gene phylogeography using PHASE: dealing with

1299 unresolved genotypes, lost alleles, and systematic bias in parameter estimation. BMC Evolutionary

$1300 \quad$ Biology 10: 118.

1301 Garrick, R. C., Bonatelli, I. A., Hyseni, C., Morales, A., Pelletier, T. A., Perez, M. F., Rice, E., Satler, J.

1302 D., Symula, R. E., Thomé, M. T. C. 2015. The evolution of phylogeographic data sets. Molecular

$1303 \quad$ Ecology 24: 1164-1171.

1304 Genome 10K Community of Scientists. 2009. A proposal to obtain whole-genome sequence for 10,000

1305 vertebrate species. Journal of Heredity 100: 659-674.

1306 Gernhard, T., 2008a. The conditioned reconstructed process. Journal of Theoretical Biology 253: 769-

$1307 \quad 778$.

1308 Gernhard, T. 2008b. New analytic results for speciation times in neutral models. Bulletin of Mathematical 1309 Biology 70: 1082-1097. 
1310 Ghiurcuta, C. G., Moret, B. M. 2014. Evaluating synteny for improved comparative studies.

1311 Bioinformatics 30: i9-i18.

1312 Goodwin, S., McPherson, J. D., McCombie, 2016. Coming of age: ten years of next-generation

1313 sequencing technologies. Nature Reviews Genetics 17: 333-351.

1314 Graybeal, A. 1998. Is it better to add taxa or characters to a difficult phylogenetic problem? Systematic

1315 Biology 47: 9-17.

1316 Gratton, P., Marta, S., Bocksberger, G., Winter, M., Trucchi, E., Kühl, H. 2016. A world of sequences:

1317 can we use georeferenced nucleotide databases for a robust automated phylogeography? Journal of

1318 Biogeography 44: 475-486.

1319 Griffiths, R. C., Marjoram, P. 1996. An ancestral recombination graph. in "IMA Volume on

1320 Mathematical Population Genetics” (P. Donnelly and S. Tavare, Eds.), pp. 257-270, Springer-

$1321 \quad$ Verlag, New York.

1322 Grigoriev, I. V., Nikitin, R., Haridas, S., Kuo, A., Ohm, R., Otillar, R., Riley, R., Salamov, A., Zhao, X.,

1323 Korzeniewski, F., Smirnova, T., Nordberg, H., Dubchak, I., Shabalov, I. 2014 MycoCosm portal:

1324 gearing up for 1000 fungal genomes. Nucleic Acids Research 42: D699-704.

1325 Guang, A., Zapata, F., Howison, M., Lawrence, C. E., Dunn, C. W. 2016. An Integrated Perspective on

1326 Phylogenetic Workflows. Trends in Ecology and Evolution 31: 116-126.

1327 Guerrero R. F., Hahn M. W. 2018. Quantifying the risk of hemiplasy in phylogenetic inference.

1328 Proceedings of the National Academy of Sciences USA 201811268. DOI: 10.1073/pnas.1811268115.

1329 Guindon S., Dufayard J.F., Lefort V., Anisimova M., Hordijk W., Gascuel O. 2010. New Algorithms and

1330 Methods to Estimate Maximum-Likelihood Phylogenies: Assessing the Performance of PhyML 3.0.

$1331 \quad$ Systematic Biology 59: 307-321.

1332 Gusfield, D. 2015. Persistent phylogeny. In: New York, New York, USA: ACM Press, 443-451.

1333 Hahn, M. W. 2018. Molecular Population Genomics. Oxford Univ. Press.

1334 Hahn, M. W., Nakhleh, L. 2016. Irrational exuberance for resolved species trees. Evolution 70: 7-17.

1335 Hammer, M. F., Woerner, A. E., Mendez, F. L., Watkins, J. C., Wall., J. D. 2011. Genetic evidence for 
1336 archaic admixture in Africa. Proceedings of the National Academy of Sciences 108: 15123-15128.

1337 Hansen, T. F. 1997. Stabilizing selection and the comparative analysis of adaptation. Evolution 51: 1341$1338 \quad 1351$.

1339 Harmon, L. J., Baumes, J., Hughes, C., Soberón, J., Specht, C. D., Tumer, W., Lisle, C., Thacker, R. W. 1340 2013. Arbor: Comparative Analysis Workflows for the Tree of Life. PLoS Currents 5:

1341 ecurrents.tol.099161de5eabdee073fd3d21a44518dc.

1342 Harvey, M. G., Smith, B. T., Glenn, T. C., Faircloth, B. C., Brumfield, R. T. 2016. Sequence Capture 1343 versus Restriction Site Associated DNA Sequencing for Shallow Systematics. Systematic Biology $1344 \quad 65: 910-924$.

1345 He, D., R. Sierra, Pawlowski, J., Baldauf, S. L. 2016. Reducing long-branch effects in multi-protein data 1346 uncovers a close relationship between Alveolata and Rhizaria. Molecular Phylogenetics and $1347 \quad$ Evolution 101: 1-7.

1348 Heath, T. A., Huelsenbeck, J. P., Stadler, T. 2014. The fossilized birth-death process for coherent 1349 calibration of divergence-time estimates. Proceedings of the National Academy of Sciences USA $1350 \quad 111:$ E2957-E2966.

1351 Hedtke, S. M., Townsend, T. M., Hillis, D. M. 2006. Resolution of Phylogenetic Conflict in Large Data 1352 Sets by Increased Taxon Sampling. Systematic Biology 55: 522-529.

1353 Heled, J., Drummond, A. J. 2010. Bayesian inference of species trees from multilocus data. Molecular $1354 \quad$ Biology and Evolution 27: 570-580.

1355 Hey, J., Nielsen, R. 2004. Multilocus methods for estimating population sizes, migration rates and 1356 divergence time, with applications to the divergence of Drosophila pseudoobscura and D. persimilis. $1357 \quad$ Genetics 167: 747-760.

1358 Hey, J., Nielsen, R. 2007. Integration within the Felsenstein equation for improved Markov chain Monte 1359 Carlo methods in population genetics. Proceedings of the National Academy of Sciences USA 104: $1360 \quad 2785-2790$.

1361 Hey, J. 1992. Using phylogenetic trees to study speciation and extinction. Evolution 46: 627-640. 
1362 Hey, J. 2010. Isolation with Migration Models for More Than Two Populations. Molecular Biology and $1363 \quad$ Evolution 27: 905-920.

1364 Hibbins, M. S., Hahn, M. W. 2018. The timing and direction of introgression under the multispecies 1365 network coalescent. bioRxiv doi: https://doi.org/10.1101/328575

1366 Hiller, M., Schaar, B. T., Indjeian, V. B., Kingsley, D. M., Hagey, L. R., Bejerano, G. 2012. A “forward 1367 genomics" approach links genotype to phenotype using independent phenotypic losses among related $1368 \quad$ species. Cell Reports 2: 817-23.

1369 Hillis, D. M. 1996. Inferring complex phylogenies. Nature 383: 130-131.

1370 Hillis, D. M. 1998. Taxonomic sampling, phylogenetic accuracy, and investigator bias. Systematic $1371 \quad$ Biology 47: 3-8.

1372 Hinchliff, C. E., Smith, S. A., Allman, J. F., Burleigh, J. G., Chaudhary, R., Coghill, L. M., Crandall, K. 1373 A., Deng, J., Drew, B. T., Gazis, R., Gude, K., Hibbett, D. S., Katz, L. A., Laughinghouse, H. D. IV, 1374 McTavish, E. J., Midford, P. E., Owen, C. L., Ree, R. H., Rees, J. A., Soltis, D. E., Williams, T., 1375 Cranston, K. A. 2015. Synthesis of phylogeny and taxonomy into a comprehensive Tree of Life. 1376 Proceedings of the National Academy of Sciences USA 112: 12764-12769.

1377 Hoban, S., Kelley, J. L., Lotterhos, K. E., Antolin, M. F., Bradburd, G., Lowry, D. B., Poss, M. L., Reed, 1378 L. K., Storfer, A., Whitlock, M. C. 2016. Finding the Genomic Basis of Local Adaptation: Pitfalls, 1379 Practical Solutions, and Future Directions. American Naturalist 188: 379-397.

1380 Hobolth, A., Christensen, O. F., Mailund, T., Schierup, M. H. 2007. Genomic relationships and speciation 1381 times of human, chimpanzee, and gorilla inferred from a coalescent hidden Markov model. PLoS 1382 Genet. 3, e7.

1383 Huang, H. T., He, Q. I., Kubatko, L. S., Knowles, L. L. 2010. Sources of error inherent in species-tree 1384 estimation: impact of mutational and coalescent effects on accuracy and implications for choosing 1385 among different methods. Systematic Biology 59: 573-583.

1386 Huang, H., Sukumaran, J., Smith, S. A., Knowles, L. L. 2017. Cause of gene tree discord? Distinguishing 1387 incomplete lineage sorting and lateral gene transfer in phylogenetics. PeerJ Preprints 
https://doi.org/10.7287/peerj.preprints.3489v1.

1389 Huang, W., Zhou, G., Marchand, M., Ash, J. R., Morris, D., Van Dooren, P., Brown, J. M., Gallivan, K.

1390 A., Wilgenbusch, J. C. 2016. TreeScaper: Visualizing and Extracting Phylogenetic Signal from Sets 1391 of Trees. Molecular Biology and Evolution 33: 3314-3316.

1392 Huber, K. T., Oxelman, B., Lott, M., Moulton, V. 2006. Reconstructing the evolutionary history of 1393 polyploids from multilabeled trees. Molecular Biology and Evolution 23: 1784-91.

1394 Hunt, G. 2013. Testing the link between phenotypic evolution and speciation: an integrated

1395 palaeontological and phylogenetic analysis. Methods in Ecology and Evolution 4: 714-23.

1396 Hunt, G., Slater, G. 2016. Integrating Paleontological and Phylogenetic Approaches to Macroevolution.

1397 Annual Review of Ecology, Evolution, and Systematics 47: 189-213.

1398 Huson, D. H. 2006. Application of Phylogenetic Networks in Evolutionary Studies. Molecular Biology 1399 and Evolution 23: 254-267.

1400 Hykin, S. M., Bi, K., McGuire, J. A. 2015. Fixing Formalin: A Method to Recover Genomic-Scale DNA

1401 Sequence Data from Formalin-Fixed Museum Specimens Using High-Throughput Sequencing. PLoS 1402 ONE 10(10): e0141579.

1403 Iqbal, Z., Caccamo, M., Turner, I., Flicek, P., McVean, G. 2012. De novo assembly and genotyping of $1404 \quad$ variants using colored de Bruijn graphs. Nature Genetics 44: 226-232.

1405 Irisarri, I., Baurain, D., Brinkmann, H., Delsuc, F., Sire, J., Kupfer, A., Petersen, J., Jarek, M., Meyer, A., 1406 Vences, M., Philippe, H. 2017. Phylotranscriptomic consolidation of the jawed vertebrate timetree.

$1407 \quad$ Nature Ecology and Evolution 1: 1370-1378.

1408 Jarvis, E. D., Mirarab, S., Aberer, A. J., Li, B., Houde, P., Li, C., Ho, S. Y. W., Faircloth, B. C., Nabholz,

1409 B., Howard, J. T., Suh, A., Weber, C. C., da Fonseca, R. R., Li, J., Zhang, F., Li, H., Zhou, L.,

1410 Narula, N., Liu, L., Ganapathy, G., Boussau, B., Bayzid, M. S., Zavidovych, V., Subramanian, S.,

1411 Gabaldon, T., Capella-Gutierrez, S., Huerta-Cepas, J., Rekepalli, B., Munch, K., Schierup, M.,

1412 Lindow, B., Warren, W. C., Ray, D., Green, R. E., Bruford, M. W., Zhan, X., Dixon, A., Li, S., Li,

1413 N., Huang, Y., Derryberry, E. P., Bertelsen, M. F., Sheldon, F. H., Brumfield, R. T., Mello, C. V., 
1414 Lovell, P. V., Wirthlin, M., Schneider, M. P. C., Prosdocimi, F., Samaniego, J. A., Velazquez, A. M.

1415 V., Alfaro-Nunez, A., Campos, P. F., Petersen, B., Sicheritz-Ponten, T., Pas, A., Bailey, T., Scofield,

1416 P., Bunce, M., Lambert, D. M., Zhou, Q., Perelman, P., Driskell, A. C., Shapiro, B., Xiong, Z., Zeng,

1417 Y., Liu, S., Li, Z., Liu, B., Wu, K., Xiao, J., Yinqi, X., Zheng, Q., Zhang, Y., Yang, H., Wang, J.,

1418 Smeds, L., Rheindt, F. E., Braun, M., Fjeldsa, J., Orlando, L., Barker, F. K., Jønsson, K. A., Johnson,

1419 W., Koepfli, K. P., O'Brien, S., Haussler, D., Ryder, O. A., Rahbek, C., Willerslev, E., Graves, G. R.,

1420 Glenn, T. C., McCormack, J., Burt, D., Ellegren, H., Alstrom, P., Edwards, S. V., Stamatakis, A.,

1421 Mindell, D. P., Cracraft, J., Braun, E. L., Warnow, T., Jun. W, Gilbert, M. T. P., Zhang, G. 2014.

1422 Whole-genome analyses resolve early branches in the Tree of Life of modern birds. Science

$1423 \quad 346: 1320-1331$.

1424 Jeffroy, O., Brinkmann, H., Delsuc, F., Philippe, H. 2006. Phylogenomics: the beginning of

1425 incongruence? Trends in Genetics 22: 225-231.

1426 Jetz, W., Thomas, G. H., Joy, J. B., Hartmann, K, Mooers, A. O. 2012. The global diversity of birds in

$1427 \quad$ space and time. Nature 491: 444-448.

1428 Jhwueng, D. C., O’Meara, B. 2015. Trait evolution on phylogenetic networks. BioRxiv

1429 doi: $\underline{\text { https://doi.org/10.1101/023986 }}$

1430 Johnson, S. S., Zaikova, E., Goerlitz, D. S., Bai, Y., Tighe, S. W. 2017. Real-Time DNA Sequencing in

1431 the Antarctic Dry Valleys Using the Oxford Nanopore Sequencer. Journal of Biomolecular

1432 Techniques 28: 2-7.

1433 Jombart, T., Kendall, M., Almagro-Garcia, J., Colijn, C. 2017. TREESPACE: Statistical exploration of

1434 landscapes of phylogenetic trees. Molecular Ecology Resources 17: 1385-1392.

1435 Jones, M. R., Good, J. M. 2016. Targeted capture in evolutionary and ecological genomics. Molecular

$1436 \quad$ Ecology 25: 185-202.

1437 Jones, G. R. 2017. Algorithmic improvements to species delimitation and phylogeny estimation under the 1438 multispecies coalescent. Journal of Mathematical Biology 74: 447-467.

1439 Jones, G. R. 2018. Divergence estimation in the presence of incomplete lineage sorting and migration. 
$1440 \quad$ Systematic Biology, syy041, https://doi.org/10.1093/sysbio/syy041

1441 Jones, G. R., Sagitov, S., Oxelman, B. 2013. Statistical Inference of Allopolyploid Species Networks in 1442 the Presence of Incomplete Lineage Sorting. Systematic Biology 62: 467-478.

1443 Jones, G. R., Aydin, Z., Oxelman, B. 2015. DISSECT: an assignment-free Bayesian discovery method for 1444 species delimitation under the multispecies coalescent. Bioinformatics 31: 991-998.

1445 Kainer, D., Lanfear, R. 2015. The Effects of Partitioning on Phylogenetic Inference. Molecular Biology 1446 and Evolution 32: 1611-1627.

1447 Kaiser, V. B., van Tuinen, M., Ellegren, H. 2007. Insertion events of CR1 retrotransposable elements 1448 elucidate the phylogenetic branching order in galliform birds. Molecular Biology and Evolution 24: $1449 \quad 338-347$.

1450 Khost, D. E., Eickbush, D. G., Larracuente, A. M. 2017. Single-molecule sequencing resolves the detailed 1451 structure of complex satellite DNA loci in Drosophila melanogaster. Genome Research 27: 709-721.

1452 Kidd, D. M. 2010. Geophylogenies and the Map of Life. Systematic Biology 59: 741-752.

1453 Kim, J. 1996. General inconsistency conditions for maximum parsimony: effects of branch lengths and 1454 increasing numbers of taxa. Systematic Biology 46: 363-374.

1455 King, N., Rokas, A. 2017. Embracing Uncertainty in Reconstructing Early Animal Evolution. Current $1456 \quad$ Biology 27: R1081-R1088.

1457 Klopfstein, S., Massingham, T., Goldman, N. 2017. More on the Best Evolutionary Rate for Phylogenetic 1458 Analysis. Systematic Biology 66: 769-785.

1459 Knowles, L. L., Smith, S. A. Huang, H., Sukumaran, J. 2018. A matter of phylogenetic scale:

1460 distinguishing incomplete lineage sorting from lateral gene transfer as the cause of gene tree discord 1461 in recent versus deep diversification histories. American Journal of Botany 105: 376-384.

1462 Kocot, K. M., Struck, T. H., Merkel, J., Waits, D. S., Todt, C., Brannock, P. M., Weese, D. A., Cannon, J.

1463 T., Moroz, L. L., Lieb, B., Halanych, K. M. 2017. Phylogenomics of Lophotrochozoa with

1464 Consideration of Systematic Error. Systematic Biology 66: 256-282.

1465 Kowada, L. A. B., Doerr, D., Dantas, S., Stoye, J. 2016. New Genome Similarity Measures Based on 
1466

1467

1468

1469

1470

1471

1472

1473

1474

1475

1476

1477

1478

1479

1480

1481

1482

1483

1484

1485

1486

1487

1488

1489

1490

1491

Conserved Gene Adjacencies. In: Singh M. (eds) Research in Computational Molecular Biology. RECOMB 2016. Lecture Notes in Computer Science, vol 9649. Springer, Cham.

Kozlov, A. M., Aberer, A. J., Stamatakis, A. 2015. ExaML version 3: a tool for phylogenomic analyses on supercomputers. Bioinformatics 31: 2577-2579.

Kriegs, J. O., Zemann, A., Churakov, G., Matzke, A., Ohme, M., Zischler, H., Brosius, J., Kryger, U., Schmitz, J. 2010. Retroposon Insertions Provide Insights into Deep Lagomorph Evolution. Molecular Biology and Evolution 27: 2678-2681.

Ksepka, D. T., Benton, M. J., Carrano, M. T., Gandolfo, M. A., Head, J. J., Hermsen, E. J., Joyce, W. G., Lamm, K. S., Patané, J. S. L., Phillips, M. J., Polly, P. D., van Tuinen, M., Ware, J. L., Warnock, R. C. M., Parham, J. F. 2011. Synthesizing and databasing fossil calibrations: divergence dating and beyond. Biology Letters 2011: 801-803.

Kubatko, L. S., Degnan, J. H. 2007. Inconsistency of phylogenetic estimates from concatenated data under coalescence. Systematic Biology 56: 17-24.

Kubatko, L. S., Gibbs, H. L., Bloomquist, E. W. 2011. Inferring species-level phylogenies and taxonomic distinctiveness using multilocus data in Sistrurus rattlesnakes. Systematic Biology 60: 393-409.

Kuhn, T.S., Mooers, A. Ø., Thomas, G. H. 2011. A Simple Polytomy Resolver for Dated Phylogenies. Methods in Ecology and Evolution 2: 427-36.

Kumar, S., Filipski, A. J., Battistuzzi, F. U., Kosakovsky, Pond, S. L, Tamura, K. 2012. Statistics and Truth in Phylogenomics. Molecular Biology and Evolution 29:457-472.

Kumar, S., Jones, M., Koutsovoulos, G., Clarke, M. 2013. Blobology: exploring raw genome data for contaminants, symbionts and parasites using taxon-annotated GC-coverage plots. Frontiers in Genetics 4: 237.

Kunin, V., Goldovsky, L., Darzentas, N. 2005. The net of life: reconstructing the microbial phylogenetic network. Genome Research 15: 954-959.

Lamichhaney, S., Berglund, B., Almén, M.S., Maqbool, K., Grabherr, M., Martinez-Barrio, A., Promerova, M., Rubin, C.J., Wang, C., Zamani, N., Grant, B.R., Grant, P.R., Webster, M.T., 
1492

1493

1494

1495

1496

1497

1498

1499

1500

1501

1502

1503

1504

1505

1506

1507

1508

1509

1510

1511

1512

1513

1514

1515

1516

1517

Andersson, L. 2015. Evolution of Darwin's finches and their beaks revealed by genome sequencing. Nature 518: 371-375.

Lanier, H. C., Knowles, L. L. 2012. Is Recombination a Problem for Species-Tree Analyses? Systematic Biology 61: 691-701.

Lanier, H. C., Knowles, L. L. 2015. Applying species-tree analyses to deep phylogenetic histories: Challenges and potential suggested from a survey of empirical phylogenetic studies. Molecular Phylogenetics and Evolution 83: 191-199.

Lanfear, R., Calcott, B., Kainer, D., Mayer, C., Stamatakis, A. 2014. Selecting optimal partitioning schemes for phylogenomic datasets. BMC Evolutionary Biology 14: 82.

Lartillot, N., Rodrigue, N., Stubbs, D., Richer, J. 2013. PhyloBayes MPI: Phylogenetic Reconstruction with Infinite Mixtures of Profiles in a Parallel Environment. Systematic Biology 62: 611-615.

Larson-Johnson, K. 2016. Phylogenetic investigation of the complex evolutionary history of dispersal mode and diversification rates across living and fossil Fagales. New Phytologist 209: 418-35.

Leaché, A. D., Oaks, J. R. 2017. The Utility of Single Nucleotide Polymorphism (SNP) Data in Phylogenetics. Annual Review of Ecology, Evolution, and Systematics 48: 69-84.

Leaché, A. D., Chavez, A. S., Jones, L. N. 2015. Phylogenomics of phrynosomatid lizards: conflicting signals from sequence capture versus restriction site associated DNA sequencing. Genome Biology 7: 706-719.

Leaché, A. D., Harris, R. B., Rannala B., Yanz Z. 2014. The influence of gene flow on species tree estimation: A simulation study. Systematic Biology 63: 17-30.

Leigh, J. W., Lapointe, F-J., Lopez, P., Bapteste, E. 2011. Evaluating Phylogenetic Congruence in the Post-Genomic Era. Genome Biology and Evolution 3: 571-587.

Lelieveld, S. H., Spielman, M., Mundlos, S., Veltman, J. A., Gilissen, C. 2015. Comparison of Exome and Genome Sequencing Technologies for the Complete Capture of Protein-Coding Regions. Human Mutation 36: 815-822.

Lemmon, A. R., Emme, S. A., Lemmon, E. M. 2012. Anchored Hybrid Enrichment for Massively High- 
1518 Throughput Phylogenomics. Systematic Biology 61: 727-744.

1519 Lemmon, E. M., Lemmon, A. R. 2013. High-Throughput Genomic Data in Systematics and

1520 Phylogenetics. Annual Review of Ecology Evolution and Systematics 44: 99-121.

1521 Leonardi, M., Librado, P., Der Sarkissian, C., Schubert, M., Alfarhan, A. H., Alquraishi, S. A., Al-

1522 Rasheid, K. A. S., Gamba, C., Willerslev, E., Orlando, L. 2017. Evolutionary Patterns and Processes:

1523 Lessons from Ancient DNA. Systematic Biology 66: e1-e29.

1524 Leprevost, F. V., Barbosa, V. C., Francisco, E. L., Perez-Riverol, Y., Carvalho, P. C. 2014. On best

1525 practices in the development of bioinformatics software. Frontiers in Genetics 5: 199.

1526 Liang, Y., Liao, Bo., Zhu, W. 2017. An Improved Binary Differential Evolution Algorithm to Infer

1527 Tumor Phylogenetic Trees. BioMed Research International, Article ID 5482750, 13.

1528 Li, G., Figueiró, H. V., Eizirik, E., Murphy, W. J. 2018. Recombination-aware phylogenomics unravels

1529 the complex divergence of hybridizing species. bioRxiv doi: https://doi.org/10.1101/485904

1530 Lin, Y., Hu, F., Tang, J. Moret, B. M. 2013. Maximum likelihood phylogenetic reconstruction from high-

1531 resolution whole-genome data and a tree of 68 eukaryotes. Pacific Symposium on Biocomputing

$1532 \quad 285-296$.

1533 Lischer, H. E., Excoffier, L., Heckel, G. 2014. Ignoring heterozygous sites biases phylogenomic estimates

1534 of divergence times: implications for the evolutionary history of Microtus voles. Molecular Biology

1535 and Evolution 31: 817-831.

1536 Liu, L., Pearl, D. K. 2007. Species trees from gene trees: reconstructing Bayesian posterior distributions

1537 of a species phylogeny using estimated gene tree distributions. Systematic Biology 56: 504-514.

1538 Liu, L., Wu, S., Yu, L. 2015. Coalescent methods for estimating species trees from phylogenomic data.

1539 Journal of Systematics and Evolution 53: 380-390.

1540 Liu, L., Xi, Z., Wu, S., Davis, C. C., Edwards, S. V. 2015. Estimating phylogenetic trees from genome-

1541 scale data. Annals of the New York Academy of Sciences 1360: 36-53.

1542 Liu, L., Xi, Z., Davis, C. C. 2015. Coalescent Methods Are Robust to the Simultaneous Effects of Long

1543 Branches and Incomplete Lineage Sorting. Molecular Biology and Evolution 32: 791-805. 
1544 Liu, L., Yu, L., Edwards, S. V. 2010. A maximum pseudo-likelihood approach for estimating species

1545 trees under the coalescent model. BMC Evolutionary Biology 10: 302.

1546 Liu, L., Yu, L., Pearl, D. K., Edwards, S. V. 2009. Estimating species phylogenies using coalescence

1547 times among sequences. Systematic Biology 58: 468-477.

1548 Liu, L., Zhang, J., Rheindt, F. E., Lei, F., Qu, Y., Wang, Y., Sullivan, C., Nie, W., Wang, J., Yang, F.,

1549 Chen, J., Edwards, S. V., Meng, J., Wu, S. 2017. Genomic evidence reveals a radiation of placental

1550 mammals uninterrupted by the KPg boundary. Proceedings of the National Academy of Science of

1551 the USA 114: E7282-7290.

1552 Long, J. C. 1991. The genetic structure of admixed populations. Genetics 127: 417-418.

1553 Lott, M., Spillner, A., Huber, K. T., Moulton, V. 2009. PADRE: A package for analyzing and displaying

1554 reticulate evolution. Bioinformatics 25: 1199-2000.

1555 Lu, H., Giordano, F., Ning, Z. 2016. Oxford Nanopore MinION Sequencing and Genome Assembly.

1556 Genomics, Proteomics \& Bioinformatics 14: 265-279.

1557 Lynch, V. J., Bedoya-Reina, O. C., Ratan, A., Sulak, M., Drautz-Moses, D. I., Perry, G. H., Miller, W.,

1558 Schuster, S. C. 2015. Elephantid Genomes Reveal the Molecular Bases of Woolly Mammoth

1559 Adaptations to the Arctic. Cell Reports 12: 217-228.

1560 Maddison, W. P. 1997. Gene trees in species trees. Systematic Biology 46: 523-536.

1561 Magee, A. F., May, M. R., Moore, B. R. 2014. The Dawn of Open Access to Phylogenetic Data. PLoS ONE 15629 9:e110268. DOI: 10.1371/journal.pone.0110268.

1563 Mai, U., Mirarab, S. 2018. TreeShrink: fast and accurate detection of outlier long branches in collections of 1564 phylogenetic trees. BMC Genomics 19(Suppl. 5): 272.

1565 Mallet, J., Besansky, N., Hahn, M. W. 2015. How reticulated are species? BioEssays 38: 140-149.

1566 Manceau, M., Lambert, A., Morlon, H. 2015. Phylogenies support out-of-equilibrium models of

1567 biodiversity. Ecology Letters 18: 347-356.

1568 Manceau, M., Lambert, A., Morlon, H. 2017. A unifying comparative phylogenetic framework including

1569 traits coevolving across interacting lineages. Systematic Biology 66: 551-568. 
1570 Mandáková, T., Joly, S., Krzywinski, M., Mummenhoff, K., Lysak, M. A. 2010. Fast Diploidization in

1571 Close Mesopolyploid Relatives of Arabidopsis. The Plant Cell 22: 2277-2290.

1572 Marcovitz, A., Jia, R., Bejerano, G. 2016. "Reverse Genomics” Predicts Function of Human Conserved

1573 Noncoding Elements. Molecular Biology and Evolution 33: 1358-1369.

1574 Marcussen, T., Sandve, S. R., Heier, L., Spannagl, M., Pfeifer, M., The International Wheat Genome

1575 Sequencing Consortium, Jakobsen, K. S., Wulff, B. B. H., Steuernagel, B., Mayer, K. F. X., Olsen,

1576 O. A. 2014. Ancient hybridizations among the ancestral genomes of bread wheat. Science 345 :

$1577 \quad 1250092$.

1578 Marcussen, T., Heier, L., Brysting, A. K., Oxelman, B., Jakobsen, K. S. 2015. From gene trees to a dated

1579 allopolyploid network: Insights from the angiosperm genus Viola (Violaceae). Systematic Biology

1580 64: 84-101.

1581 Matzke, A., Churakov, G., Berkes, P., Arms, E. M., Kelsey, D., Brosius, J., Kriegs, J. O., Schmitz, J.

1582 2012. Retroposon Insertion Patterns of Neoavian Birds: Strong Evidence for an Extensive Incomplete

1583 Lineage Sorting Era. Molecular Biology and Evolution 29: 1497-1501.

1584 Matzke, N. J., Wright, A. 2016. Inferring node dates from tip dates in fossil Canidae: the importance of

$1585 \quad$ tree priors. Biology Letters 12: 20160328.

1586 McCormack, J. E., Hird, S. M., Zellmer, A. J., Carstens, B. C., Brumfield, R. T. 2013. Applications of

1587 next-generation sequencing to phylogeography and phylogenetics. Molecular Phylogenetics and

$1588 \quad$ Evolution 66: 526-538.

1589 McCormack, J. E., Tsai, W. L. E., Faircloth, B. C. 2016. Sequence capture of ultraconserved elements

1590 from bird museum specimens. Molecular Ecology Resources 16: 1189-1203.

1591 McCormack, J. E., Rodríguez-Gómez, F., Tsai, W. L. E., Faircloth, B. C. 2017. Transforming Museum

1592 Specimens into Genomic Resources. Pp. 143-156 in M. S. Webster (editor), The Extended

1593 Specimen: Emerging Frontiers in Collections-based Ornithological Research. Studies in Avian

1594 Biology (no. 50), CRC Press, Boca Raton, FL.

1595 McTavish, E. J., Drew, B. T., Redelings, B., Cranston, K. A. 2017. How and why to build a unified Tree 
1596 of Life. BioEssays 1700114.

1597 McTavish, E. J., Hinchliff, C. E., Allman, J. F., Brown, J., Cranston, K. A., Holder, M. T., Rees, J. A.,

1598 Smith, S. A. 2015. Phylesystem: A git-based data store for community-curated phylogenetic

1599 estimates. Bioinformatics 31:2794-2800.

1600 Mendes, F. K., Fuentes-González, J. A., Schraiber, J. G., Hahn, M. W. 2018. A multispecies coalescent

1601 model for quantitative traits. eLife 7:e36482.

1602 Mendes, F. K., Hahn, Y., Hahn, M. W. 2016. Gene tree discordance can generate patterns of diminishing

1603 convergence over time. Molecular Biology and Evolution 33: 3299-3307.

1604 Merker, J. D., Wenger, A. M., Sneddon, T., Grove, M., Zappala, Z., Fresard, L., Waggott, D., Utiramerur,

1605 S., Hou, Y., Smith, K. S., Montgomery, S. B., Wheeler, M., Buchan, J. G., Lambert, C. C., Eng, K.

1606 S., Hickey, L., Korlach, J., Ford, J., Ashley, E. A. 2018. Long-read genome sequencing identifies

1607 causal structural variation in a Mendelian disease. Genetics in Medicine 20: 159-163.

1608 Meyer, M., Kircher, M., Gansauge, M. T., Li, H., Racimo, F., Mallick, S., Schraiber, J. G., Jay, F., Prüfer,

1609 K., de Filippo, C., Sudmant, P. H., Alkan, C., Fu1, Q., Do, R., Rohland, N., Tandon, A., Siebauer,

1610 M., Green, R. E., Bryc, K., Briggs, A. W., Stenzel, U., Dabney, J., Shendure, J., Kitzman, J.,

1611 Hammer, M. F., Shunkov, M. V, Derevianko, A. P., Patterson, N., Andrés, A. M., Eichler, E. E.,

1612 Slatkin, M., Reich, D., Kelso, J., Pääbo, S. 2012. A high-coverage genome sequence from an archaic

1613 Denisovan individual. Science 338: 222-226.

1614 Mirarab, S., Warnow, T. 2015. ASTRAL-II: coalescent-based species tree estimation with many hundreds 1615 of taxa and thousands of genes. Bioinformatics 31: i44-i52.

1616 Mirarab, S., Bayzid, M. S., Warnow, T. 2016. Evaluating summary methods for multilocus species tree

1617 estimation in the presence of incomplete lineage sorting. Systematic Biology 65: 366-380.

1618 Misof, B., Liu, S., Meusemann, K., Peters, R. S., Donath, A., Mayer, C., Frandsen, P. B., Ware, J., Flouri,

1619 T., Beutel, R. G., Niehuis, O., Petersen, M., Izquierdo-Carrasco, F., Wappler, T., Rust, J., Aberer, A.

1620 J., Aspock, U., Aspock, H., Bartel, D., Blanke, A., Berger, S., Bohm, A., Buckley, T. R., Calcott, B.,

1621 Chen, J., Friedrich, F., Fukui, M., Fujita, M., Greve, C., Grobe, P., Gu, S., Huang, Y, Jermiin, L. S., 
1622

1623

1624

1625

1626

1627

1628

1629

1630

1631

1632

1633

1634

1635

1636

1637

1638

1639

1640

1641

1642

1643

1644

1645

1646

1647

Kawahara, A. Y., Krogmann, L., Kubiak, M., Lanfear, R., Letsch, H., Li, Y., Li, Z., Li, J., Lu, H., Machida, R., Mashimo, Y., Kapli, P., McKenna, D. D., Meng, G., Nakagaki, Y., Navarrete-Heredia, J. L., Ott, M., Ou, Y., Pass, G., Podsiadlowski, L., Pohl, H., von Reumont, B. M., Schutte, K., Sekiya, K., Shimizu, S., Slipinski, A., Stamatakis, A., Song, W., Su, X., Szucsich, N. U., Tan, M., Tan, X., Tang, M., Tang, J., Timelthaler, G., Tomizuka, S., Trautwein, M., Tong, X., Uchifune, T., Walzl, M. G., Wiegmann, B. M., Wilbrandt, J., Wipfler, B., Wong, T. K., Wu, Q., Wu, G., Xie, Y., Yang, S., Yang, Q., Yeates, D. K., Yoshizawa, K., Zhang, Q., Zhang, R., Zhang, W., Zhang, Y., Zhao, J., Zhou, C., Zhou, L., Ziesmann, T., Zou, S., Li, Y., Xu, X., Zhang, Y., Yang, H., Wang, J., Wang, J., Kjer, K. M., Zhou. X. 2014. Phylogenomics resolves the timing and pattern of insect evolution. Science 346: 763-767.

Mitchell, A., Mitter, C., Regier, J. C. 2000. More taxa or more characters revisited: Combining data from nuclear protein-encoding genes for phylogenetic analyses of Noctuoidea (Insecta: Lepidoptera). Systematic Biology 49: 202-224.

Montague, M. J., Li, G., Gandolfi, B., Khan, R., Aken, B. L., Searle, S. M. J., Minx, P., Hillier, L. W., Koboldt, D. C., Davis, B. W., Driscoll, C. A., Barr, C. S., Blackistone, K., Quilez, J., LorenteGaldos, B., Marques-Bonet, T., Alkan, C., Thomas, G. W. C., Hahn, M. W., Menotti-Raymond, M., O’Brien, S. J., Wilson, R. K., Lyons, L. A., Murphy, W. J., Warren, W. C. 2014. Comparative analysis of the domestic cat genome reveals genetic signatures underlying feline biology and domestication. Proceedings of the National Academy of Sciences USA 111: 17230-17235.

Mora, C., Tittensor, D. P., Adl, S., Simpson, A. G. B., Worm, B. 2011. How Many Species Are There on Earth and in the Ocean? PLoS Biology 9(8):e1001127.

Morlon, H. 2014. Phylogenetic approaches for studying diversification. Ecology Letters 17: 508-525.

Morlon, H., Parsons, T.L., Plotkin, J. 2011. Reconciling molecular phylogenies with the fossil record Proceedings of the National Academy of Sciences USA 108: 16327-16332.

Murphy, W. J., Larkin, D. M., Everts-van der Wind, A, Bourque, G., Tesler, G., Auvil, L., Beever, J. E, Chowdhary, B. P., Galibert, F., Gatzke, L., Hitte, C., Meyers, S. N., Milan, D., Ostrander, E. A., 
1648

1649

1650

1651

1652

1653

1654

1655

1656

1657

1658

1659

1660

1661

1662

1663

1664

1665

1666

1667

1668

1669

1670

1671

1672

1673

Pape, G., Parker, H. G., Raudsepp, T., Rogatcheva, M. B., Schook, L. B., Skow, L. C., Welge, M., Womack, J. E., O'Brien, S. J., Pevzner, P. A., Lewin, H. A. 2005. Dynamics of mammalian chromosome evolution inferred from multispecies comparative maps. Science 309: 613-617.

Murphy, W. J., Pringle, T. H., Crider, T. A., Springer, M. S., Miller, W. 2007. Using genomic data to unravel the root of the placental mammal phylogeny. Genome Research 17: 413-421.

Nabhan, A. R., Sarkar, I. N. 2012. The impact of taxon sampling on phylogenetic inference: a review of two decades of controversy. Briefings in Bioinformatics 13: 122-134.

Nee, S., Mooers, A. O., Harvey, P. H. 1992. Tempo and mode of evolution revealed from molecular phylogenies. Proceedings of the National Academy of Sciences USA 89: 8322-8326.

Nguyen, L-T., Schmidt, H. A., von Haeseler, A., Minh, B. Q. 2015. IQ-TREE: A Fast and Effective Stochastic Algorithm for Estimating Maximum-Likelihood Phylogenies. Molecular Biology and Evolution 32: 268-274.

Ogilvie, H. A., Bouckaert, R. R., Drummond, A. J. 2017. StarBEAST2 Brings Faster Species Tree Inference and Accurate Estimates of Substitution Rates. Molecular Biology and Evolution 34: 21012114.

Olave, M., Sola E., Knowles L. L. 2014. Upstream analyses create problems with DNA-based species delimitation. Systematic Biology 63: 263-271.

Oxelman, B., Yoshikawa, N., McConaughy, B. L., Luo, J., Denton, A. L., Hall, B. D. 2004. RPB2 Gene Phylogeny in Flowering Plants, with Particular Emphasis on Asterids. Molecular Phylogenetics and Evolution 32: 462-79.

Pamilo, P., Nei, M. 1988. Relationships between gene trees and species trees. Molecular Biology and Evolution 5: 568-583.

Park, S. D. E., Magee, D. A., McGettigan, P. A., Teasdale, M. D., Edwards, C. J., Lohan, A. J, Murphy, A., Braud, M., Donoghue, M. T., Liu, Y., Chamberlain, A. T, Rue-Albrecht, K., Schroeder, S., Spillane, C., Tai, S., Bradley, D. G., Sonstegard, T. S., Loftus, B. J., McHugh, D. E. 2015. Genome sequencing of the extinct Eurasian wild aurochs, Bos primigenius, illuminates the phylogeography 
1674 and evolution of cattle. Genome Biology 16: 234.

1675 Patel, S., Kimball., R.T., Braun, E. L. 2013. Error in Phylogenetic Estimation for Bushes in the Tree of 1676 Life. Journal of Phylogenetics and Evolutionary Biology 1: 110.

1677 Payseur, B. A., Rieseberg, L. H. 2016. A genomic perspective on hybridization and speciation. Molecular 1678 Ecology 25: 2337-2360.

1679 Pease, J. B., Haak, D. C., Hahn, M. W., Moyle, L. C. 2016. Phylogenomics Reveals Three Sources of $1680 \quad$ Adaptive Variation during a Rapid Radiation. PloS Biology 14: e1002379.

1681 Pennell, M. W., FitzJohn, R. G., Cornwell, W. K. 2016. A simple approach for maximizing the overlap of 1682 phylogenetic and comparative data. Methods in Ecology and Evolution 7: 751-758.

1683 Pennell, M. W., Harmon, L. J. 2013. An integrative view of phylogenetic comparative methods:

1684 Connections to population genetics, community ecology, and paleobiology. Annals of the New York 1685 Academy of Sciences 1289: 90-105.

1686 Peterson, A. T., Moyle, R. G., Nyári, Á. S., Robbins, M. B., Brumfield, R. T., Remsen, J. V. Jr. 2007. The 1687 need for proper vouchering in phylogenetic studies of birds. Molecular Phylogenetics and Evolution $1688 \quad 45: 1042-1044$.

1689 Pfeil, B. E., C. L. Brubaker, L. A. Craven, Crisp, M. D. 2004. Paralogy and orthology in the Malvaceae $1690 \quad$ rpb2 gene family: Investigation of gene duplication in Hibiscus. Molecular Biology and Evolution $1691 \quad 21: 1428-1437$.

1692 Philippe, H., Brinkmann, H., Lavrov, D. V., Littlewood, D. T. J, Manuel, M., Wörheide, G., Baurain, D. 1693 2011. Resolving Difficult Phylogenetic Questions: Why More Sequences Are Not Enough. PLoS 1694 Biology 9: e1000602.

1695 Philippe, H., de Vienne, D. M., Ranwez, V., Roure, B., Baurain, D., Delsuc, F. 2017. Pitfalls in 1696 supermatrix phylogenomics. European Journal of Taxonomy 283: 1-25.

1697 Piel, W. H., Chan, L., Dominus, M. J., Ruan, J., Vos, R. A., Tannen, V. 2009. Treebase v. 2: A Database 1698 of Phylogenetic Knowledge. e-Biosphere.

1699 Pleijel, F., Jondelius, U., Norlinder, E., Nygren, A., Oxelman, B., Schander, C., Sundberg, P., Thollesson, 
1700 M. 2008. Phylogenies without roots? A plea for the use of vouchers in molecular phylogenetic $1701 \quad$ studies. Molecular Phylogenetics and Evolution 48: 369-371.

1702 Poe, S. 1998. Sensitivity of phylogeny estimation to taxonomic sampling. Systematic Biology 47: 18-31.

1703 Potts, A. J., Hedderson, T. A., Grimm, G. W. 2014. Constructing Phylogenies in the Presence Of Intra-

1704 Individual Site Polymorphisms (2ISPs) with a Focus on the Nuclear Ribosomal Cistron. Systematic

1705 Biology 63: 1-16.

1706 Prum, R. O., Berv, J. S., Dornburg, A., Field, D. J., Townsend, J. P. 2015. A comprehensive phylogeny of 1707 birds (Aves) using targeted next-generation DNA sequencing. Nature 526: 569-573.

1708 Pyron, R. A. 2011. Divergence time estimation using fossils as terminal taxa and the origins of 1709 Lissamphibia. Systematic Biology 60: 466-81.

1710 Pyron, R. A. 2015. Post-molecular systematics and the future of phylogenetics. Trends in Ecology \& $1711 \quad$ Evolution 30: 384-389.

1712 Pyron, R. A., Burbrink, F. T. 2012. Trait-dependent diversification and the impact of paleontological data 1713 on evolutionary hypothesis testing in New World ratsnakes (tribe Lampropeltini). Journal of 1714 Evolutionary Biology 25: 497-508.

1715 Quail, M. A., Smith, M., Coupland, P., Otto, T. D., Harris, S. R., Connor, T. R., Bertoni, A., Swerdlow, 1716 H. P., Gu, Y. 2012. A tale of three next generation sequencing platforms: comparison of Ion Torrent, 1717 Pacific Biosciences and Illumina MiSeq sequencers. BMC Genomics 13: 341.

1718 Quintero, I., P. Keil., W. Jetz., Crawford, F. W. 2015. Historical Biogeography Using Species

1719 Geographical Ranges. Systematic Biology 64: 1059-1073.

1720 Rabosky, D. L. 2015. No substitute for real data: a cautionary note on the use of phylogenies from birth1721 death polytomy resolvers for downstream comparative analyses. Evolution 69: 3207-3216.

1722 Ramadugu, C., Pfeil, B. E., Manjunath, K. L., Lee, R. F., Maureira-Butler, I. J., Roose, M. L. 2013.

1723 Coalescence simulation testing of hybridization versus lineage sorting in Citrus (Rutaceae) using six 1724 nuclear genes. PLoS One 8: e68410.

1725 Rannala, B., Yang, Z. H. 2003. Bayes estimations of species divergence times and ancestral population 
1726 sizes using DNA sequences from multiple loci. Genetics 164: 1645-1656.

1727 Rannala, B., Yang Z. H. 2008. Phylogenetic inference using whole genomes. Annual Review of 1728 Genomics and Human Genetics 9: 217-231.

1729 Ranwez, V., Delsuc, F. D. R., Ranwez, S., Belkhir, K., Tilak, M-K., Douzery, E. J. 2007. OrthoMaM: A 1730 database of orthologous genomic markers for placental mammal phylogenetics. BMC Evolutionary $1731 \quad$ Biology 7: 241-12.

1732 Rasmussen, M. D., Hubisz, M. J., Gronau, I., Siepel, A. 2014. Genome-Wide Inference of Ancestral 1733 Recombination Graphs. PLoS Genetics 10(5): e1004342.

1734 Reddy, S., Kimball, R. T., Pandey, A., Hosner, P. A., Braun, M. J., Hackett, S. J., Han, K-L., Harshman, 1735 J., Huddleston, C. J., Kingston, S., Marks, B. D., Miglia, K. J., Moore, W. S., Sheldon, F. H., Witt, C. 1736 C., Yuri, T., Braun, E. L. 2017. Why Do Phylogenomic Data Sets Yield Conflicting Trees? Data 1737 Type Influences the Avian Tree of Life more than Taxon Sampling. Systematic Biology 66: 857$1738 \quad 879$.

1739 Redon, R., Ishikawa, S., Fitch, K. R., Feuk, L., Perry, G. H., Andrews, T. D., Fiegler, H., Shapero, M. H., 1740 Carson, A. R., Chen, W., Cho, E. K., Dallaire, S., Freeman, J. L., González, J. R., Gratacòs, M. N., 1741 Huang, J., Kalaitzopoulos, D., Komura, D., MacDonald, J. R., Marshall, C. R., Mei, R., 1742 Montgomery, L., Nishimura, K., Okamura, K., Shen, F., Somerville, M. J., Tchinda, J., Valsesia, A., 1743 Woodwark, C., Yang, F., Zhang, J., Zerjal, T., Zhang, J., Armengol, L., Conrad, D. F., Estivill, X., 1744 Tyler-Smith, C., Carter, N. P., Aburatani, H., Lee, C., Jones, K. W., Scherer, S. W., Hurles, M. E. 1745 2006. Global variation in copy number in the human genome. Nature 444: 444-454.

1746 Reid, N. M., Hird, S. M., Brown, J. M., Pelletier, T. A., McVay, J. D., Satler, J. D., Carstens, B. C. 2014. 1747 Poor fit to the multispecies coalescent is widely detectable in empirical data. Systematic Biology 63: $1748 \quad 322-333$.

1749 Rhoads, A., Au, K. F. 2015. PacBio Sequencing and Its Applications. Genomics, Proteomics \& $1750 \quad$ Bioinformatics 13: 278-289.

1751 Ricketts, C., Popic, V., Toosi, H., Hajirasouliha, I. 2018. Using LICHeE and BAMSE for Reconstructing 
1752 Cancer Phylogenetic Trees. Current Protocols in Bioinformatics 62: e49.

1753 Rogozin, I. B., Thomson, K., Csürös, M., Carmel, L., Koonin, E. V. 2008. Homoplasy in genome-wide 1754 analysis of rare amino acid replacements: the molecular-evolutionary basis for Vavilov's law of 1755 homologous series. Biology Direct 2008 3: 7.

1756 Rogozin, I. B., Wolf, Y. I., Babenko, B. N., Koonin, E. V. 2006. Dollo parsimony and the reconstruction 1757 of genome evolution. In: Albert VA ed. Parsimony, Phylogeny, and Genomics. Oxford University 1758 Press, p.p. 190-200.

1759 Rokas, A. 2005. More Genes or More Taxa? The Relative Contribution of Gene Number and Taxon $1760 \quad$ Number to Phylogenetic Accuracy. Molecular Biology and Evolution 22: 1337-1344.

1761 Rokas, A. 2011. Phylogenetic Analysis of Protein Sequence Data Using the Randomized Axelerated 1762 Maximum Likelihood (RAXML) Program. Current Protocols in Molecular Biology 96: 19.11.1$1763 \quad 19.11 .14$

1764 Rokas, A., Holland, P. W. H. 2000. Rare genomic changes as a tool for phylogenetics. Trends in Ecology 1765 and Evolution 15: 454-459.

1766 Rokas, A., Williams, B. L., King, N., Carroll, S. B. 2003. Genome-scale approaches to resolving 1767 incongruence in molecular phylogenies. Nature 425: 798-804.

1768 Romiguier, J., Cameron, S. A., Woodard, S. H., Fischman, B. J., Keller, L., Praz, C. J. 2016.

1769 Phylogenomics Controlling for Base Compositional Bias Reveals a Single Origin of Eusociality in 1770 Corbiculate Bees. Molecular Biology and Evolution 33: 670-678.

1771 Romiguier, J., Roux, C. 2017. Analytical Biases Associated with GC-Content in Molecular Evolution.

$1772 \quad$ Frontiers in Genetics 8: 16.

1773 Roncal, J., Guyot, R., Hamon, P., Crouzillat, D., Rigoreau, M., Konan, O. N., Rakotomalala, J. J., Nowak, 1774 M. D., Davis, A. P., de Kochko, A. 2016. Active transposable elements recover species boundaries 1775 and geographic structure in Madagascan coffee species. Molecular Genetics and Genomics 291: 1551776168. 
1777 Ronquist, F., Klopfstein, S., Vilhelmsen, L., Schulmeister, S., Murray, D. L., Rasnitsyn, A. P. 2012. A

1778 total-evidence approach to dating with fossils, applied to the early radiation of the Hymenoptera.

$1779 \quad$ Systematic Biology 61: 973-99.

1780 Rosenberg, N. A., Nordborg, M. 2002. Genealogical trees, coalescent theory and the analysis of genetic

1781 polymorphisms. Nature Reviews Genetics 3: 380-390.

1782 Rosindell, J., Cornell, S. J., Hubbell S. P., Etienne, R. S. 2010. Protracted speciation revitalizes the

1783 neutral theory of biodiversity. Ecology Letters 13: 716-727.

1784 Rosindell, J., Harmon, L. J. 2012. OneZoom: A Fractal Explorer for the Tree of Life. PLoS Biology

1785 10(10): e1001406.

1786 Rosindell, J., Harmon, L. J., Etienne, R. S. 2015. Unifying ecology and macroevolution with

1787 individual-based theory. Ecology Letters 18: 472-482.

1788 Rota-Stabelli, O., Campbell, L., Brinkmann, H., Edgecombe, G. D., Longhorn, S. J., Peterson, K. J.,

1789 Pisani, D., Philippe, H., Telford, M. J. 2011. A congruent solution to arthropod phylogeny:

1790 phylogenomics, microRNAs and morphology support monophyletic Mandibulata. Proceedings of the

$1791 \quad$ Royal Society B 278: 298.

1792 Ruane, S., Austin, C. C. 2017. Phylogenomics using formalin-fixed and 100+ year-old intractable natural

1793 history specimens. Molecular Ecology Resources 17: 1003-1008.

1794 Ryan, J. F., Pang, K., Schnitzler, C. E., Nguyen, A-D., Moreland, R. T., Simmons, D. K., Koch, B. J.,

1795 Francis, W. R., Havlak, P., Comparative Sequencing Program NISC, Smith, S. A., Putnam, N. H.,

1796 Haddock, S. H. D., Dunn, C. W., Wolfsberg, T. G., Mullikin, J. C., Martindale, M. Q., Baxevanis, A.

1797 D. 2013. The genome of the ctenophore Mnemiopsis leidyi and its implications for cell type

$1798 \quad$ evolution, Science 342: 1242592.

1799 Sagitov, S., Bartoszek, K. 2012. Interspecies correlation for neutrally evolving traits. Journal of

$1800 \quad$ Theoretical Biology 309: 11-19.

1801 Sanderson, M. J. 1992. Estimating Absolute Rates of Molecular Evolution and Divergence Times: A

1802 Penalized Likelihood Approach. Molecular Biology and Evolution 19: 101-109. 
1803 Sanderson, M. J., Donoghue, M. J., Piel, W. H., Eriksson, T. 1994. TreeBASE: a prototype database of

1804 phylogenetic analyses and an interactive tool for browsing the phylogeny of life. American Journal of $1805 \quad$ Botany 81: 183.

1806 Sayyari, E., Mirarab, S. 2016. Fast Coalescent-Based Computation of Local Branch Support from Quartet $1807 \quad$ Frequencies. Molecular Biology and Evolution 33: 1654-1668.

1808 Scally, A., Dutheil, J. Y., Hillier, L. W., Jordan, G. E., Goodhead, I., Herrero, J., Hobolth, A., 1809 Lappalainen, T., Mailund, T., Marques-Bonet, T., McCarthy, S., Montgomery, S. H., Schwalie, P. C., 1810 Tang, Y. A., Ward, M. C., Xue, Y., Yngvadottir, B., Alkan, C., Andersen, L. N., Ayub, Q., Ball, E. 1811 V., Beal, K., Bradley, B. J., Chen, Y., Clee, C. M., Fitzgerald, S., Graves, T. A., Gu, Y., Heath, P., 1812 Heger, A., Karakoc, E., Kolb-Kokocinski, A., Laird, G. K., Lunter, G., Meader, S., Mort, M., 1813 Mullikin, J. C., Munch, K., O'Connor, T. D., Phillips, A. D., Prado-Martinez, J., Rogers, A. S., 1814 Sajjadian, S., Schmidt, D., Shaw, K., Simpson, J. T., Stenson, P. D., Turner, D. J., Vigilant, L., 1815 Vilella, A. J., Whitener, W., Zhu, B., Cooper, D. N., de Jong, P., Dermitzakis, E. T., Eichler, E. E., 1816 Flicek, P., Goldman, N., Mundy, N. I., Ning, Z., Odom, D. T., Ponting, C. P., Quail, M. A., Ryder, O. 1817 A., Searle, S. M., Warren, W. C., Wilson, R. K., Schierup, M. H., Rogers, J., Tyler-Smith, C., 1818 Durbin, R. 2012. Insights into hominid evolution from the gorilla genome sequence. Nature 483: $1819 \quad 169-175$.

1820 Schrempf, D., Minh, B. Q., De Maio, N., von Haeseler, A., Kosiol. C. 2016. Reversible polymorphism1821 aware phylogenetic models and their application to tree inference. Journal of Theoretical Biology $1822 \quad 407: 362-370$.

1823 Schwartz, R., Schäffer, A. A. 2017. The evolution of tumour phylogenetics: Principles and practice.

$1824 \quad$ Nature Reviews Genetics 18: 213-229.

1825 Scotch, M., Sarkar, I. N., Mei, C., Leaman, R., Cheung, K-H., Ortiz, P., Singraur, A., Gonzalez, G. 2011.

1826 Enhancing phylogeography by improving geographical information from GenBank. Journal of 1827 Biomedical Informatics 44: S44-S47.

1828 Shen, X-X., Hittinger, C. T., Rokas, A. 2017. Contentious relationships in phylogenomic studies can be 
1829 driven by a handful of genes. Nature Ecology and Evolution 1: 0126.

1830 Shi, C.-M., Yang, Z. 2018. Coalescent-Based Analyses of Genomic Sequence Data Provide a Robust

1831 Resolution of Phylogenetic Relationships among Major Groups of Gibbons. Molecular Biology and 1832 Evolution 35: 159-179.

1833 Siepel, A. 2009. Phylogenomics of primates and their ancestral populations. Genome Research 19: 192918341941.

1835 Simion, P., Philippe, H., Baurain, D., Muriel, J., Richter, D. J., Di Franco, A., Roure, B., Satoh, N., 1836 Quéinnec, E., Ereskovsky, A. 2017. A Large and Consistent Phylogenomic Dataset Supports 1837 Sponges as the Sister Group to All Other Animals. Current Biology 27: 958-967.

1838 Siu-Ting. K., Gower, D. J., Pisani, D., Kassahun, R., Gebresenbet, F., Menegon, M., Mengistu, A. A., 1839 Saber, S. A., de Sá, R., Wilkinson, M., Loader, S. P. 2014. Evolutionary relationships of the 1840 Critically Endangered frog Ericabatrachus baleensis Largen, 1991 with notes on incorporating 1841 previously unsampled taxa into large-scale phylogenetic analyses. BMC Evolutionary Biology 14:44.

1842 Sjödin, P., Jakobsson, M. 2012. Population genetic nature of copy number variation. Population Genetic 1843 Nature of Copy Number Variation. In: Feuk L. (eds) Genomic Structural Variants. Methods in 1844 Molecular Biology (Methods and Protocols), vol 838. Springer, New York, NY.

1845 Slater, G. J. 2015 Iterative adaptive radiations of fossil canids show no evidence for diversity-dependent 1846 trait evolution. Proceedings of the National Academy of Sciences USA 112: 4897- 4902.

1847 Smith, S. A., Brown, J. W. 2018. Constructing a broadly inclusive seed plant phylogeny. American $1848 \quad$ Journal of Botany 105: 302-314.

1849 Smith, S. A., Moore, M. J., Brown, J. W., Yang, Y. 2015. Analysis of phylogenomic datasets reveals

1850 conflict, concordance, and gene duplications with examples from animals and plants. BMC

$1851 \quad$ Evolutionary Biology 15: 150.

1852 Smith, S. A., O’Meara, B. C. 2012. treePL: divergence time estimation using penalized likelihood for 1853 large phylogenies. Bioinformatics 28: 2689-2690.

1854 Solís-Lemus, C., Ané, C. 2016. Inferring Phylogenetic Networks with Maximum Pseudolikelihood under 
Incomplete Lineage Sorting. PLoS Genet 12: e1005896.

1856 Solís-Lemus, C., Knowles, L. L., Ané, C. 2015. Bayesian species delimitation combining multiple genes 1857 and traits in a unified framework. Evolution 69: 492-507.

1858 Solís-Lemus, C., Bastide, P., Ané, C. 2017. PhyloNetworks: A Package for Phylogenetic Networks.

$1859 \quad$ Molecular Biology and Evolution 34: 3292-3298.

1860 Song, S., Liu, L., Edwards, S. V., Wu, S. 2012. Resolving conflict in eutherian mammal phylogeny using 1861 phylogenomics and the multispecies coalescent model. Proceedings of the National Academy of 1862 Sciences USA 112: E6079-E6079.

1863 Sousa, F., Bertrand, Y. J. K., Doyle, J. J., Oxelman, B., Pfeil, B. E. 2017. Using genomic location and 1864 coalescent simulation to investigate gene tree discordance in Medicago L. Systematic Biology 66: $1865934-949$.

1866

1867

1868

1869

1870

1871

1872

1873

1874

1875

1876

1877

1878

1879

1880

Springer, M. S., Gatesy, J. 2016. The gene tree delusion. Molecular Phylogenetics and Evolution 94: 133.

Staats, M., Erkens, R. H. J., van de Vossenberg, B., Wieringa, J. J., Kraaijeveld, K., Stielow, B., Geml, J., Richardson, J. E., Bakker, F. T. 2013. Genomic treasure troves: complete genome sequencing of herbarium and insect museum specimens. PLoS ONE 8: e69189.

Stadler, T., 2009. On incomplete sampling under birth-death models and connections to the samplingbased coalescent. Journal of Theoretical Biology 261: 58-68.

Stadler, T. 2013. Recovering speciation and extinction dynamics based on phylogenies. Journal of Evolutionary Biology 26: 1203-1219.

Stadler, T., Steel, M., 2012. Distribution of branch lengths and phylogenetic diversity under homogeneous speciation models. Journal of Theoretical Biology 297: 33-40.

Stamatakis, A. 2014. RAxML Version 8: A tool for Phylogenetic Analysis and Post-Analysis of Large Phylogenies. Bioinformatics 30: 1312-1313.

Stephens, M., Smith, N.J., Donnelly, P. 2001. A new statistical method for haplotype reconstruction from population data. The American Journal of Human Genetics 68: 978-989. 
1881 Stoltzfus, A., O’Meara, B., Whitacre, J., Mounce, R., Gillespie, E. L., Kumar, S., Rosauer, D. F., Vos R.

1882 A. 2012. Sharing and re-use of phylogenetic trees (and associated data) to facilitate synthesis. BMC

$1883 \quad$ Research Notes 5:574

1884 Struck, T. H. 2013. The Impact of Paralogy on Phylogenomic Studies - A Case Study on Annelid 1885 Relationships. PLoS ONE 8: e62892.

1886 Suarez, A. V., Tutsui, N. D. 2004. The value of museum collections for research and society. BioScience $1887 \quad 54: 66-74$.

1888 Suh, A., Paus, M., Kiefmann, M., Churakov, G., Franke, F. A., Brosius, J., Kriegs, J. O., Schmitz, J.

1889 2011. Mesozoic retroposons reveal parrots as the closest living relatives of passerine birds. Nature $1890 \quad$ Communications 2: 443.

1891 Suh, A., Smeds, L. A., Ellegren, H. 2015. The Dynamics of Incomplete Lineage Sorting across the 1892 Ancient Adaptive Radiation of Neoavian Birds. PLoS Biology 13: e1002224-18.

1893 Sukumaran, J., Knowles, L. L., 2017. Multispecies coalescent delimits structure, not species. Proceedings 1894 of the National Academy of Sciences USA 114: 1607-1612.

1895 Talavera, G., Castresana, J. 2007. Improvement of phylogenies after removing divergent and ambiguously 1896 aligned blocks from protein sequence alignments. Systematic Biology 56: 564-577.

1897 Tang, J., Moret, B. M. E., Cui, L., dePamphilis, C. W. 2004. Phylogenetic reconstruction from arbitrary 1898 gene-order data. in Proceedings. Fourth IEEE Symposium on Bioinformatics and Bioengineering $1899 \quad 592-599$.

1900 Todd, E. V., Black, M. A., Gemmell, N. J. 2016. The power and promise of RNA-seq in ecology and $1901 \quad$ evolution. Molecular Ecology 25: 1224-1241.

1902 Tonini, J. F. R., Beard, K. H., Ferreira, R. B., Jetz, W., Pyron, R. A. 2016. Fully-sampled phylogenies of 1903 squamates reveal evolutionary patterns in threat status. Biological Conservation 204: 23-31.

1904 Toprak, Z., Pfeil, B.E., Jones, G., Marcussen, T., Ertekin, A.S., Oxelman, B. 2016. Species Delimitation 1905 Without Prior knowledge: DISSECT Reveals Extensive Cryptic Speciation in the Silene aegyptiaca 1906 complex (Caryophyllaceae). Molecular Phylogenetics and Evolution 102: 1-8. 
1907 Troudet, J., Vigness-Lebbe, R., Grandcolas, P., Legendre, F. 2018. The Increasing Disconnection of

1908 Primary Biodiversity Data from Specimens: How Does It Happen and How to Handle It? Systematic

$1909 \quad$ Biology 67: 1110-1119.

1910 Turney, S., Cameron, E. R., Cloutier, C. A, Buddle, C. M. 2015. Non-repeatable science: assessing the

1911 frequency of voucher specimen deposition reveals that most arthropod research cannot be verified.

1912 PeerJ 3: e1168-16.

1913 Ulitsky, I. 2016. Evolution to the rescue: using comparative genomics to understand long non-coding

1914 RNAs. Nature Reviews Genetics 17: 601-614.

1915 Urrutia, E., Chen, H., Zhou, Z., Zhang, N. R., Juang, Y. 2018. Integrative pipeline for profiling DNA

1916 copy number and inferring tumor phylogeny. Bioinformatics 34: 2126-2128.

1917 Villar, D., Berthelot, C., Alridge, S., Rayner, T. F., Lukk, M., Pignatelli, M., Park, T. J., Deaville, R.,

1918 Erichsen, J. T., Jasinska, A. J., Turner, J. M., Bertelsen, M. F., Murchison, E. P., Flicek, P., Odom, D.

1919 T. 2015. Enhancer evolution across 20 mammalian species. Cell 160: 554-566.

1920 Vision, T. 2010. Open data and the social contract of scientific publishing. BioScience 60: 330.

1921 Warnow, T. 2018. Supertree Construction: Opportunities and Challenges. arXiv:1805.03530v1.

1922 Wen, D., Nakhleh L. 2018. Co-estimating Reticulate Phylogenies and Gene Trees from Multi-locus

1923 Sequence Data. Systematic Biology 67: 439-457.

1924 Wen, D., Yu Y., Hahn M. W., Nakhleh L. 2016. Reticulate evolutionary history and extensive

1925 introgression in mosquito species revealed by phylogenetic network analysis. Molecular Ecology 25:

$1926 \quad 2361-2372$.

1927 Wesche, P. L., Gaffney, D. J., Keightley, P. D. 2004. DNA Sequence Error Rates in Genbank Records

1928 Estimated Using the Mouse Genome as a Reference. DNA Sequence 15(5-6): 362-64.

1929 Wiedenhoeft, J., Brugel, E., Schliep, A. 2016. Fast Bayesian Inference of Copy Number Variants using

1930 Hidden Markov Models with Wavelet Compression. PLoS Computational Biology 12(5): e1004871.

1931 Will, K. P., Mishler, B. D., Wheeler, Q. D. 2005. The perils of DNA Barcoding and the need for

1932 integrative taxonomy. Systematic Biology 54: 844-851. 
1933 Wilson, G., Aruliah, D. A., Brown, C. T., Chue-Hong N. P., Davis, M., Guy, R. T., Haddock, S. H. D,

1934 Huff, K. D., Mitchell, I. M., Plumbley, M. D, Waugh, B., White, E. P., Wilson, P. 2014. Best

1935 Practices for Scientific Computing. PLoS Biology 12(1): e1001745.

1936 Xi, Z., Ruhfel, B. R., Schaefer, H., Amorim, A. M., Sugumaran, M., Wurdack, K. J., Endress, P. K.,

1937 Matthews, M. L., Stevens, P. F., Mathews, S., Davis, C. C. 2012. Phylogenomics and a posteriori

1938 data partitioning resolve the Cretaceous angiosperm radiation Malpighiales. Proceedings of the

1939 National Academy of Sciences USA 109: 17519-17524.

1940 Xi, Z., Liu, L., Davis, C. C. 2015. Genes with minimal phylogenetic information are problematic for

1941 coalescent analyses when gene tree estimation is biased. Molecular Phylogenetics and Evolution 92:

$1942 \quad 63-71$.

1943 Xu, B., Yang, Z. 2016. Challenges in Species Tree Estimation Under the Multispecies Coalescent Model.

$1944 \quad$ Genetics 204: 1353-1368.

1945 Yang Z, Rannala B, 2014. Unguided species delimitation using DNA sequence data from multiple loci.

1946 Molecular Biology and Evolution 31: 3125-3135.

1947 Yu, Y., Dong J., Liu K. J., Nakhleh, L. 2014. Maximum likelihood inference of reticulate evolutionary

1948 histories. Proceedings of the National Academy of Sciences USA 111: 16448-16453.

1949 Zanne, A. E., Tank, D. C., Cornwell, W. K., Eastman, J. M., Smith, S. A, FitzJohn, R. G., McGlinn, D. J.,

1950 O’Meara, B. C., Moles, A. T., Reich, P. B., Royer, D. L., Soltis, D. E., Stevens, P. F., Westoby, M.,

1951 Wright, I. J., Aarssen, L., Bertin, R. I. Calaminus, A., Govaerts, R., Hemmings, F., Leishman, M. R.,

1952 Oleksyn, J., Soltis, P. S., Swenson, N. G., Warman, L., Beaulieu, J. M. 2014. Three keys to the

1953 radiation of angiosperms into freezing environments. Nature 506: 89-92.

1954 Zhang, C., Ogilvie, H. A., Drummond, A. J., Stadler, T. 2018. Bayesian Inference of Species Networks

1955 from Multilocus Sequence Data. Molecular Biology and Evolution 35: 504-517.

1956

1957 
1958

1959

1960

1961

1962

1963

1964

1965

1966

1967

1968

1969

1970

1971

1972

1973

1974

1975

1976

1977

1978

1979

1980

1981

1982

1983

1984

1985

1986

1987

1988

1989

1990

1991

1992

1993

1994

1995

1996

1997

1998

1999

2000

2001

2002

2003

2004

2005

2006

2007

2008

\section{Figures}

Figure 1. A posteriori marker selection from whole genome alignments for phylogenomics and phylogeography. Whole genome analysis (A) permits researchers to choose different markers for specific purposes $(\mathrm{B}-\mathrm{D})$. By contrast, subsampling methods such as Rad-seq or hybrid capture, which dominate phylogenomics today, usually yield a specific set of markers that the researcher has chosen a priori. The generation of WGA thus greatly increases the use of genomic data in biological research, beyond the initial goals of the researcher producing those data. Here, we show how a hypothetical WGA that includes seven different loci (different colors) for four individuals allows extracting sequence data to generate gene trees (B), identifying SNPs to genotype individuals (C), and measuring copy depth to infer CNVs across genomic regions (D). Ultimately, these different kinds of data can be translated into species tree inferences $(\mathrm{B}-\mathrm{D})$. In the case of CNVs, only locus number 3 (orange) shows significant CNV. Because CNVs are measured as continuous characters (i.e., copy depth), the orange shading represents a hypothetical evolutionary scenario of copy number variation of genomic region number 3 within the inferred species tree, which is incongruent with those based on sequence and SNP data from other loci in the genome.

Figure 2. Trends in phylogenomic data sets since the emergence of HTS. Based on a sample of 164 phylogenomic papers published since 2004 (see Supplementary Table S1), we observed no increase in the number of species per data set over time (A). On the other hand, there is a significant increase in the number of loci (B), total alignment length (C), and total data set size, as measured by the product of species times locus number (Data set size 1, E) and species times total alignment length (Data set size 2, F). Moreover, the advent of HTS does not support the notion of a tradeoff between the number of species and the number of loci in phylogenomic studies.

Figure 3. Some examples of violations of the multispecies coalescent. In event A, there is gene flow; in event $\mathrm{B}$ there is homoploid hybridization; in event $\mathrm{C}$, there is a gene duplication; and in event $\mathrm{D}$, incomplete lineage sorting. All of these processes contribute to gene tree heterogeneity but fall outside the standard multispecies coalescent model. Importantly, all of these processes also yield strictly dichotomous gene trees, whereas recombination (not illustrated here) does not.

Figure 4. Gene duplication and loss creates patterns that can mimic incomplete lineage sorting and can lead to spurious inferences of the species history. Genes and genomes of three species A, B, and C. Multicolored bars show (parts of) their genomes with a number of loci indicated in different colors. The orange gene is duplicated in species A and it was lost in species B. The blue gene was duplicated before the divergence between species $\mathrm{A}$ and the ancestor of species $\mathrm{B}$ and $\mathrm{C}$. However, one of these copies was lost in species A, whereas both copies were maintained in species B and C. Reconstruction of the orange gene tree based on extant diversity will yield a wrong inference of its history due to the absence of data for species B. On the other hand, a phylogenetic reconstruction of the blue gene is difficult to predict. Depending on which of the duplicates are sampled for species B and C, different outcomes can be expected regarding the relationship among the three species. The duplication and loss history of these two genes may cause serious issues for phylogenetic reconstruction because no specific pattern can be expected between them.

Figure 5. Complex patterns of gene lineages with polyploidization and interspecific gene flow. Genes and genomes of four species A, B, C and D. Multi-colored bars show (parts of) genomes with a number of loci indicated in different colors. Two gene trees, one orange and one blue, evolve within the species network. Species B is an allopolyploid containing two genomes.

Figure 6. Gradual speciation or isolation-with migration. After starting to split, gene flow between species decreases gradually. Such a gradual decrease in the extent of gene flow between species might present an 
2009 especially useful extension of the standard multispecies coalescent model. Colors depict different gene 2010 pools and their gradual change along branches describes how species gradually differentiate despite the 2011 existence of migration over time. Thickness and color intensity of arrows show that gene flow becomes 2012 weaker as species gradually isolate.

2014 Figure 7. Two possible species phylogenies producing similar observations at present time. On the left 2015 (A), there is a species tree with gene flow. On the right (B), there is a species network with homoploid 2016 hybridization. Distinguishing two such scenarios usually requires simulations and comparison of 2017 observed and expected summary statistics. 


\section{Figure 1 (on next page)}

A posteriori marker selection from whole genome alignments for phylogenomics and phylogeography.

Whole genome analysis (A) permits researchers to choose different markers for specific purposes (B - D). By contrast, subsampling methods such as Rad-seq or hybrid capture, which dominate phylogenomics today, usually yield a specific set of markers that the researcher has chosen a priori. The generation of WGA thus greatly increases the use of genomic data in biological research, beyond the initial goals of the researcher producing those data. Here, we show how a hypothetical WGA that includes seven different loci (different colors) for four individuals allows extracting sequence data to generate gene trees (B), identifying SNPs to genotype individuals (C), and measuring copy depth to infer CNVs across genomic regions (D). Ultimately, these different kinds of data can be translated into species tree inferences (B - D). In the case of CNVs, only locus number 3 (orange) shows significant CNV. Because CNVs are measured as continuous characters (i.e., copy depth), the orange shading represents a hypothetical evolutionary scenario of copy number variation of genomic region number 3 within the inferred species tree, which is incongruent with those based on sequence and SNP data from other loci in the genome. 
Ind. 1

Ind. 2

Ind. 3

Ind. 4
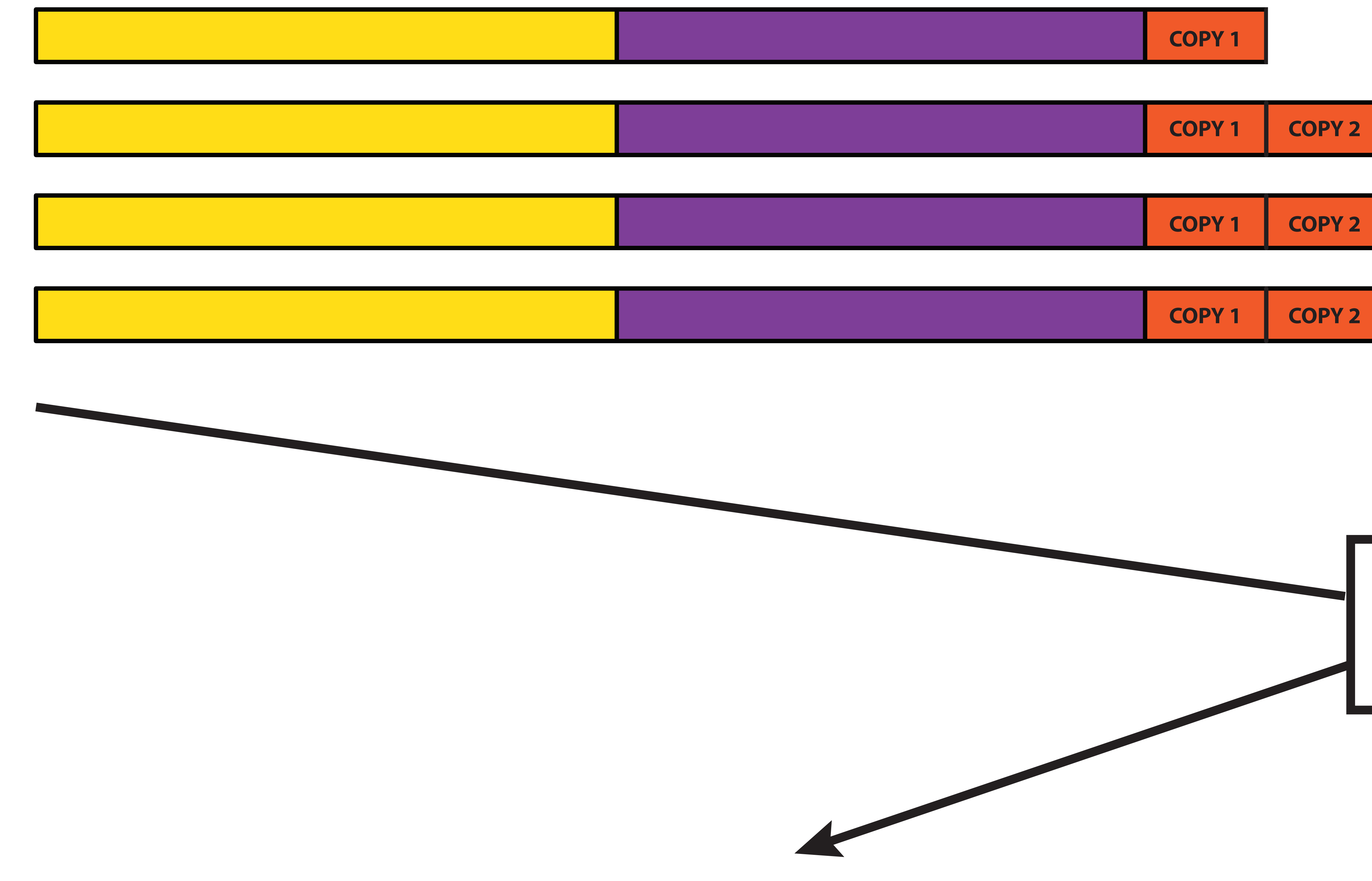

Selected markers

C

SNPs

D

Genome-level

B

Sequence data

Ind. 1

Ind. 2

Ind. 3

Ind. 4
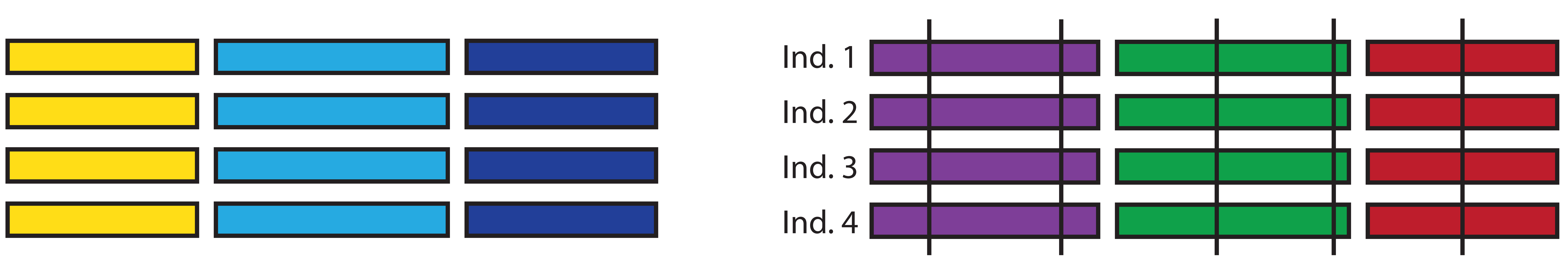

YY YY

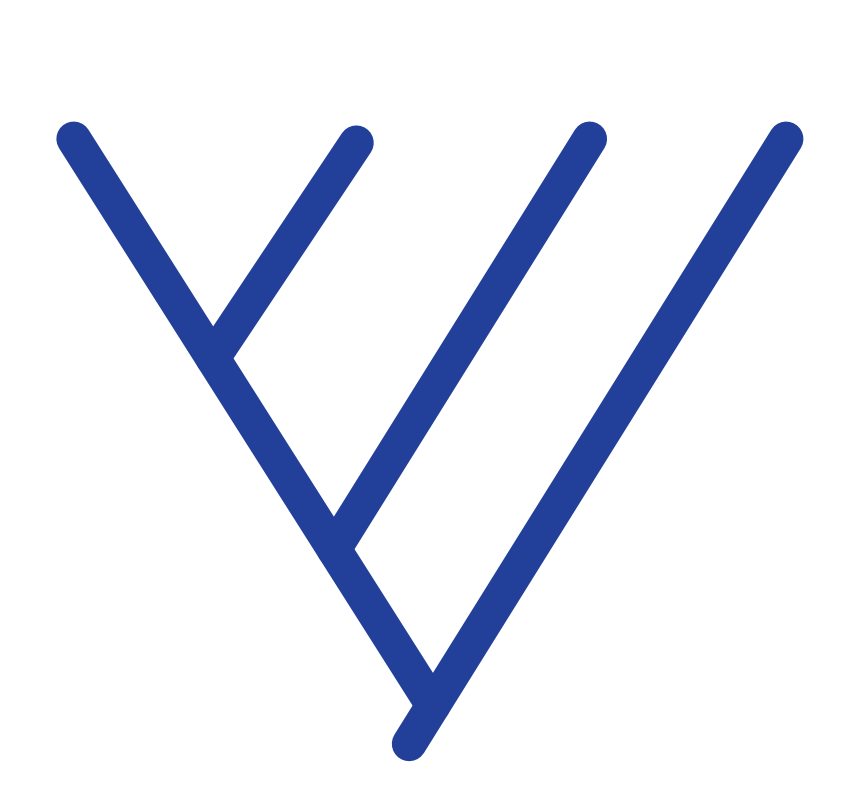

\begin{tabular}{|ll}
$\mathrm{A}$ & $\mathrm{T}$ \\
$\mathrm{G}$ & $\mathrm{C}$ \\
$\mathrm{C}$ &
\end{tabular}

\begin{tabular}{|l|l|}
\hline $\mathrm{A}$ & $\mathrm{G}$ \\
$/$ & $\mathrm{T}$ \\
$\mathrm{T}$ & $\mathrm{T}$ \\
\hline
\end{tabular}

$\mathrm{A}$
$\mathrm{C}$
$\mathrm{C}$

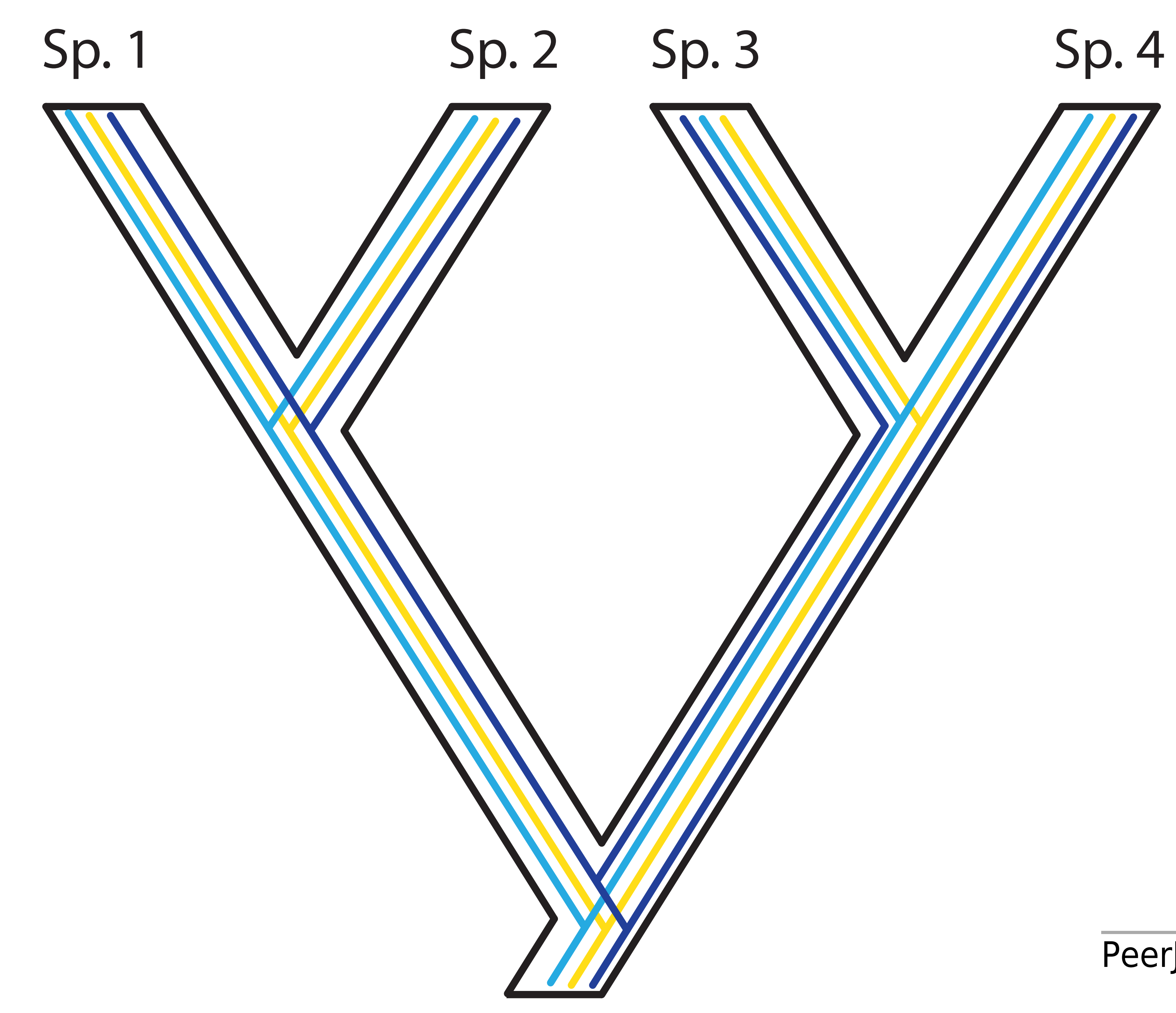

Peer) reviewing PDF | (2018:01:23715:2:0:NEW 22 Dec 201020

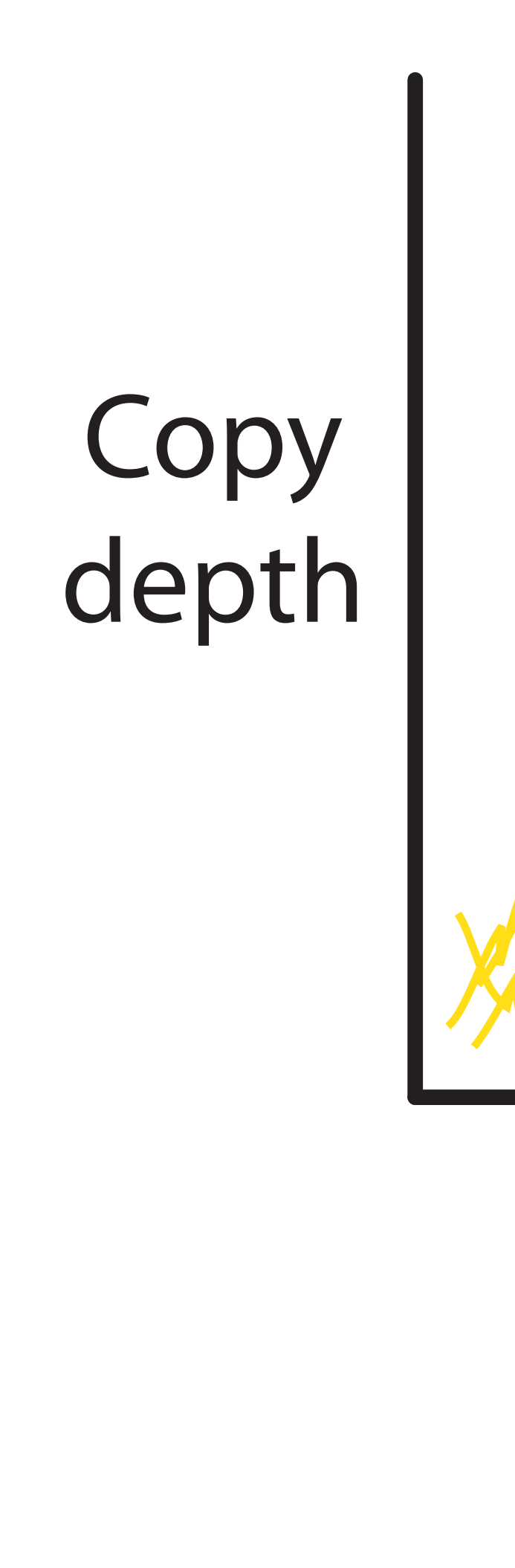

characters (e.g., CNVs)
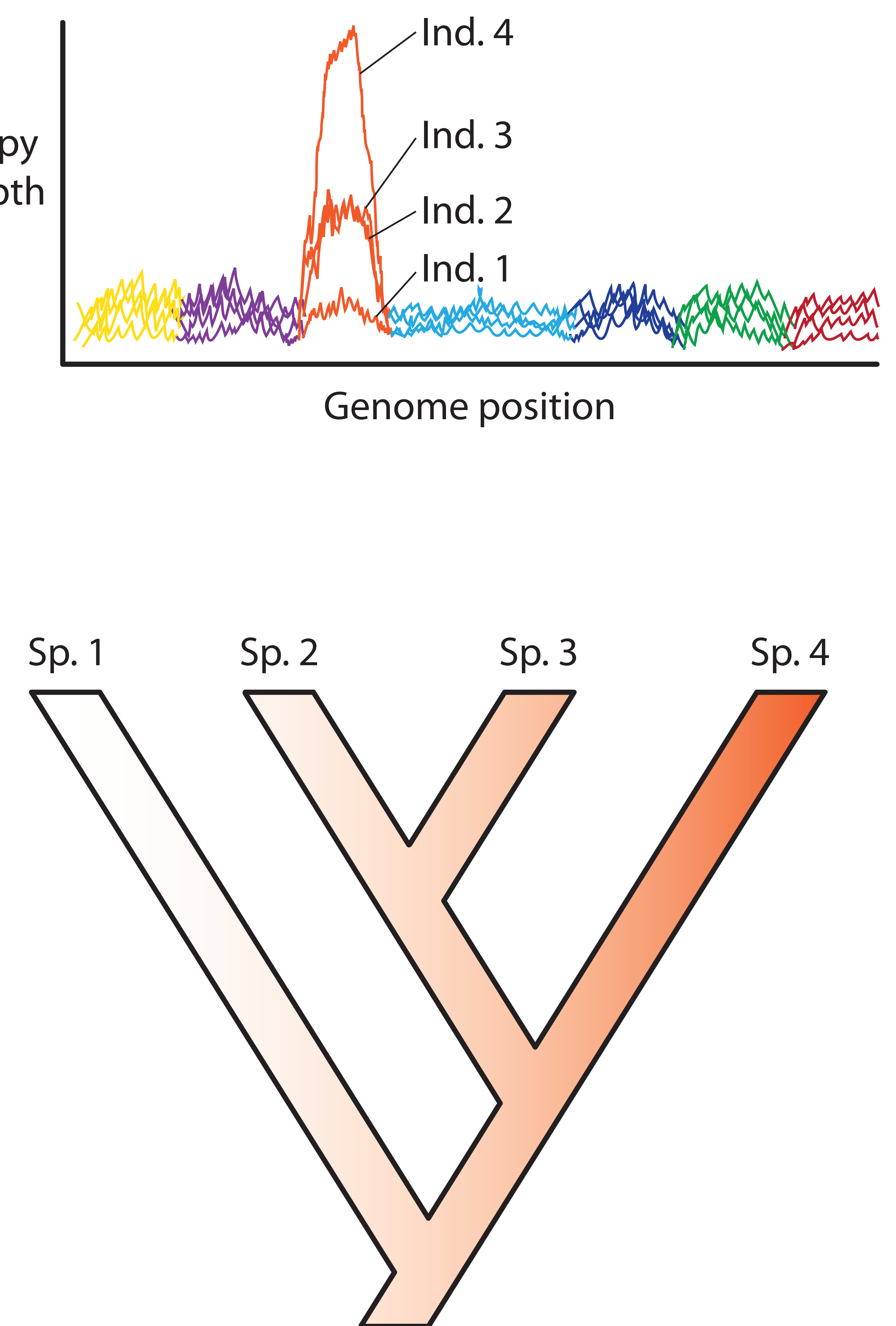


\section{Figure 2 (on next page)}

Trends in phylogenomic data sets since the emergence of HTS.

Based on a sample of 164 phylogenomic papers published since 2004 (see Supplementary Table S1), we observed no increase in the number of species per data set over time (A). On the other hand, there is a significant increase in the number of loci (B), total alignment length (C), and total data set size, as measured by the product of species times locus number (Data set size 1, E) and species times total alignment length (Data set size 2, F). Moreover, the advent of HTS does not support the notion of a tradeoff between the number of species and the number of loci in phylogenomic studies. 
A PeerJ

Adj. $R^{2}=0.011$

$\mathrm{P}=0.096$

$y=0.043 x-83.94$

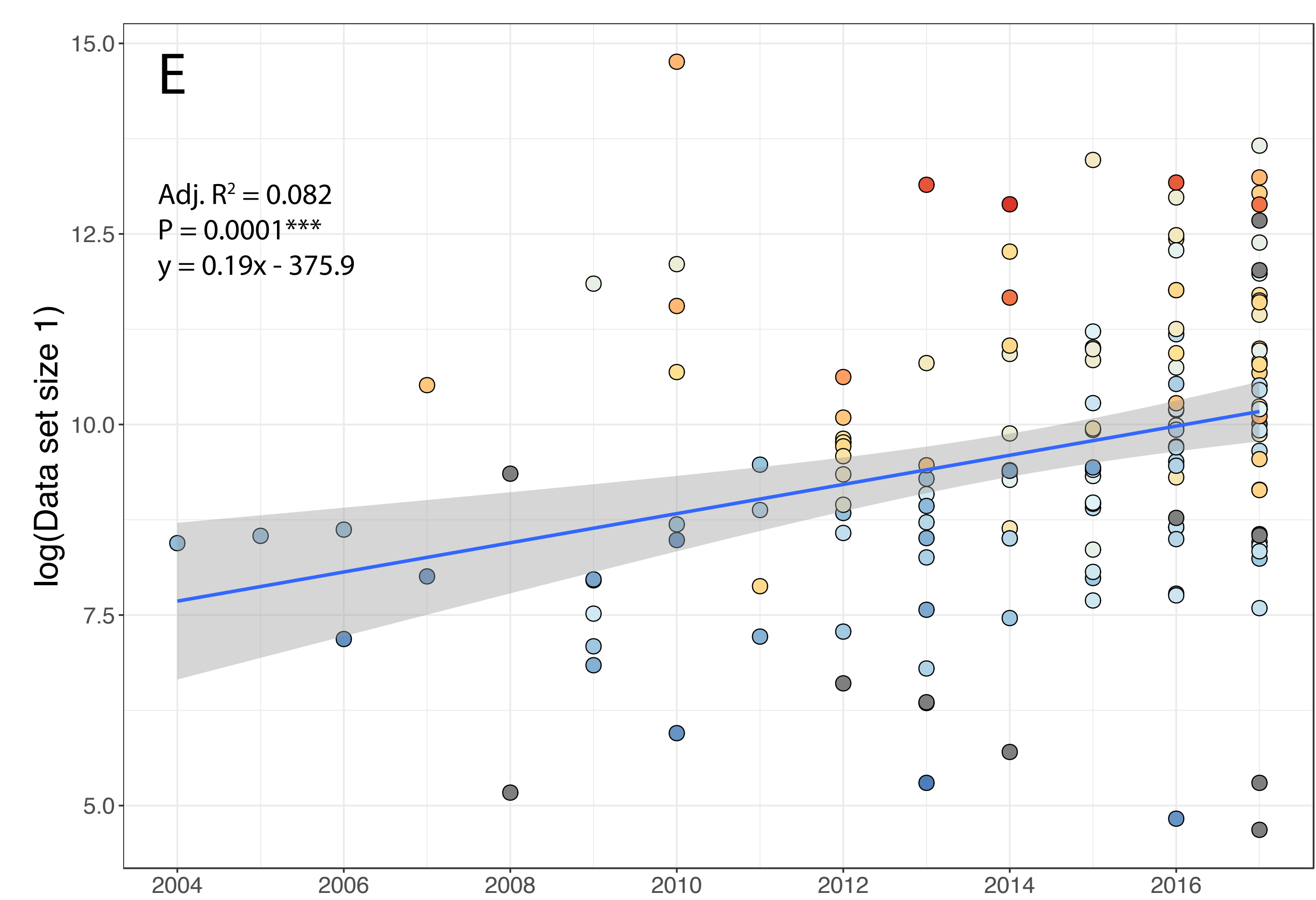

Year
PeerJ reviewing P PrF | (2018:01:23715:2:0:NEW 22 Dec 2018) log(Alignment length)

$\begin{array}{llllllllllllll}2004 & 2005 & 2006 & 2007 & 2008 & 2009 & 2010 & 2011 & 2012 & 2013 & 2014 & 2015 & 2016 & 2017\end{array}$

- Unreported number of loci $\quad \log \left(\right.$ Number of loci) $\begin{array}{llll}2.5 & 5.0 & 7.5 & 10.0\end{array}$

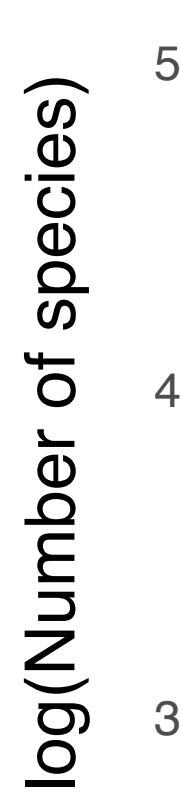

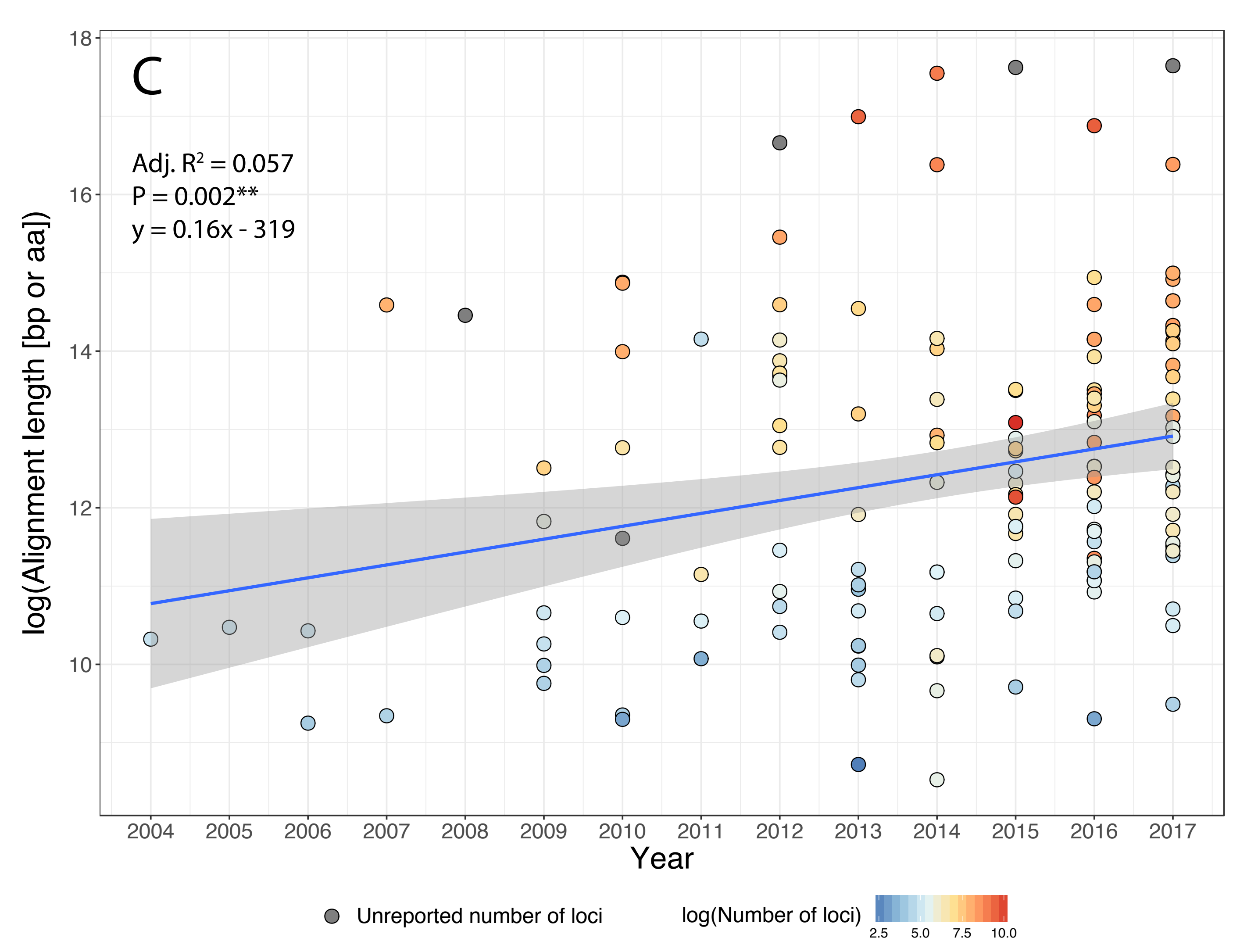

${ }^{\mathrm{B}}$ Manuscript to be reviewed

Adj. $R^{2}=0.064$

$\mathrm{P}=0.0008^{* * *}$

$y=0.15 x-296.3$

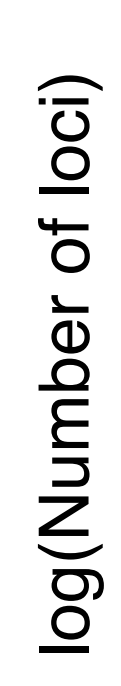
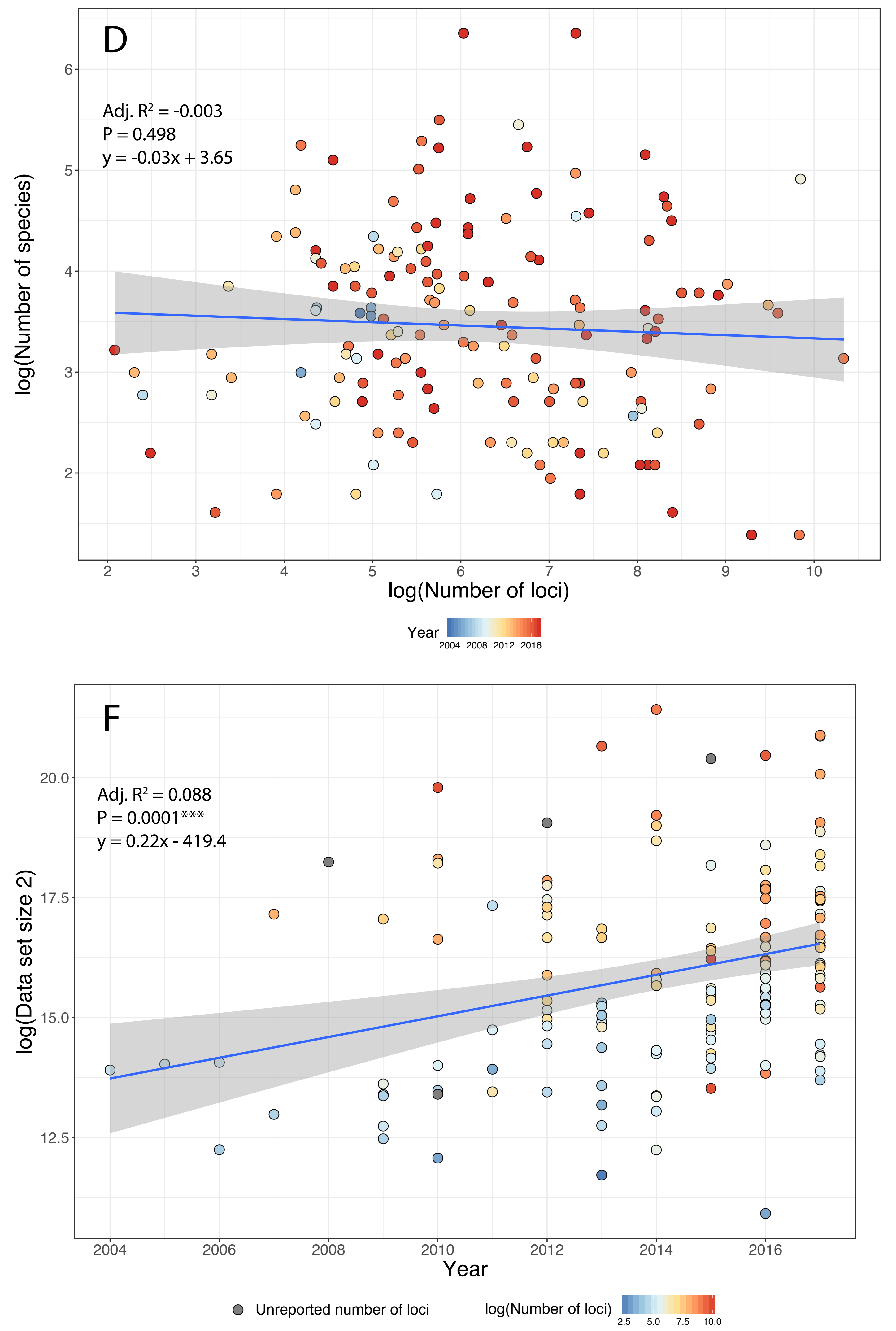
Figure 3 (on next page)

Some examples of violations of the multispecies coalescent.

In event A, there is gene flow; in event B there is homoploid hybridization; in event $\mathrm{C}$, there is a gene duplication; and in event $D$, incomplete lineage sorting. All of these processes contribute to gene tree heterogeneity but fall outside the standard multispecies coalescent model. Importantly, all of these processes also yield strictly dichotomous gene trees, whereas recombination (not illustrated here) does not. 


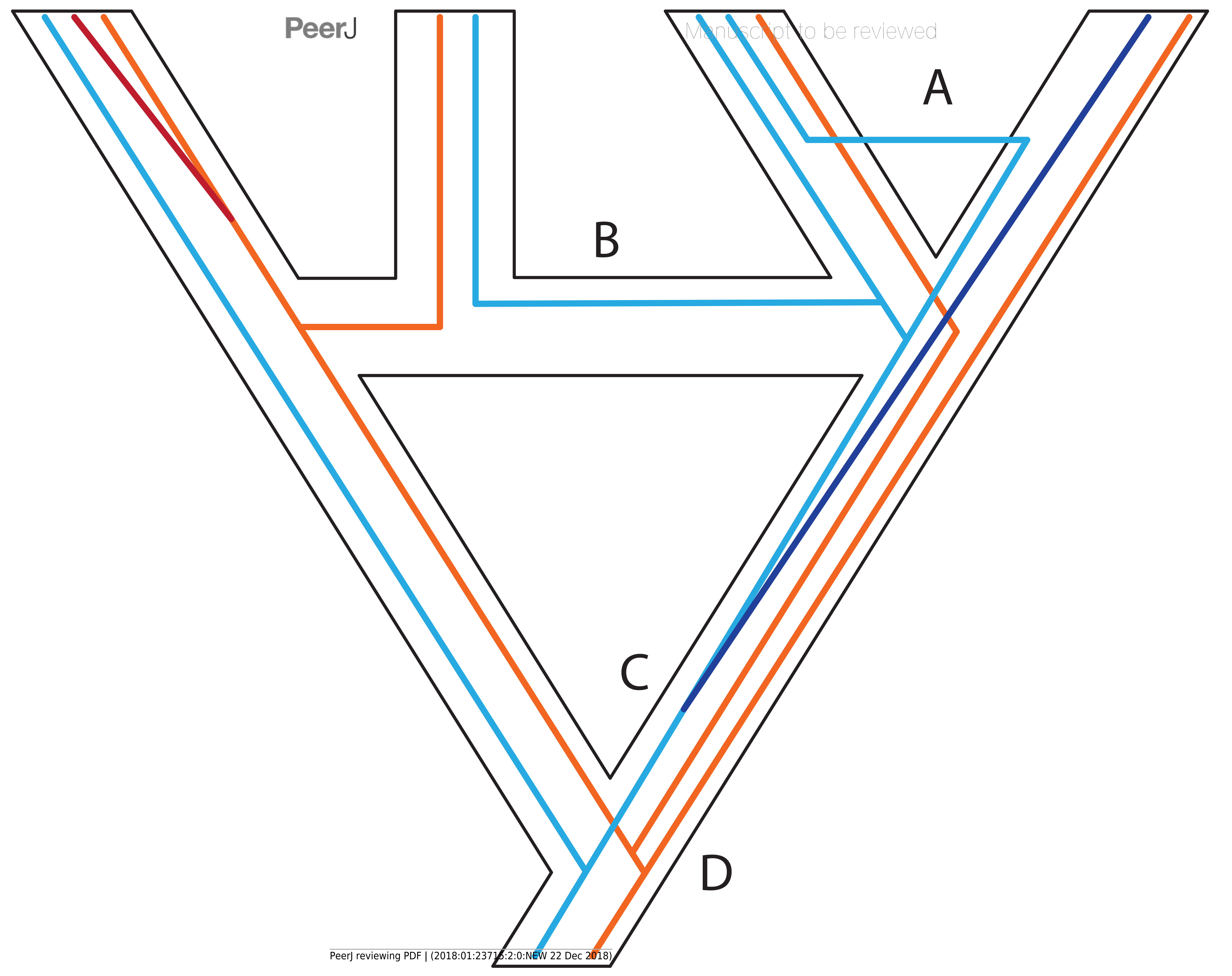




\section{Figure 4 (on next page)}

Gene duplication and loss creates patterns that can mimic incomplete lineage sorting and other processes. can lead to spurious inferences of the species history.

Genes and genomes of three species A, B, and C. Multi-colored bars show (parts of) their genomes with a number of loci indicated in different colors. The orange gene is duplicated in species $A$ and it was lost in species $B$. The blue gene was duplicated before the divergence between $B$ and $C$. However, both copies are maintained in species B and only one copy persists in species $C$. species A and the ancestor of species B and C. However, one of these copies was lost in species $A$, whereas both copies were maintained in species $B$ and $C$. Reconstruction of the orange gene tree based on extant diversity will yield a wrong inference of its history due to the absence of data for species B. On the other hand, a phylogenetic reconstruction of the blue gene is difficult to predict. Depending on which of the duplicates are sampled for species B and C, different outcomes can be expected regarding the relationship among the three species. The duplication and loss history of these two genes may cause serious issues for phylogenetic reconstruction because no specific pattern can be expected between them. 


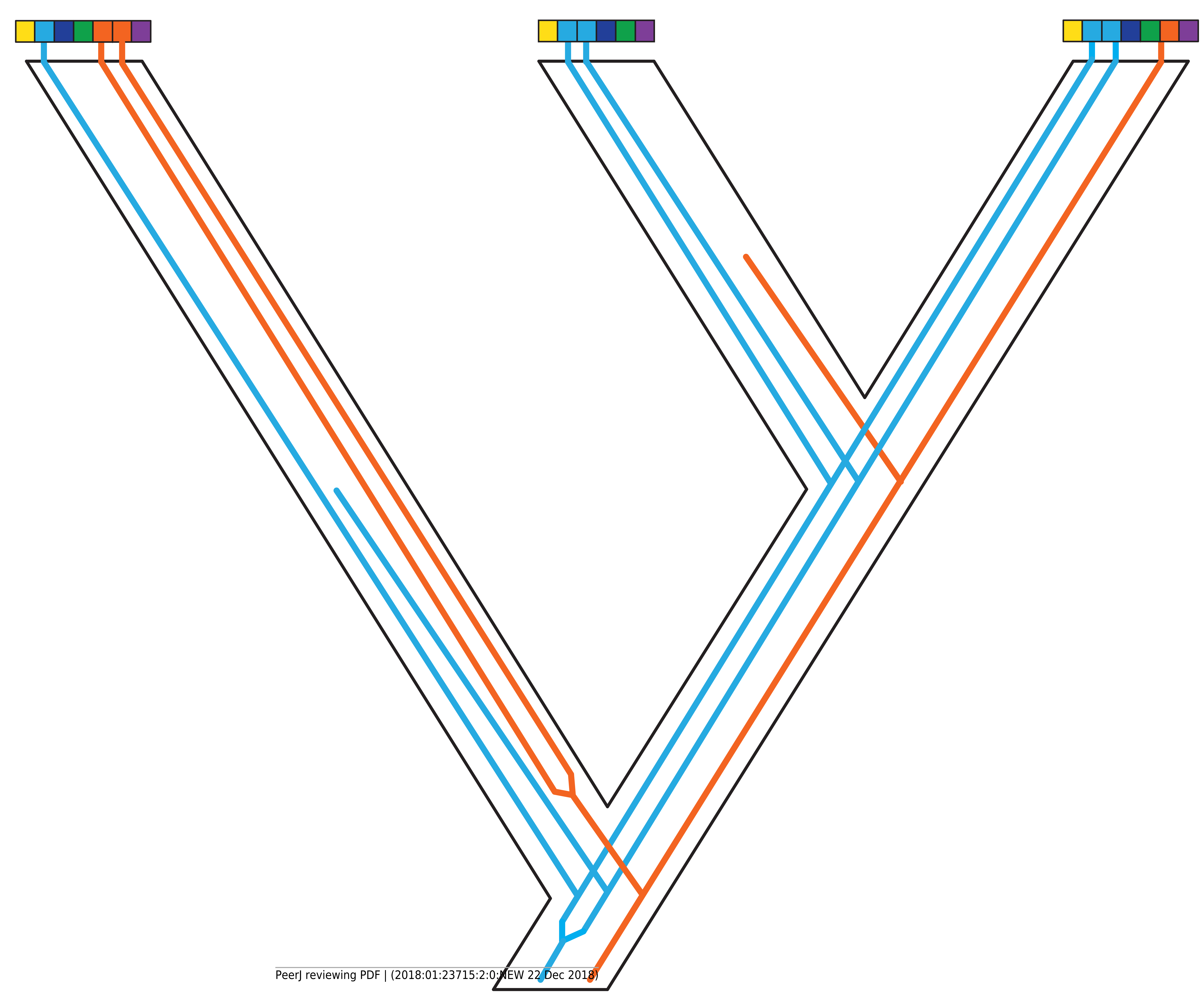


Figure 5 (on next page)

Complex patterns of gene lineages with polyploidization and interspecific gene flow.

Genes and genomes of four species A, B, C and D. Multi-colored bars show (parts of)

genomes with a number of loci indicated in different colors. Two gene trees, one orange and one blue, evolve within the species network. Species B is an allopolyploid containing two genomes. 


\section{Figure 6 (on next page)}

Gradual speciation, or isolation-with migration.

After starting to split, gene flow between species decreases gradually. Such a gradual decrease in the extent of gene flow between species might present an especially useful extension of the standard multispecies coalescent model. Colors depict different gene pools and their gradual change along branches describes how species gradually differentiate despite the existence of migration over time. Thickness and color intensity of arrows show that gene flow becomes weaker as species gradually isolate. 


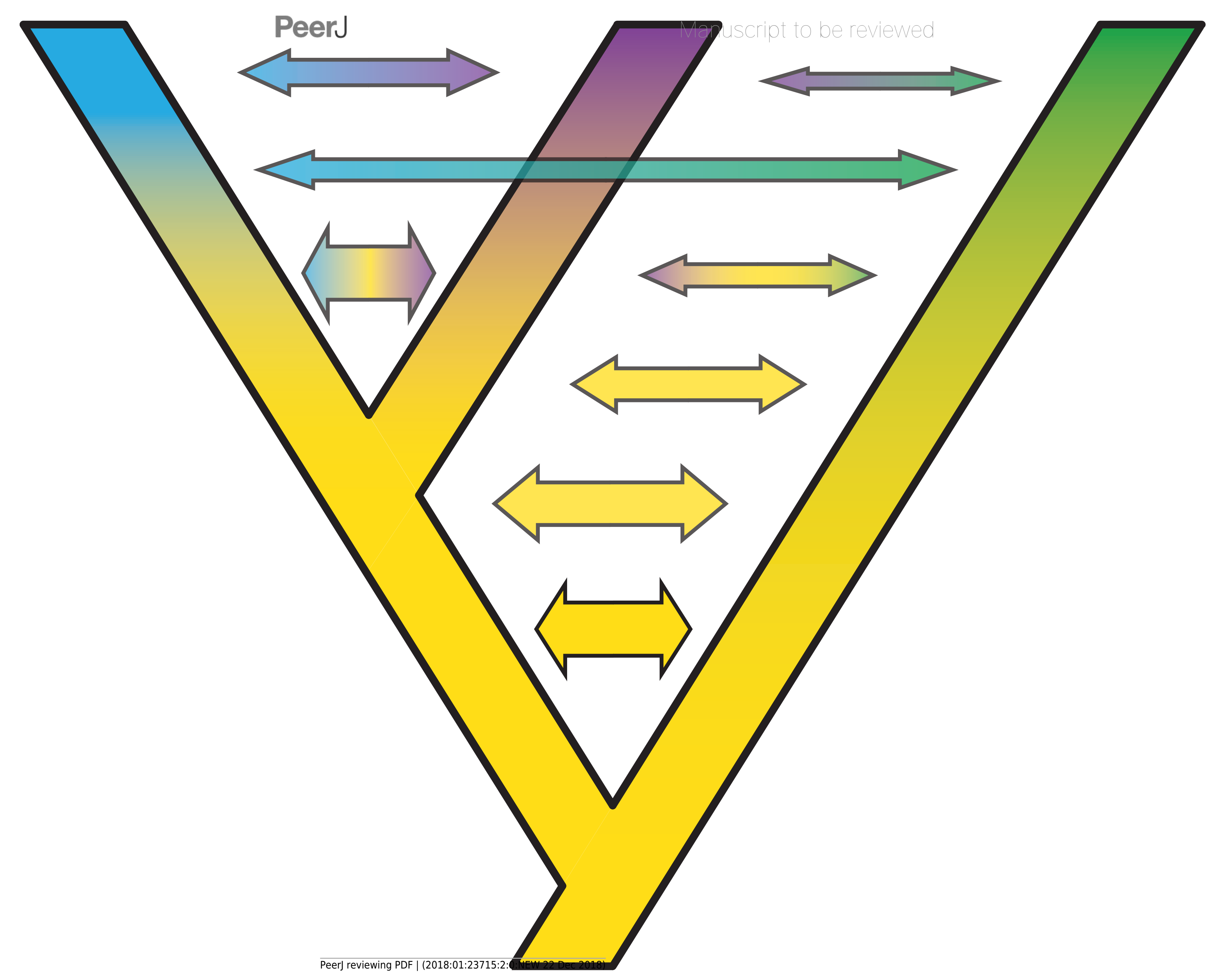




\section{Figure 7 (on next page)}

Two possible species phylogenies producing similar observations at present time.

On the left (A), there is a species tree with gene flow. On the right (B), there is a species network with homoploid hybridization. Distinguishing two such scenarios usually requires simulations and comparison of observed and expected summary statistics. 


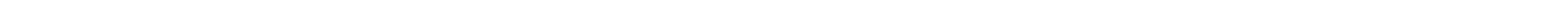


Table $\mathbf{1}$ (on next page)

Definitions of core concepts used in this article 
1 Table 1. Definitions of core concepts used in this article

2

\begin{tabular}{|c|c|}
\hline Concept & Definition \\
\hline $\begin{array}{c}\text { ToL } \\
\text { The Tree of Life }\end{array}$ & $\begin{array}{l}\text { This idea, originally articulated by Darwin and others, refers to } \\
\text { the grand vision of understanding the branching pattern of all } \\
\text { life on earth. Today the idea conveys the use of morphological } \\
\text { and molecular data to reconstruct the phylogenetic relationships } \\
\text { of all life forms. In some usages, the idea also includes } \\
\text { reconstructing reticulate evolutionary events, such as } \\
\text { introgression and hybridization, which are now thought to be } \\
\text { common in many lineages. }\end{array}$ \\
\hline $\begin{array}{c}\text { HTS } \\
\text { High-throughput sequencing }\end{array}$ & $\begin{array}{l}\text { Also referred to as "next generation sequencing", this term refers } \\
\text { to the plethora of new DNA and RNA sequencing technologies } \\
\text { that in the last fifteen years have allowed biologists to } \\
\text { dramatically increase the number of bases sequenced for a given } \\
\text { species or clade. HTS technologies can be applied to sequencing } \\
\text { whole genomes or transcriptomes and have been embraced by } \\
\text { phylogeneticists interested in increasing the size of comparative } \\
\text { molecular data sets. See Goodwin, McPherson \& McCombie } \\
\text { (2016) for a review on the progress of HTS. }\end{array}$ \\
\hline $\begin{array}{c}\text { MSC } \\
\text { The multispecies coalescent model }\end{array}$ & $\begin{array}{l}\text { A generalization of the standard, single population coalescent } \\
\text { model to multiple species related in a phylogeny. The MSC } \\
\text { applies the single-population coalescent model to each branch of } \\
\text { a phylogenetic tree, including both terminal and internal } \\
\text { branches. In the MSC, alleles sampled in terminal species will } \\
\text { coalesce to a smaller number of ancestral alleles at a rate } \\
\text { depending on the effective population size within the branch. } \\
\text { The gene tree lineages in a branch of the species tree do not } \\
\text { necessarily coalesce within that branch as one goes backwards in } \\
\text { time; multiple alleles may persist into ancestral branches. This } \\
\text { phenomenon is called incomplete lineage sorting (see next } \\
\text { definition). The decrease in the number of alleles and the time } \\
\text { to coalescence to a single allele in a lineage follows the standard } \\
\text { neutral coalescent model, until all alleles coalesce from all } \\
\text { species. See Rannala \& Yang (2003) and Degnan \& Rosenberg } \\
\text { (2009) for a full discussion. }\end{array}$ \\
\hline $\begin{array}{c}\text { ILS } \\
\text { Incomplete lineage sorting }\end{array}$ & $\begin{array}{l}\text { This phenomenon, originally described by John Avise (see } \\
\text { Avise et al. 1987) refers to the tendency of alleles in an ancestral } \\
\text { species to persist across multiple speciation events, resulting in a } \\
\text { situation in which the gene tree ("allele tree") differs from the } \\
\text { species tree. In ILS, alleles fail to "sort" by genetic drift as } \\
\text { species diverge from one another, resulting in different species } \\
\text { retaining the same alleles, or their descendants, causing } \\
\text { discordance with the overarching species or population tree. The } \\
\text { language of this phrase is looking forward in time, as opposed to } \\
\text { the language of coalescence, which looks backwards in time. See } \\
\text { Degnan \& Rosenberg } 2009 \text { for a full discussion. }\end{array}$ \\
\hline
\end{tabular}




\begin{tabular}{|c|c|}
\hline $\begin{array}{c}\text { GDL } \\
\text { Gene duplication and loss }\end{array}$ & $\begin{array}{l}\text { This concept describes the process by which a gene in an } \\
\text { ancestral species can duplicate, forming paralogs and one or } \\
\text { more of the paralogs can subsequently be deleted from the } \\
\text { genome, resulting in complex patterns of relationships among } \\
\text { paralogs and orthologs. Gene duplication is another mechanism, } \\
\text { in addition to ILS, that can render the gene tree different from } \\
\text { the species tree. As a result of gene (paralog) loss, inferring the } \\
\text { correct ortholog/paralog relationships and history of branching } \\
\text { events in a multigene family can be challenging. Phylogenetic } \\
\text { models incorporating GDL try to use patterns in multigene } \\
\text { families to deduce the branching history of the constituent } \\
\text { species. See Degnan \& Rosenberg (2009) and Souza et al., } \\
\text { (2017) for a full discussion. }\end{array}$ \\
\hline $\begin{array}{c}\text { ARG } \\
\text { Ancestral recombination graph }\end{array}$ & $\begin{array}{l}\text { This is a complete record of the coalescent and recombination } \\
\text { events in the history of a set of DNA sequences. As a } \\
\text { consequence of incorporating recombination events, ARGs do } \\
\text { not necessarily depict trees, but often have a network structure. } \\
\text { The accurate estimation of ARGs remains challenging but they } \\
\text { enhance our ability to estimate recombination rates, ancestral } \\
\text { effective population sizes, population divergence times, rates of } \\
\text { gene flow between populations, and detect selective sweeps. See } \\
\text { Griffiths \& Marjoram (1996), Siepel (2009), and Rasmussen et } \\
\text { al., (2014) for a full discussion. }\end{array}$ \\
\hline $\begin{array}{l}\text { LGT } \\
\text { Lateral gene transfer }\end{array}$ & $\begin{array}{l}\text { This process occurs when genes jump taxonomic and } \\
\text { phylogenetic boundaries, moving between unrelated species and } \\
\text { therefore causing discordances between genetic and lineage } \\
\text { history. LGT, along with ILS and GDL was among the three } \\
\text { primary causes of discordance between gene and species trees } \\
\text { identified by Maddison (1997). LGT has been documented to } \\
\text { occur between bacterial lineages, between bacteria and viruses, } \\
\text { and between these two and eukaryotes, including plants and } \\
\text { vertebrates. If not identified prior to phylogenetic analysis, LGT } \\
\text { can cause many algorithms for phylogenetic inference to fail. } \\
\text { Without prior identification, LGT essentially amounts to errors } \\
\text { in data sets and sequence alignments. At the same time, LGT can } \\
\text { be a source of adaptation and evolutionary novelty for recipient } \\
\text { genomes and has had a major impact on the history of life. See } \\
\text { Gogarten \& Townsend (2005) for a full review. }\end{array}$ \\
\hline
\end{tabular}


Table 2 (on next page)

Challenges in the fields of coalescent-based phylogenomics and implications for unraveling character evolution and the Tree of Life. 
1 Table 2. Challenges in the fields of coalescent-based phylogenomics and implications for unraveling 2 character evolution and the Tree of Life.

3

\begin{tabular}{|c|c|c|}
\hline Category & Challenge & Proposed strategy \\
\hline \multirow[t]{2}{*}{ Data } & $\begin{array}{l}\text { Integration and } \\
\text { assessment of large } \\
\text { amounts of data with } \\
\text { heterogeneous } \\
\text { phylogenetic signal. }\end{array}$ & $\begin{array}{l}\text { Protocols for marker selection should assess markers' } \\
\text { biological relevance and adequacy for the study organism, } \\
\text { given the temporal and spatial scales in question, and not } \\
\text { only logistical convenience. A posteriori (after data } \\
\text { generation) marker selection from whole-genome } \\
\text { alignments can be useful to inform these aspects as well as } \\
\text { minimize the effects of missing data and varying data } \\
\text { quality. Until then, researchers should attempt a higher } \\
\text { standardization of markers to facilitate combinatory } \\
\text { analyses. } \\
\text { To discern true phylogenomic heterogeneity from noise } \\
\text { and error as well as to identify violations of the MSC, } \\
\text { adequate filtering of large phylogenomic datasets should } \\
\text { be conducted based on biological and statistical properties } \\
\text { of markers (e.g., analyses of gene-tree outliers and rogue } \\
\text { taxa). } \\
\text { Further research on filtering methods as well as on their } \\
\text { impact on phylogenomic estimation is still required. }\end{array}$ \\
\hline & $\begin{array}{l}\text { Inclusion of } \\
\text { additional character } \\
\text { types into } \\
\text { phylogenomic } \\
\text { analyses. }\end{array}$ & $\begin{array}{l}\text { Research efforts focused on the adequate identification } \\
\text { and utilization of rare genomic changes other than } \\
\text { nucleotide substitutions, such as indels, transpositions, } \\
\text { inversions, CNVs, and chromosomal rearrangements. } \\
\text { Development of new methods not only to infer } \\
\text { phylogenetic hypotheses based on these characters but also } \\
\text { to integrate them with more traditional sequence data. }\end{array}$ \\
\hline $\begin{array}{l}\text { Phylogenetic } \\
\text { inference } \\
\text { models and } \\
\text { methods }\end{array}$ & $\begin{array}{l}\text { Analyses of genome- } \\
\text { scale data for large } \\
\text { numbers of species } \\
\text { within a coalescent } \\
\text { framework. }\end{array}$ & $\begin{array}{l}\text { Continue the development of models and methods that } \\
\text { allow simultaneous gene tree and species tree estimation } \\
\text { within a Bayesian framework (e.g., Ogilvie, Bouckaert \& } \\
\text { Drummond, 2017) for increasingly large and complex } \\
\text { datasets. } \\
\text { For the time being, two-step methods, particularly those } \\
\text { based on biological models and permitting statistical tests }\end{array}$ \\
\hline
\end{tabular}




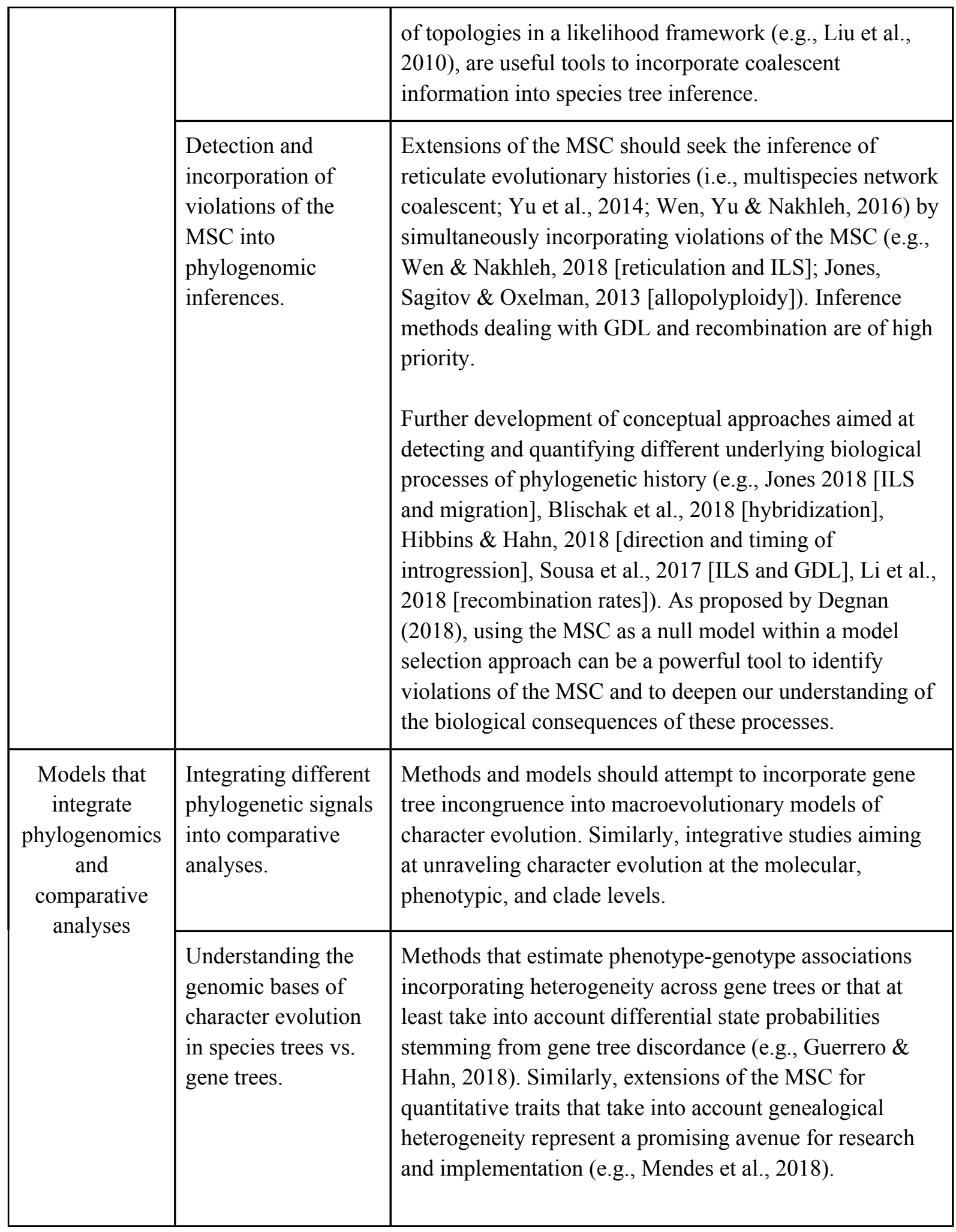




\begin{tabular}{|c|l|l|}
\hline $\begin{array}{c}\text { Best practices } \\
\text { for building the } \\
\text { ToL }\end{array}$ & $\begin{array}{l}\text { Increasing the } \\
\text { number of species } \\
\text { represented in the } \\
\text { ToL while ensuring } \\
\text { reproducibility and } \\
\text { encouraging } \\
\text { community } \\
\text { participation }\end{array}$ & $\begin{array}{l}\text { Natural history museums must be central players for } \\
\text { providing and analyzing genome-scale data. Genetic } \\
\text { resources and specimen collections are fundamental for } \\
\text { allowing the acquisition of data for extinct and poorly } \\
\text { accessible species. Open access community initiatives } \\
\text { must continue to be relevant repositories of the ToL. } \\
\text { Adequate methods for curation of data and analytical tools } \\
\text { must continue to be a high priority. }\end{array}$ \\
\hline
\end{tabular}

4

5

6

7

8

9

10

11 